Florida International University FIU Digital Commons

$11-20-2003$

\title{
The effects of semantic and syntactic instruction on user performance and satisfaction in search user interface design
}

Jennifer M. Bandos

Florida International University

DOI: $10.25148 /$ etd.FI14050422

Follow this and additional works at: https://digitalcommons.fiu.edu/etd

Part of the Industrial Engineering Commons

\section{Recommended Citation}

Bandos, Jennifer M., "The effects of semantic and syntactic instruction on user performance and satisfaction in search user interface design" (2003). FIU Electronic Theses and Dissertations. 1385.

https://digitalcommons.fiu.edu/etd/1385 
Miami, Florida

THE EFFECTS OF SEMANTIC AND SYNTACTIC INSTRUCTION ON USER PERFORMANCE AND SATISFACTION IN SEARCH USER INTERFACE DESIGN

A thesis submitted in partial fulfillment of the requirements for the degree of

MASTER OF SCIENCE

in

INDUSTRIAL AND SYSTEMS ENGINEERING

by

Jennifer M. Bandos

2003 
To: Dean Vish Prasad

College of Engineering

This thesis, written by Jennifer M. Bandos, and entitled The Effects of Semantic and Syntactic Instruction on User Performance and Satisfaction in Search User Interface Design, having been approved in respect to style and intellectual content, is referred to you for judgment.

We have read this thesis and recommend that it be approved.

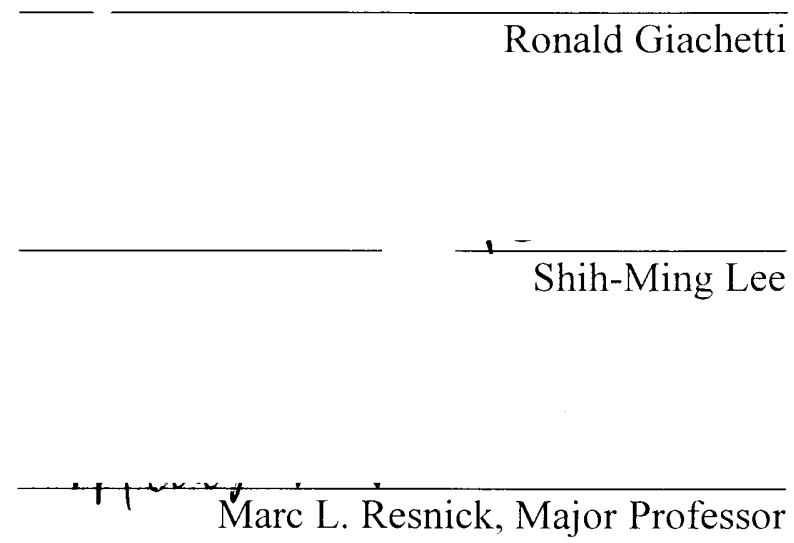

Date of Defense: November 20, 2003

The thesis of Jennifer M. Bandos is approved.

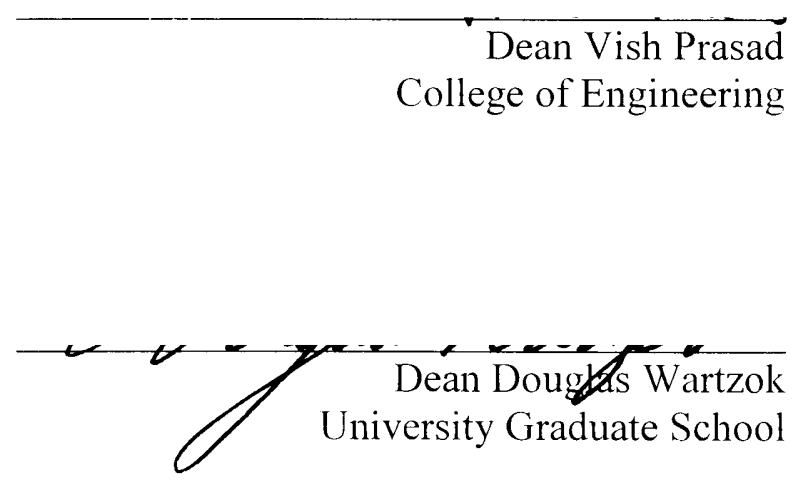

Florida International University, 2003 


\section{DEDICATION}

I dedicate this thesis to Mom, Papi and Melissa. Their unconditional love, support and encouragement is the underlying factor of all my academic achievements and success. 


\section{ACKNOWLEDGMENTS}

I wish to give my heartfelt thanks and deepest appreciation to my major professor, Dr. Marc Resnick. Without his incredible enthusiasm, optimism and intelligence, the completion of this thesis would not have been possible. He successfully managed to strengthen my determination which allowed me to find and realize my potential, and to make this contribution to the field of Human Factors. His dedication to helping me succeed is genuinely appreciated. I also want to express my sincere gratitude to the members of my committee, Dr. Ronald Giachetti and Dr. Shih-Ming Lee. The guidance and insight they graciously provided me with played a crucial role in the success of this thesis. I wish to thank them for the time and effort they dedicated to this work.

I convey my appreciation to the staff of the Industrial and Systems Engineering department, Mrs. Sylvia Sharpe and Mrs. Nancy Urbina, who have helped and supported me in innumerable ways throughout my graduate studies. I also wish to express my sincere appreciation to Julian Sanchez. His practical and emotional support throughout this academic journey will forever be cherished. 
ABSTRACT OF THE THESIS

THE EFFECTS OF SEMANTIC AND SYNTACTIC INSTRUCTION ON USER

PERFORMANCE AND SATISFACTION IN SEARCH USER INTERFACE DESIGN

by

Jennifer M. Bandos

Florida International University, 2003

Miami, Florida

Professor Marc L. Resnick, Major Professor

The design of interfaces to facilitate user search has become critical for search engines, ecommerce sites, and intranets. This study investigated the use of targeted instructional hints to improve search by measuring the quantitative effects of users' performance and satisfaction.

The effects of syntactic, semantic and exemplar search hints on user behavior were evaluated in an empirical investigation using naturalistic scenarios. Combining the three search hint components, each with two levels of intensity, in a factorial design generated eight search engine interfaces. Eighty participants participated in the study and each completed six realistic search tasks.

Results revealed that the inclusion of search hints improved user effectiveness, efficiency and confidence when using the search interfaces, but with complex interactions that require specific guidelines for search interface designers. These design guidelines will allow search designers to create more effective interfaces for a variety of search applications. 


\section{TABLE OF CONTENTS}

CHAPTER

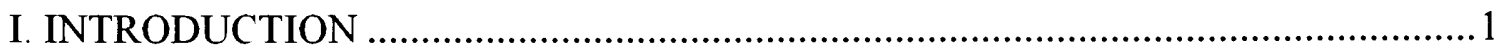

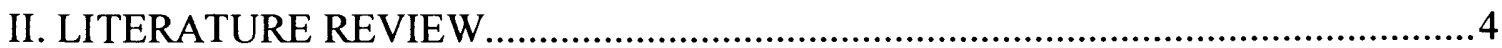

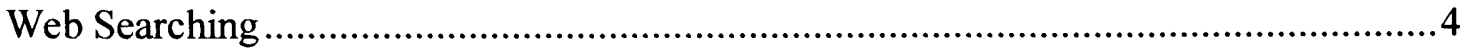

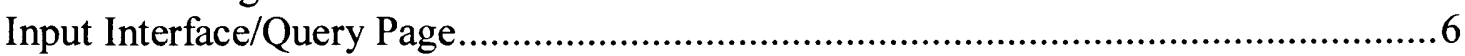

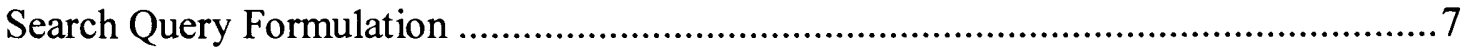

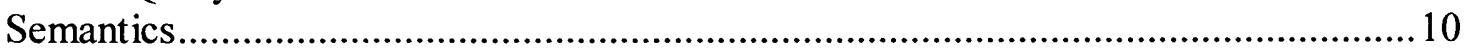

Syntax

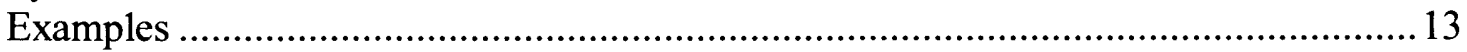

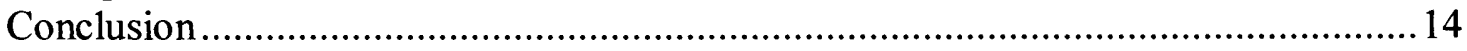

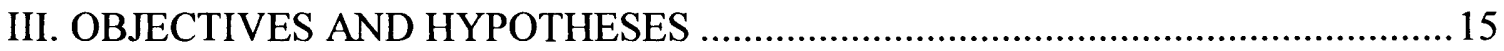

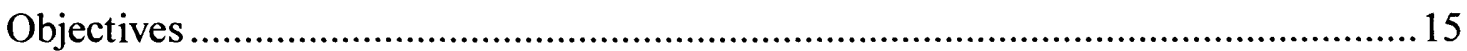

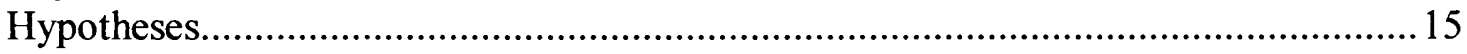

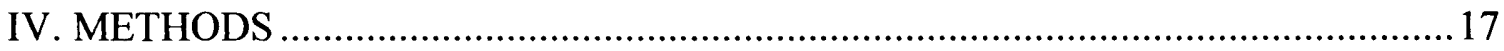

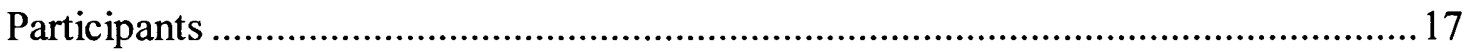

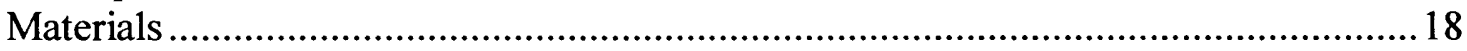

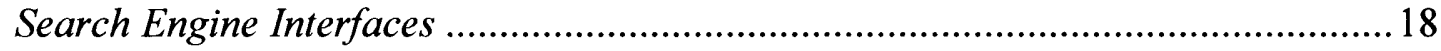

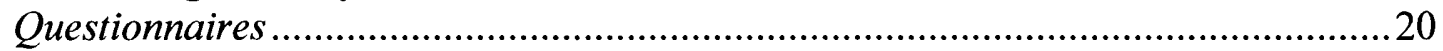

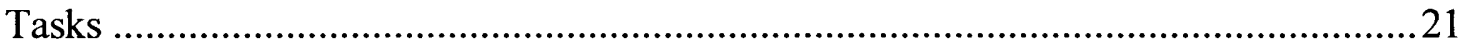

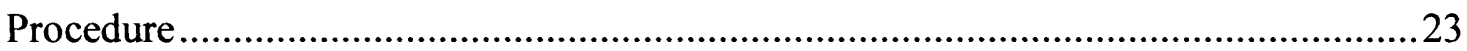

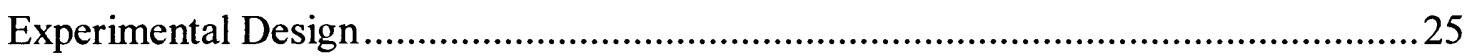

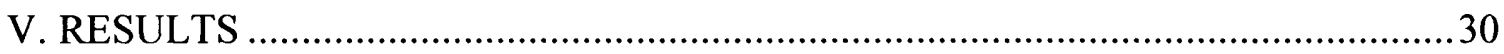

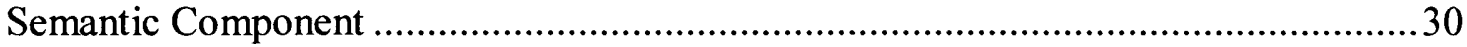

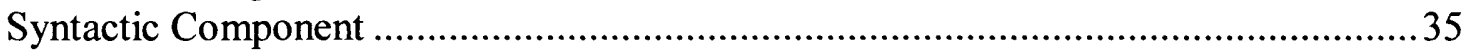

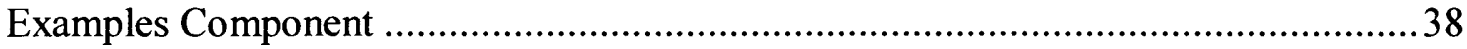

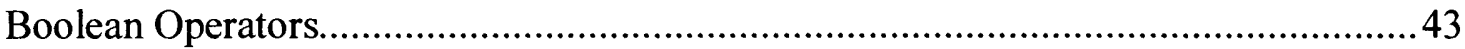

Boolean Operators \& Search Hint Components ..........................................................47

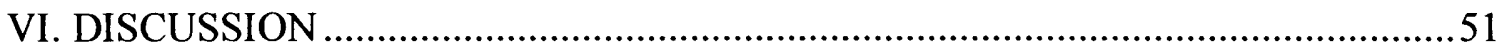

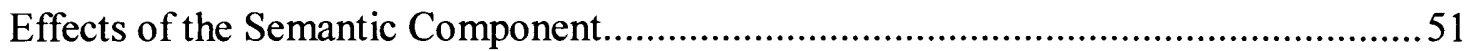

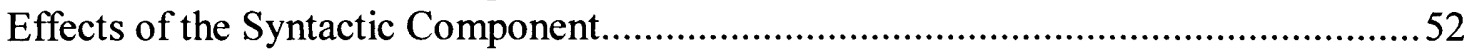

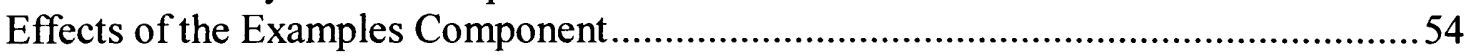

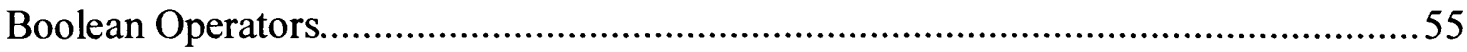

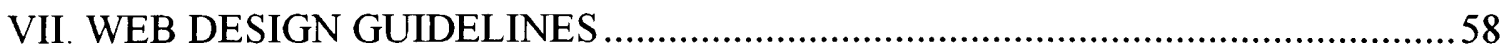

VIII. RECOMMENDATIONS FOR FUTURE RESEARCH.....................................59

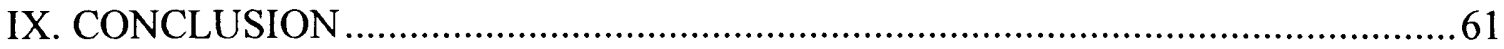

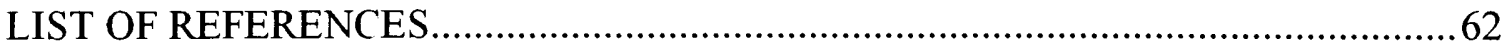

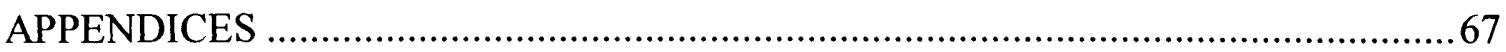




\section{LIST OF FIGURES}

FIGURE

PAGE

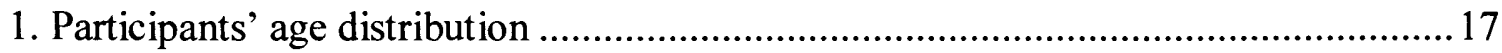

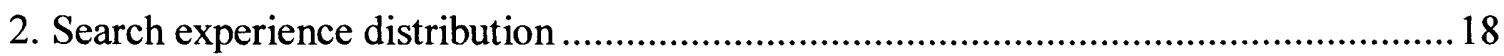

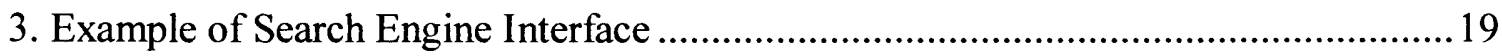

4. Average success rate of syntax and semantics in the 2 levels of the semantic

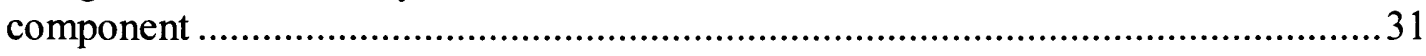

5. Average pre-click confidence in the 2 levels of the semantic component ....................32

6. Average satisfaction ratings in the 2 levels of the semantic component ......................33

7. Average completion times in the 2 levels of the semantic component .........................34

8. Average success rate of syntax and semantics in the 2 levels of the syntactic

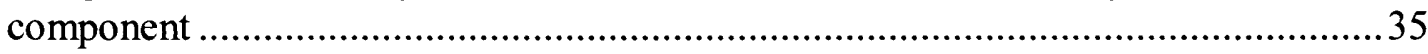

9. Average pre-click confidence in the 2 levels of the syntactic component ....................36

10. Average satisfaction ratings in the 2 levels of the syntactic component ....................37

11. Average completion times in the 2 levels of the syntactic component ......................38

12. Average success rate of syntax and semantics in the 2 levels of the examples

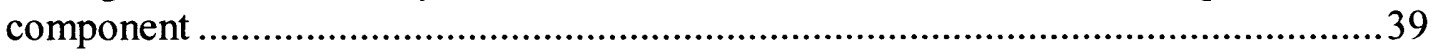

13. Average pre-click confidence in the 2 levels of the examples component.................41

14. Average satisfaction ratings in the 2 levels of the examples component ...................41

15. Average completion times in the 2 levels of the examples component.....................42

16. Average semantic success rate for the 3 Boolean operators.....................................44

17. Average syntax success rate for the 3 Boolean operators........................................45

18. Average pre-click confidence for the 3 Boolean operators .....................................46

19. Average completion time for the 3 Boolean operators...........................................4

20. Average semantic success rate for the 3 Boolean operators in the 2 levels of the

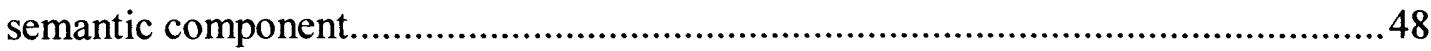

21. Average semantic success rate for the 3 Boolean operators in the 2 levels of the examples component.

22. Average completion time for the 3 Boolean operators in the 2 levels of the examples component 


\section{INTRODUCTION}

The difficulty of retrieving relevant material from the vast amount of information available on the World Wide Web (WWW) has become an increasingly imperative issue for a great majority of search users. Alexa (2000) found that an overwhelming number of Internet users are not particularly efficient at reaching their online destinations. A study conducted in 2000 by NPD New Media Services surveyed 33,000 search engine users and found that $60 \%$ of the respondents reported finding relevant information most of the time and only $21 \%$ reported being able to find what they are looking for every time.

Thousands of agencies, institutions, and individuals make information available, but because there is no single controlling entity or organization over the Internet, there is no controlled structure, vocabulary, or means of access to the information. Consequently, this has led to confusion and frustration among users (Herring, 1999). Roper Starch Worldwide (2000) conducted a "Web Rage" survey and found that $71 \%$ of the respondents get frustrated when looking for information on the Internet and $86 \%$ felt that a more efficient way to search the Web for accurate information should be in place (Search Engine Watch, 2001).

Retrieving relevant information is far from certain, especially with such a diversity of content and enormous volume of information on the Internet (Gordon and Pathak, 1999). The Internet Domain Survey (2000) estimated that the number of host machines on the Internet was over 72 million, over 16 million more than the year before. There is no reason to believe these numbers ceased increasing over the past few years. Nielsen 
(2000) reported that the Internet was expected to undergo an increase from 10 million sites in 1999 to 200 million sites in 2005 .

The increasing amount of information available on the web, therefore, raises new and challenging problems for the information retrieval (IR) community (Savoy and Picard, 2001). Though many Internet-enabled applications and services are currently available, the primary use of the Internet, other than e-mail, is for information retrieval (Gordon and Pathak, 1999). Users rate searching as the most important activity conducted on the Internet (Jupiter Research, 2000).

Search engines are considered the IR systems of the Internet (Jansen and Pooch, 2000). A study commissioned by RealNames found that over $75 \%$ of web users use search engines to navigate the web (Search Engine Watch, 2000). One in every 28 pages viewed on the Web is a search results page (Alexa Insider, 2000). An IR system is a system that is capable of storage, retrieval, and maintenance of information (Kowalski, 1997). Common components of an IR system include document selection, indexing, searching, matching, and the user interface (Lancaster and Warner, 1993).

The user interface design is a critical aspect and an essential component of IR systems (Lancaster and Warner, 1993). The results of a study performed by $\mathrm{Hu}$ et al. (1999) suggest that interface design may have a significant effect on system-user concept communication. In fact, many commercial online retrieval systems have failed to serve users effectively, in part because they incorporate interfaces that have not been well- 
accepted by the average user (Harman, 1992). Consistent with the goal of developing information technology (IT) for direct use by the general public, a trend towards designing IR systems for end-users rather than the once-targeted professional intermediaries has become increasingly prevalent (Reynolds, 1985).

In this connection, an IR system should include an effective user interface through which users can interact with the system to complete their search tasks successfully and efficiently (Hu et al., 1999). In order to accomplish this goal, it is critical to obtain information regarding user performance, satisfaction and preference among various search interfaces. Only then can designers make informed decisions with regards to improving the design and effectiveness of search user interfaces. 


\section{LITERATURE REVIEW}

Web Searching

The efficient retrieval of information has gained new importance with the vast development of the Internet (Herring, 1999). The World Wide Web (WWW) possesses an ever-changing and extremely heterogeneous document collection of immense proportions (Jansen and Pooch, 2000), therefore the process of creating a tool to effectively and efficiently retrieve information from the WWW is of great value. Efficiently exploring the enormous amount of valuable information from the Web requires the employment of effective search tools. Search engines are currently the major portals for users of the Web and are considered the information retrieval (IR) systems of the Internet (Jansen and Pooch, 2000).

Information scientists and software designers have consistently tried to improve the accessibility of information on the Internet by developing sophisticated and advanced retrieval tools. However, despite their efforts, search engines still largely perform only the routine actions of a search, leaving the brainwork to the user (Lazonder et al., 2000). Efficiently searching the WWW involves considerable thinking, especially because of the tremendous volume of ill structured information that is available on the Web (Lazonder et al., 2000). Thus, it is of no surprise that search engine users, whether expert or novice, are regularly overcome with feelings of frustration while performing even the most mundane search (Search Engine Watch, 2000). 
A plethora of systems have been designed to improve and advance the current state of the information retrieval process. Nonetheless, even with the extensive number of studies and attempted advancement of search engines, there is still considerable room for improvement in web-based searching. Effectively searching the web is a task far too difficult for most search users. Today the knowledgeable Internet user, as well as the novice, can be confused and frustrated not only by the huge amount of hard-to-locate information, but by the need to choose from among an ever-increasing number of tools to find what he or she is looking for, each of them with their own advantages, disadvantages, and use of protocols (Herring, 1999).

The functions of retrieval systems are becoming more complex and the resources available within those systems are increasingly rich and varied. One of the ongoing concerns of systems designers has been to create systems with increasingly multifaceted functions that are still user-friendly and easily accessible to users, whether those users are experienced with retrieval tools or novices seeking information (Jin and Fine, 1996). As the number of functions in an information retrieval system increases, it becomes more important to design the interface to be compatible with what the user needs at the time it is needed to insure the user's satisfaction with the system, even while appreciating its complexity (Jin and Fine, 1996). Within the retrieval process, the user interface is the communication bridge that links the user with the information retrieval system, and the effectiveness of the interface plays a crucial role in the success of the interaction (Jin and Fine, 1996). 


\section{Input Interface/Query Page}

The input interface or query page of a search engine is the first introduction a user has to the system. The opening screen of a typical query-based search engine presents an input box in which users are to type their selected queries and possibly a choice as to how the query terms are to be processed (Schwartz, 1998). It is of great importance that the user's first impression of the search tool be as intuitive as possible. If the information retrieval system is difficult to use because it has too many steps or because the commands are unclear, users tend to avoid using the system and settle for less relevant or less complete information. Studies have shown that when unable to find what they are looking for, most web users will try another search engine, but nearly $20 \%$ completely give up (Search Engine Watch, 2000).

For many search users, the tradeoff between convenience and the value of the information found is resolved in favor of convenience. This principle is basic in human information seeking behavior and must therefore be central to the design of the search interface (Jin and Fine, 1996). The key to an effective search system is that it provides a convenient and simple interface while returning relevant and sufficient information (Jin and Fine, 1996). Both aspects are necessary.

Another limitation of human information processing is a tendency to maintain familiar behaviors despite small and even moderate changes in task demands. When using search engines, this manifests as a dependence on familiar databases, information retrieval evaluation models and retrieval terminology even if the user's information requirements 
have changed and the user's familiar patterns are not the most appropriate to the situation at hand. If the information retrieval system interface could interpret and model users' problems and their contexts, it could help them select databases, choose evaluation methods and determine retrieval terms that are most compatible with the intention of the search at hand (Jin and Fine, 1996).

A third tradeoff that must be considered in the design of a search input interface contrasts the need to provide sufficient instructions for users to take advantage of the power of the search engine with the reluctance of users to read instructions. As with any product or system, when people engage in the task of searching for information, their expectation is that the system's descriptions and instructions will be clear, precise and simple (Jin and Fine, 1996). Interfaces should be designed to guide users by providing suggestions and setting expectations (Hagan et al., 2000). The amount and nature of the information presented on the initial input page of a search engine must therefore be carefully considered and designed. Too much information may overwhelm a potential user and discourage him/her from utilizing the system. However, too little may prevent the user from achieving his/her goals (Jin and Fine, 1996).

\section{Search Query Formulation}

The assumption that a search engine user knows how to clearly express a query or even that the user has formulated the correct query should not be made (Jin and Fine, 1996). According to Crouch et al. (2002), the average IR user is unaware of the fine details concerning query construction and simply submits whatever term or terms he/she deems 
most useful for retrieval purposes. Users of Internet search engines are primarily concerned with results, rarely understanding or even considering the mechanisms involved with these systems (Schwartz, 1998). A search user with the need to retrieve specific information from the Web is typically concerned with the task at hand and rarely makes full use of the capabilities provided by sophisticated search tools (Schwartz, 1998). The average user is normally unable to formulate effective queries and requires the assistance of trained intermediaries (Willett, 1988). This must be kept in mind when designing a search interface intended for all web searchers. If no expert is available, the interface must either facilitate the novice creating effective queries him/herself or interpret queries to improve the quality of the results.

Spink et al. (2001) conducted an analysis of over one million queries by more than 200,000 anonymous users and found that less than $5 \%$ of all queries used any advanced operators. There are several aspects of query construction that users must learn in order to generate effective searches. For instance, gaining knowledge surrounding the existence and usage of advanced operators, as well as the distinct syntax associated with each particular search engine, is of great importance when formulating a sophisticated search query.

The term semantics refers to having an understanding of what advanced operators exist and how these operators actually work. For instance, semantic knowledge involves recognizing that Boolean operators such as "AND", “+”, or "and" placed between a set of keywords will assure their presence in the search results. Semantics are application- 
independent, and thus knowledge of semantics can be applied to any search engine that is selected by the user, providing that it supports Boolean operations.

On the other hand, syntax refers to the specific rules regarding the advanced operators that have special meaning to a particular search engine. For instance, a common method followed by most search engines to denote an adjacency operator requires users to place quotation marks around a set of two or more search terms in order to ensure the terms' adjacency in the results. The precise format in which complex search queries are to be constructed is not consistent among search engines. For example, the search engine Google, requires a "+" immediately before a common word that is essential for relevant results. On the other hand AltaVista requires the operator "AND" between a set of keywords to assure their presence in the results. This inconsistency among Internet search engines may be the reason that many web searchers who use Boolean operators to construct their queries make mistakes while doing so. A study performed by Spink et al. (2001) found that the most common mistake was not capitalizing the Boolean operator, as required by certain search engines. While semantics simply refers to the general understanding of advanced operators, syntax refers to the precise format these operators must be expressed in.

An overwhelming number of Web users do not use the advanced search features found on typical search engines, whether using the basic or advanced search interfaces. Spink et al. (2001) suggests this may be because of low usability, functionality, or desirability. However, poor retrieval sets suggest that the use of this functionality would improve 
search results. This contrast suggests the continuation of research into new types of user interfaces that provide advanced search more easily (Jansen et al., 1998). But despite the existence of over 3,200 search engines on the Web (Search Engine Watch, 2000), none currently achieve this goal.

Common advanced capabilities include: Boolean search, adjacency, truncation, exact phrase match, proximity searching, fielded search, specification as to case sensitivity, restriction by date, domain, language, and file type (Schwartz, 1998).

\section{Semantics}

Most operational information retrieval (IR) systems use Boolean logic during search as the semantic structure (Frants et al., 1999). Regardless of its popularity among IR systems, numerous criticisms have been associated with Boolean capabilities. One of the most common criticisms is that the construction of a search query using Boolean operators is often far too difficult for most users. Willett (1988) claims that there are severe problems associated with the use of retrieval systems that encompass Boolean searching. These difficulties are primarily associated with the formulation of a search query using the Boolean operators of AND, OR, and NOT. Thus, the typical end-user is generally unable to formulate effective queries (Willett, 1988).

Although researchers interpret these difficulties in many ways, the apparent complexity among users is considered one of the major shortcomings of Boolean systems (Frants et al., 1999). The intricacy of Boolean systems may be the reason that search users rarely 
use Boolean operators in their search queries. Search users are simply not at ease with Boolean operators and other advanced search features.

Even experienced users may not be proficient in Boolean logic. Moreover, they might be unaware that the system they are using is a Boolean system (Frants et al., 1999). Frants et al. (1999) pointed out that criticisms regarding Boolean systems do not discredit the Boolean principle in any way as a means of information retrieval. However, systems designed for casual users should only make use of control systems that are prevalent among the general population.

A study conducted by Bandos and Resnick (2002) focused on determining whether the poor use of Boolean and other operators is due to logical errors (semantic) or syntactical errors. A generic search engine interface was provided that only allowed participants to enter their query into a text box. It had no labels or syntax hints. The logic behind all tasks presented in the study was structured in such a way that an equal percentage of them required the use of AND, OR and NOT logic. The results provided a clear illustration of how typical search engine users develop the logic used in their search queries. Regardless of the logic behind each task, participants typically strung together all relevant keywords using the AND operator. The operator AND is typically used the most, when compared to the operators OR and NOT (Bandos and Resnick, 2002; Spink et al., 2001). It seems that Web searchers are not sufficiently aware of the specific Boolean operators to successfully choose the correct one. 
A study performed by Mead et al. (2000) examined the effects of general computer experience and age on library system search performance. It was found that $30 \%$ of both high and low computer experience participants demonstrated poor conceptual understanding of Boolean AND by incorrectly indicating that 'find title gold and title silver' would match titles containing only one of the two keywords.

\section{Syntax}

Even when users are aware of the semantic rules required for constructing a query, they still must use the correct syntactic format. Search engines provide only rudimentary data query capabilities, and require a detailed syntactic specification to retrieve relevant results (Chiang et al., 2001).

Wang, Hawk, and Tenopir (2000) reviewed a number of studies of Web searching, concluding that users generally are not very successful, that they experience difficulties with search engine syntax and that some $30 \%$ of searches result in zero hits. Contrary to the behavioral assumptions of most users, search engines have particular syntax rules that must be followed to effectively use even the most basic commands (Bandos and Resnick, 2002). In a study performed by Jansen et al. (2000) that consisted of analyzing transaction logs containing 51,473 queries, it was noted that the most common mistake was not capitalizing the Boolean operator.

The study performed by Bandos and Resnick (2002) found that users did not learn the syntax for each search engine, but rather learned one set of rules and applied that to all 
search engines. This supports Monaghan and Andre's (2000) conclusion that users generally do not view learning syntax as a value-adding use of their time. It seems that when users are using an advanced search feature, it is as likely that they will use it correctly (as required by the system) as incorrectly (Spink et al., 2001).

\section{Examples}

When teaching a new skill or concept, examples are often presented to illustrate the main points (Lee and Hutchison, 1998). An example is an instructional device that provides a model for solving a particular type of problem and is intended to provide the learner with an expert's solution (Atkinson, 2002). People sometimes have difficulty following instructions. One reason for this difficulty is that users are unsure how to apply the instructions to the particular case on which they are working (Catrambone, 1995). The implementation of examples within instructions may help alleviate its intricacy. In addition, learners have been shown to ignore instructions in favor of examples (LeFevre and Dixon, 1986). One reason examples are often favored may be that they provide an instantiation of a procedure to guide behavior (Catrambone, 1995).

Catrambone (1995) demonstrated that general instructions can be improved through examples. This study showed that participants receiving an example that matched the initial task outperformed the participants that were not presented with an example. The fact that the combination of general instructions with an example leads to superior initial performance suggests that the strengths of these two information sources dominate their individual weaknesses when they are combined. In addition, the results of this study also 
found that the participants' overall reading time was not significantly increased by the additional text required to provide the example. However, no study has examined the effects of providing examples in search user interface design.

\section{Conclusion}

Web search tools are the only automated retrieval mechanisms available for guidance in the rapidly growing and changing universe of the WWW (Nicholson, 2000). Increasing Internet access is bringing the need for information seeking skills to an increasing volume and diversity of end users (Ford et al., 2001). However, users have become increasingly frustrated by not being able to effectively formulate search queries and retrieve relevant results. Also, the average user may have problems with the intricacies of the Boolean logic that is used by most search engines to combine keywords into a query statement (Hou and Cercone, 2001).

It is unrealistic to assume that Web searchers understand and fully grasp the subtleties involved with varying search engines or that users will even take the initiative in attempting to learn them. The interface of a search engine is the first impression and only true interaction a user has with such an IR tool. Therefore, the need to design an interface that will guide and allow all Web searchers, from novice to expert, to construct effective complex search queries is of utmost importance. 


\section{OBJECTIVES AND HYPOTHESES}

\section{Objectives}

The objective of this study was to determine the effects of displaying search hints while formulating search queries and provide designers with valuable information regarding the design of search user interfaces. Three components of the search hints were manipulated in the study. The search hints consisted of a combination of semantic information, syntactic information and examples of search queries. Search hints were presented on the interface, or query page, of a generic Internet search engine. The effects of presenting the semantic, syntactic and examples components were measured in terms of user performance and satisfaction. Interactions between the components' effects were also evaluated.

\section{Hypotheses}

\section{Semantic}

1a. Participants will construct more effective search queries, measured by the presence and appropriateness of advanced search operators, when using interfaces with the semantic component than when using interfaces without the semantic component.

1b. Participants will have higher pre-click confidence when using interfaces with the semantic component than when using interfaces without the semantic component.

1c. Participants will report higher satisfaction when using interfaces with the semantic component than when using interfaces without the semantic component.

1d. Participants will complete tasks faster when using interfaces with the semantic component than when using interfaces without the semantic component. 


\section{Syntactic}

2a. Participants will construct more effective search queries, measured by the presence and appropriateness of advanced search operators, when using interfaces with the syntactic component than when using interfaces without the syntactic component.

2b. Participants will have higher pre-click confidence when using interfaces with the syntactic component than when using interfaces without the syntactic component.

2c. Participants will report higher satisfaction when using interfaces with the syntactic component than when using interfaces without the syntactic component.

2d. Participants will complete tasks faster when using interfaces with the syntactic component than when using interfaces without the syntactic component.

\section{Examples}

3a. Participants will construct more effective search queries, measured by the presence and appropriateness of advanced search operators, when using interfaces with the examples component than when using interfaces without the examples component.

3b. Participants will have higher pre-click confidence when using interfaces with the examples component than when using interfaces without the examples component.

3c. Participants will report higher satisfaction when using interfaces with the examples component than when using interfaces without the examples component.

3d. Participants will complete tasks faster when using interfaces with the examples component than when using interfaces without the examples component.

4. As the number of search hint components displayed on the interface increases, the incremental magnitude of effect on all dependent variables will decrease. 


\section{METHODS}

\section{Participants}

There were a total of 80 participants recruited for the study. Participants with ages ranging from 19 to 40 years old were targeted to reduce the effects of age on the results. The distribution of the participants' age can be seen in Figure 1. Participants were required to have at least minimal experience utilizing computer search tools. This was to assure that every participant had no less than a slight understanding of the basic functions of these search tools. The distribution of the participants' search experience is illustrated in Figure 2.

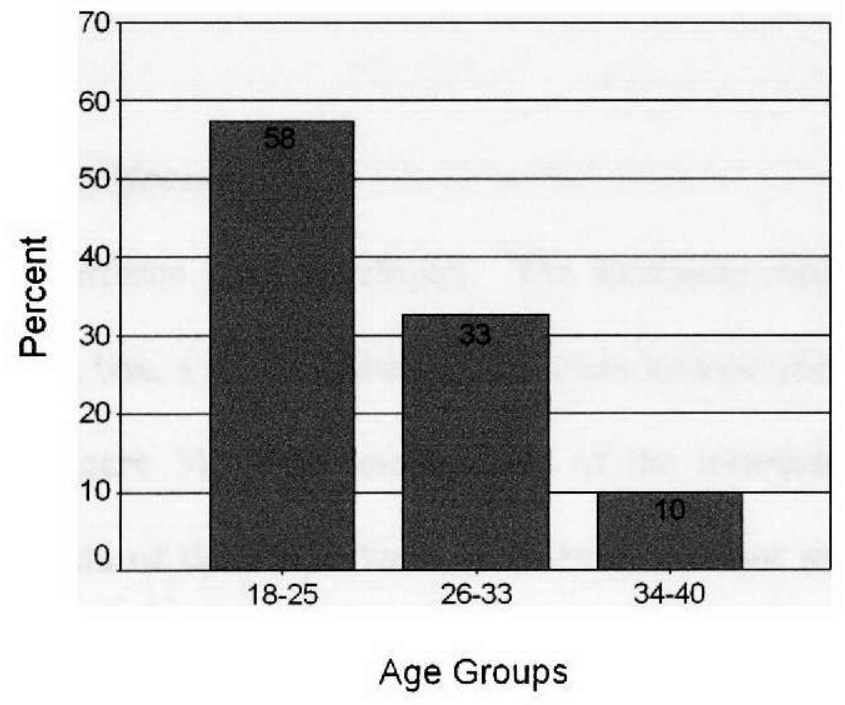

Figure 1. Participants' age distribution 


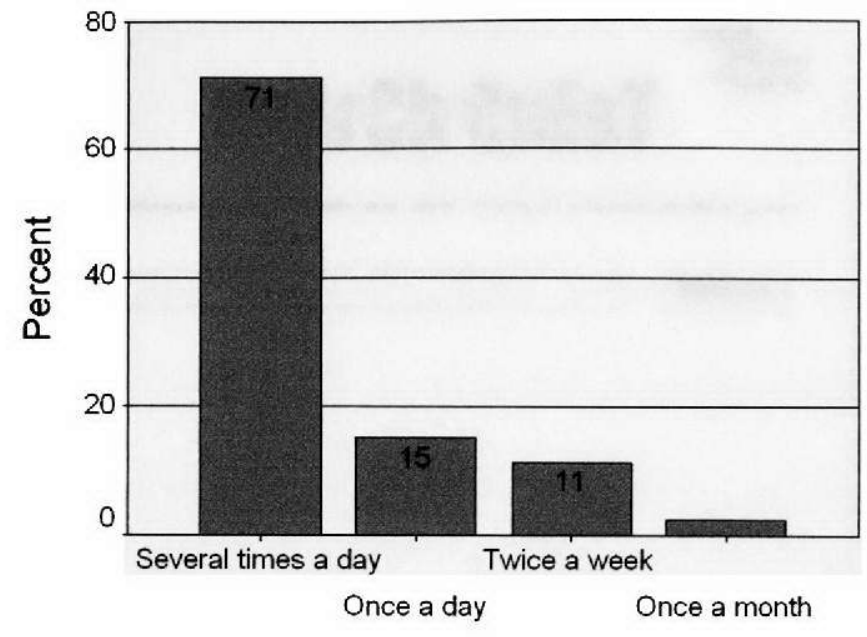

Frequency of Search Engine Use

Figure 2. Search experience distribution

\section{Materials}

Search Engine Interfaces

Eight search engine interfaces were developed. The interfaces designed for this study consisted of a single text box, a set of written search hints located above the text box, and a search button (see Figure 3). The screen shots of the interfaces can be found in Appendix A. All aspects of these interfaces were held constant except for the search hints displayed within them. These search hints were intended to guide the participants and assist them in constructing their search query. 


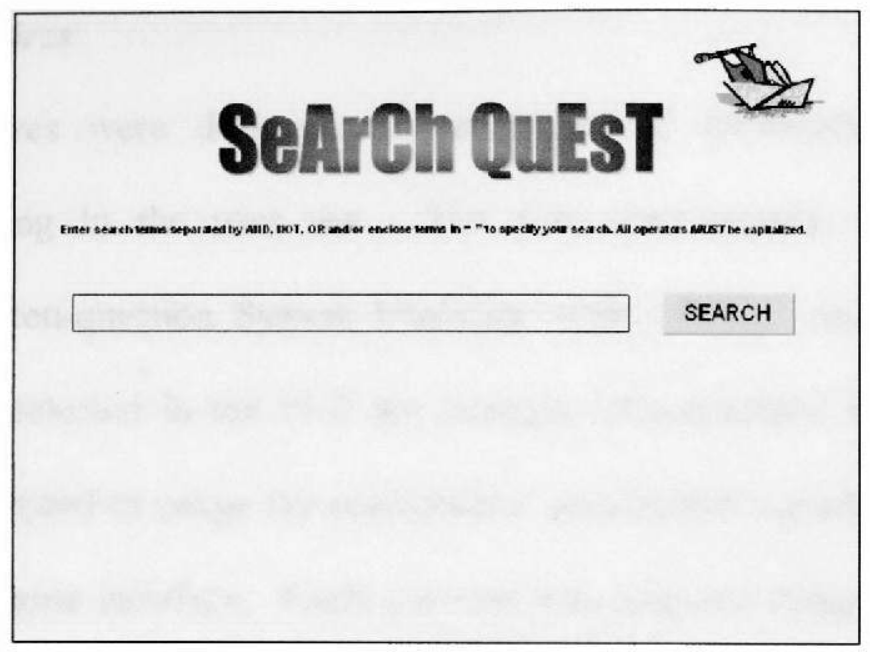

Figure 3. Example of Search Engine Interface

Three components of the search hints were manipulated in the study. The search hints consisted of a combination of syntactic information, semantic information and examples of search queries. Search hints contained between zero and three of these components.

The syntactic component provided details regarding the precise syntax that was accepted by the system. Syntax refers to the specific structure and grammatical rules pertaining to the Boolean operators that are recognized by search engines. The syntax that was most commonly used by commercial search engines was used. The semantic component explained the logic behind the Boolean operators and the precise circumstances in which they should be used. This component provided participants with information concerning the effect of employing proper advanced operators within a search query. The examples component consisted of a set of four examples of search queries. Each example pertained to one of the four advanced operators discussed in the search hints (AND, NOT, OR, “”). 


\section{Questionnaires}

Three questionnaires were designed to gather crucial information regarding each participant partaking in the user test. The first questionnaire (Appendix B) was comprised of the ten-question System Usability Scale (SUS). According to Brookes (1996), the items selected in the SUS are strongly intercorrelated at 0.7 to 0.9 . This questionnaire attempted to gauge the participants' satisfaction regarding their interaction with the search engine interface. Each question was assessed using a five point Likert scale with the verbal anchors ranging from 'strongly disagree' for one to 'strongly agree' for five. The questionnaire was administered at the completion of the test so as not to bias participants' performance.

The second questionnaire (Appendix C) consisted of a set of questions intended to gather basic demographics, as well as system experience and expertise. The demographics section of the questionnaire requested a participant's age and gender to insure that a representative sample had been recruited. The subsequent questions were intended to gauge a participant's general experience and expertise with search tools and functions by inquiring about the participant's confidence while searching, frequency of usage of search functions and the most common operators used while searching. In addition, participants were asked if they would be in favor of using the new interface, as well as if they would prefer to use it over their current means for searching. This questionnaire was administered at the completion of the first questionnaire. 
The third questionnaire (Appendix D) consisted of four multiple choice questions and attempted to gauge a participant's knowledge and understanding of Boolean operators. Each question pertained to a different Boolean operator and required participants to match a search query to its corresponding outcome. This questionnaire was also administered at the completion of the test so that participants would not be cued to use Boolean operators within their search queries.

\section{Tasks}

Six realistic search tasks were created for the purpose of this study. All tasks were presented as an information need, rather than precise keywords, so participants would be compelled to choose their own keywords and operators while formulating their search query. Participants were not allowed to perform iterative searches during the user-test. They only had one attempt to obtain the desired response and were strongly encouraged to obtain the correct answer in a single try. This was intended to provoke the employment of advanced search features and formulation of complex search queries.

All six tasks required more than one keyword in the search query to obtain relevant results in a single attempt. Thus, the use of advanced search operators in the search queries for any of the six tasks presented would retrieve a higher level of precision in terms of the ensuing results. The six tasks were separated into three groups. The tasks were constructed so that two required each of the Boolean operators "AND", "NOT", and "OR" in the search query. All of the tasks required the use of adjacency operators. 
In addition to these six search tasks, a short and simple practice task was generated. This practice task was always the first task presented to each participant. No data was gathered from this task. It was, however, treated as any other task and participants were not made aware that they were in fact performing a practice trial. The purpose of the practice task was to introduce the search engine interface to the participant prior to collecting data and to ensure that the participant understood the instructions. Once this task was performed, the participant was then familiarized with the interface and was asked to search for the remaining six tasks, one at a time, using the same interface.

The following was the practice task used in this study:

1) Please find all pages containing your name.

The following were the six experimental tasks, classified by their respective Boolean operator:

$A N D$

1) What was the name of the elementary school Dean Martin attended in Ohio?

2) At what age did Jeff Gordon become the second youngest champion in NASCAR history?

NOT

3) The Johnson family is planning their yearly vacation and feels it is time to do something different than visit Mickey Mouse for yet another year in a row. Search for Florida theme parks, excluding Walt Disney World.

4) Search for infamous dictators, with the exception of Adolf Hitler. 
5) Diane has recently been having many car problems and is interested in purchasing a new vehicle. One thing she is sure of is that she prefers an American made car. Search for automobiles manufactured in the United States that are sold at either Maroone or Sunshine dealerships.

6) Jack is interested in purchasing new cell phones for his employees. He has narrowed down his options to two models, either Nokia or Motorola. No preference is given to either one. Search for a location where either one is sold.

\section{Procedure}

Prior to the commencement of the test, it was determined whether a potential participant was suitable to partake in the user test. This was done by verifying that he/she was within the specified age range and had at least minimal experience utilizing computer search tools.

Each participant was greeted and given a thorough explanation and detailed instructions regarding his/her role in the experiment. He/she was asked to read and sign the consent form (Appendix E) and was encouraged to voice all questions and concerns regarding the experiment. Once all questions were addressed, the experiment began. The test administrator first read the practice task out loud. The task was repeated to the participant, if necessary. When the participant felt ready to begin the search, he/she was then presented with one of the eight search engine interfaces used to input his/her queries. 
Upon the completion of the practice task, the search engine interface used to complete the task was minimized. Then one of the six experimental tasks were randomly selected and read to the participant. As soon as the participant indicated that he/she was ready to begin the new search, a new screen with the search interface was maximized. Each participant interacted with only one of the eight search engine interfaces and performed all seven tasks (the practice task and six experimental tasks) using this interface. Timing commenced as soon as the screen was maximized and the participant was presented with the search engine interface. The timing for that particular task concluded at the moment the participant clicked on the Search button. The data collection sheet can be found in Appendix F. The order in which the tasks were presented to each participant was randomized, with the exception of the practice task.

Upon the completion of each experimental task, the participant was then asked to answer a single question pertaining to the confidence he/she felt regarding the generated search query. This question assessed how confident the participant was that his/her query would find the correct response and was answered using the 7-point Likert scale developed by Lergier and Resnick (2001). The Search button did not lead the participant to a subsequent screen, but rather denoted the conclusion of a particular task. At no point during the user-test was the participant presented with the output results of his/her search query.

Once the participant completed all seven tasks, he/she was asked to fill out the SUS questionnaire. This was done in an attempt to measure the participant's satisfaction with 
his/her interaction with the search engine interface. A second questionnaire was administered upon the completion of the first. The purpose of the second questionnaire was to gather information regarding basic demographics, search experience and expertise and overall interface approval. Lastly, a third questionnaire was distributed to obtain a better understanding of the participant's knowledge and understanding of Boolean operators. Upon the completion of all tasks and questionnaires, the participant was thanked for his/her participation in the experiment and dismissed.

Experimental Design

The study included three independent variables, each with two respective levels of intensity. The independent variables, along with their levels of intensity, are listed in Table 1.

Table 1. Independent Variables with Respective Levels of Intensity

\begin{tabular}{cl}
\hline \multirow{2}{*}{ Syntactic } & $\begin{array}{l}\text { Displayed } \\
\text { Not displayed }\end{array}$ \\
\hline \multirow{2}{*}{ Semantic } & $\begin{array}{l}\text { Displayed } \\
\text { Not displayed }\end{array}$ \\
\hline \multirow{2}{*}{ Examples } & $\begin{array}{l}\text { Displayed } \\
\text { Not displayed }\end{array}$ \\
\hline
\end{tabular}

The syntactic component provided participants with details regarding the precise syntax accepted by the search engine created for this experiment. The semantic component described the logic behind the Boolean operators that are specifically recognized by this system. The examples component consisted of a set of four examples of search queries, one for each of the four advanced operators discussed in the search hints. These 
components were displayed on the search engine interface in a manner that was easy to read and understand.

The following is the wording of each component as it was displayed on the search engine interfaces presented to the participants:

\section{Syntactic:}

Enter search terms separated by AND, NOT, OR and/or enclose terms in " " to specify your search. All operators MUST be capitalized.

\section{Semantic:}

AND: finds documents containing all keywords and phrases

NOT: excludes documents containing the specified word or phrase

OR: finds documents containing at least one of the specified words or phrases

“": finds documents with the exact phrase included within quotes

\section{Examples:}

i.e. Swingline AND stapler

i.e. Homer NOT Simpson

i.e. dogs $\mathrm{OR}$ cats

i.e. "United States"

The combination of all the levels produced a complete factorial design, generating eight treatment combinations $(2 \times 2 \times 2=8)$. Each lettered cell found in Table 2 is representative of each of the search engine interfaces used in this experiment. Every 
possible combination of each variation of the independent variables made up one of the search engine interfaces. For instance, the interface that was representative of cell A contained all three independent variables, the interface that was representative of cell B contained only the syntactic and examples component, and so on. The same process was used to design all eight interfaces from $\mathrm{A}$ through $\mathrm{H}$, with $\mathrm{H}$ representing the control group.

Table 2: Treatment Combinations

\begin{tabular}{|c|c|c|c|c|c|}
\hline & \multicolumn{4}{|c|}{ Syntactic } \\
\hline & & \multicolumn{2}{|c|}{ Yes } & \multicolumn{2}{|c|}{ No } \\
\hline & & \multicolumn{2}{|c|}{ Semantic } & \multicolumn{2}{|c|}{ Semantic } \\
\hline & & Yes & No & Yes & No \\
\hline \multirow{2}{*}{$\frac{\tilde{y}}{\bar{z}}$} & Yes & A & B & $\mathrm{C}$ & D \\
\hline & No & $\mathrm{E}$ & $F$ & $\mathrm{G}$ & $\mathrm{H}$ \\
\hline
\end{tabular}

The dependent variables of this study consisted of:

\section{Performance}

Syntax

Performance was measured by determining whether or not the participant successfully followed the displayed instructions and constructed a correct search query. There were two measures of correctness. One measure consisted of using the correct form of syntax. The correct form of syntax refers to constructing a search query with the proper syntax, such as capitalizing all Boolean operators. 


\section{Semantics}

The second measure of correctness consisted of applying the appropriate semantics, such as using some form of the Boolean operator "AND" between the set of keywords that were collectively desired in the results. Therefore, the definition of a correct query was a search query that contained the correct usage of both syntax and semantics and coincided with the instructions found on the search engine interfaces. The precise keywords within the search queries were not evaluated. The focus was only on the proper usage of the advanced search features.

As part of a post-test questionnaire, participants were asked if they utilize advanced search operators while formulating search queries, as well as which form of Boolean operator syntax they used most often.

\section{Pre-click confidence (PCC)}

Participants were asked to rate their pre-click confidence at the completion of each task using a 7-point Likert scale with verbal anchors at all odd numbers.

\section{Satisfaction}

Participants were asked to rate their satisfaction with the search engine interface using the SUS Questionnaire. In addition, participants were asked if they would be in favor of using the interface and if they would prefer to use this interface over the interface of the search engine they used most often. 


\section{Time}

The time it took each participant to complete his or her search query was recorded.

Timing commenced just as the participant was presented with a particular search engine interface and concluded the moment the participant clicked on the Search button of that interface. 


\section{RESULTS}

Analyses of variance (ANOVAs) were computed individually for each of the dependent variables using SPSS version 11.0. The Bonferroni method was used in the Post Hoc tests. Pairwise comparisons were also used to further analyze the interactions of the independent variables. The complete summary of the statistical output can be found in Appendix G.

\section{Semantic Component}

Hypothesis la: Participants will construct more effective search queries, measured by the presence and appropriateness of advanced search operators, when using interfaces with the semantic component than when using interfaces without the semantic component.

Participants using interfaces with the semantic component constructed significantly more effective search queries, in terms of the correct usage of semantics, than participants using interfaces without the semantic component, $F(1,456)=7.448, p<0.05$. Participants interacting with interfaces with the semantic component had an average success rate of 0.579 while those interacting with interfaces without the semantic component had an average success rate of 0.463 (see Figure 4). 


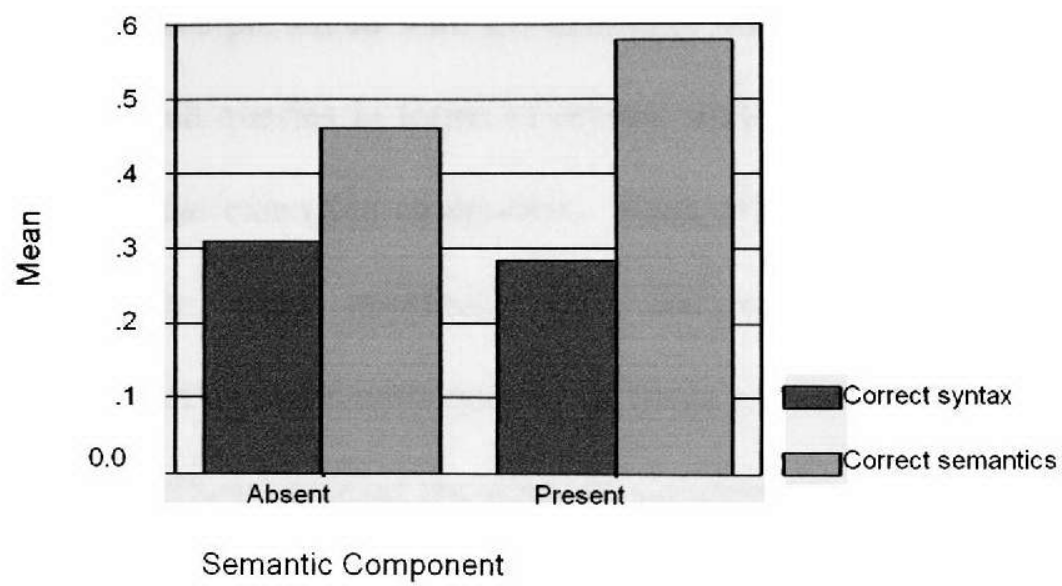

Figure 4. Average success rate of syntax and semantics in the 2 levels of the semantic component

The presence of the semantic component did not have any significant effect on the correct usage of syntax, $\mathrm{F}(1,456)=0.389, \mathrm{p}>0.05$. However, the interaction between the semantic component and syntactic component was significant, $F(1,456)=7.298, \mathrm{p}<0.05$, in terms of the correct usage of syntax. A pairwise comparison indicated that when the semantic component was absent, participants who were presented with the syntactic component constructed significantly more effective search queries in terms of correct syntax $(\mathrm{p}<0.001)$, than those using interfaces without the syntactic component. Also, when the syntactic component was present, participants using interfaces with the semantic component as well constructed significantly less effective search queries in terms of syntax $(\mathrm{p}<0.05)$, than those using interfaces without the semantic component.

Furthermore, the interaction between the semantic component and examples component was significant, $F(1,456)=10.982, p<0.005$, in terms of the correct usage of semantics. A pairwise comparison indicated that when the semantic component was absent, 
participants who were presented with the examples component constructed significantly more effective search queries in terms of correct semantics $(p<0.001)$, than those using interfaces without the examples component. Also, when the examples component was absent, participants using interfaces with the semantic component constructed significantly more effective search queries in terms of semantics $(p<0.001)$, than those interacting with interfaces without the semantic component.

Hypothesis 1b: Participants will have higher pre-click confidence when using interfaces with the semantic component than when using interfaces without the semantic component.

Participants interacting with interfaces with the semantic component were significantly more confident about their search queries than those interacting with interfaces without the semantic component, $\mathrm{F}(1,456)=3.898, \mathrm{p}<0.05$. Interfaces with the semantic component had an average pre-click confidence of 4.338 and interfaces without the semantic component had an average pre-click confidence of 4.108 (see Figure 5).

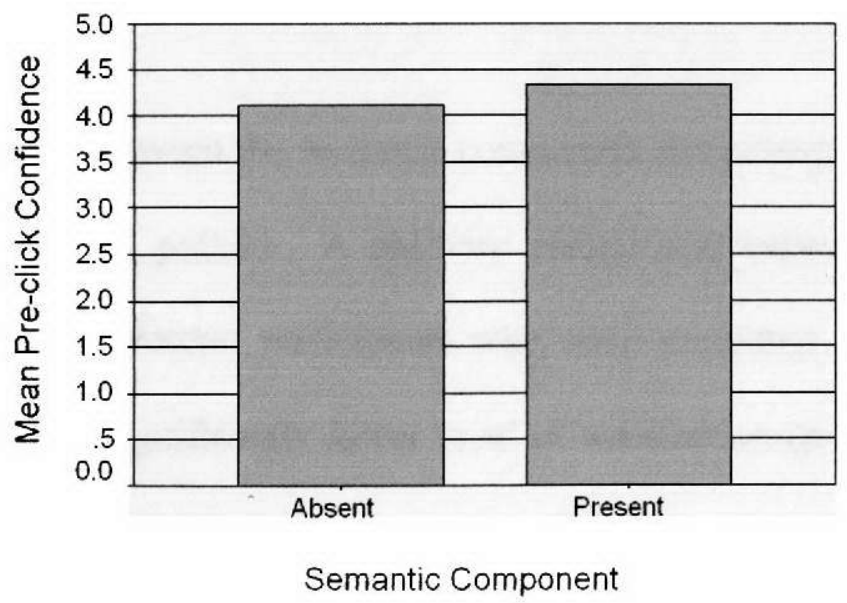

Figure 5. Average pre-click confidence in the 2 levels of the semantic component 
Hypothesis 1c: Participants will report higher satisfaction when using interfaces with the semantic component than when using interfaces without the semantic component.

There was no significant difference in the level of satisfaction reported between participants using interfaces with the semantic component and participants using interfaces without the semantic component, $F(1,456)=1.468, \mathrm{p}>0.05$. On the SUS scale, participants using interfaces with the semantic component reported an average satisfaction rating of 77.9 while those using interfaces without the semantic component reported an average satisfaction rating of 79.3 (see Figure 6).

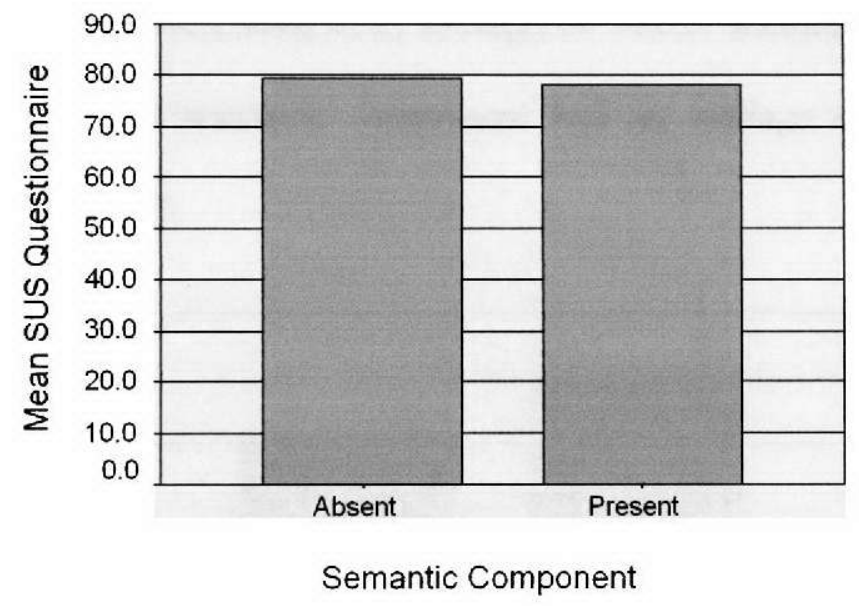

Figure 6. Average satisfaction ratings in the 2 levels of the semantic component

However, the interaction between the semantic component and examples component was significant, $F(1,456)=4.380, \mathrm{p}<0.05$. A pairwise comparison indicated that when the semantic component was present, participants who were presented with the examples component as well had a significantly lower level of satisfaction $(\mathrm{p}<0.001)$, than those using interfaces without the examples component. Also, when the examples component was present, participants using interfaces with the semantic component as well had a 
significantly lower level of satisfaction $(\mathrm{p}<0.05)$, than those interacting with interfaces without the semantic component.

Hypothesis 1d: Participants will complete tasks faster when using interfaces with the semantic component than when using interfaces without the semantic component.

Participants using interfaces with the semantic component took a significantly longer amount of time completing tasks than participants using interfaces without the semantic component, $\mathrm{F}(1,456)=3.910, \mathrm{p}<0.05$. Participants using interfaces with the semantic component completed the search tasks in an average of 30.637 seconds while participants using interfaces without the semantic component had an average completion time of 25.813 seconds (see Figure 7).

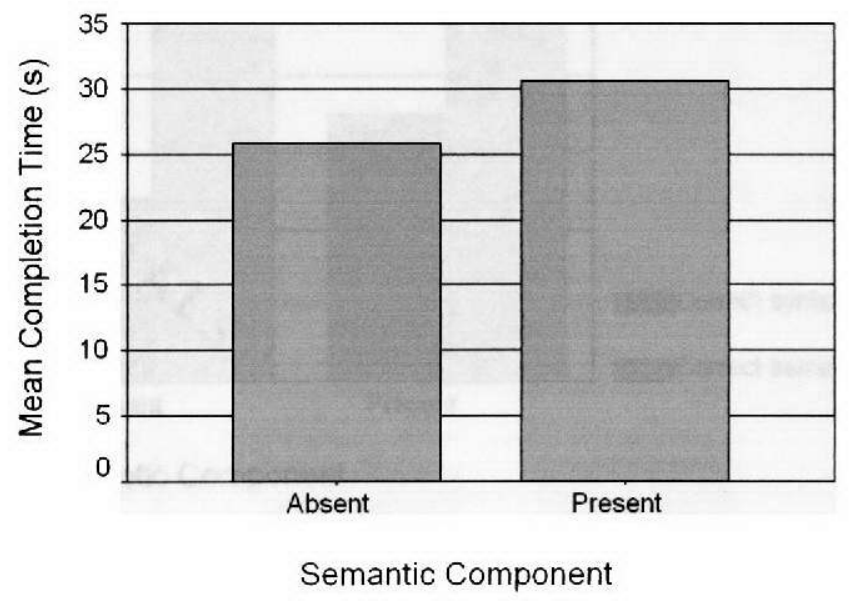

Figure 7. Average completion times in the 2 levels of the semantic component 


\section{Syntactic Component}

Hypothesis 2a: Participants will construct more effective search queries, measured by the presence and appropriateness of advanced search operators, when using interfaces with the syntactic component than when using interfaces without the syntactic component.

Participants using interfaces with the syntactic component constructed significantly more effective search queries, in terms of the correct usage of syntax, than participants using interfaces without the syntactic component, $F(1,456)=7.298, p<0.05$. Participants interacting with interfaces with the syntactic component had an average success rate of 0.350 while those interacting with interfaces without the syntactic component had an average success rate of 0.242 (see Figure 8).

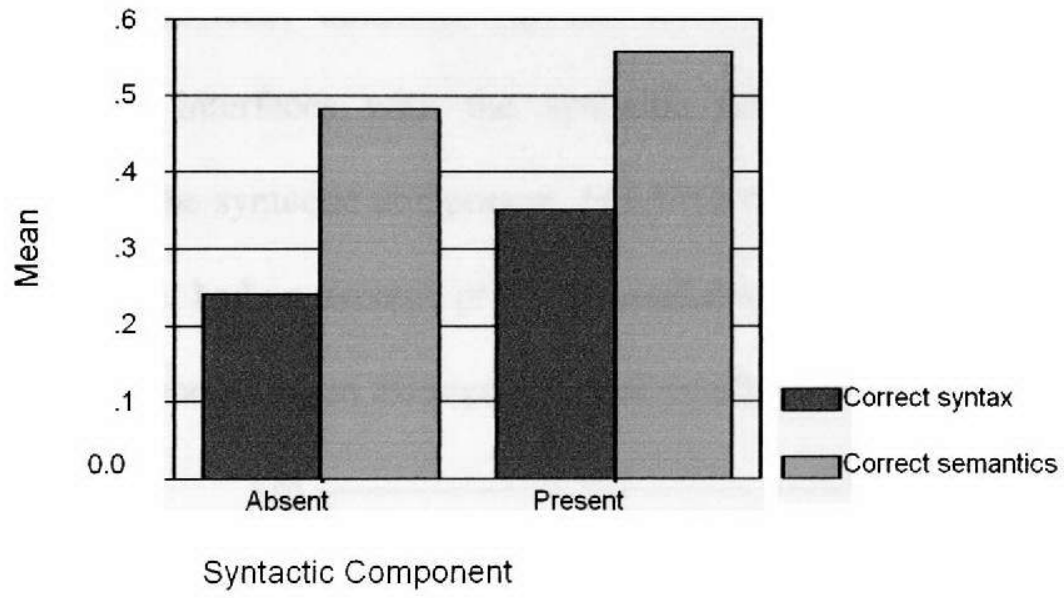

Figure 8. Average success rate of syntax and semantics in the 2 levels of the syntactic component

The presence of the syntactic component did not have any significant effect on the correct usage of semantics, $F(1,456)=3.078, p>0.05$. However, the interaction between the syntactic component and examples component was significant, $F(1,456)=5.472, p<0.05$, in terms of the correct usage of semantics. A pairwise comparison indicated that when 
the syntactic component was absent, participants who were presented with the examples component constructed significantly more effective search queries in terms of the correct use of semantics ( $p<0.005)$, than those using interfaces without the examples component. Also, when the examples component was absent, participants using interfaces with the syntactic component constructed significantly more effective search queries in terms of semantics $(\mathrm{p}<0.05)$, than those using interfaces without the syntactic component.

Hypothesis 2b: Participants will have higher pre-click confidence when using interfaces with the syntactic component than when using interfaces without the syntactic component.

There was no significant difference in the level of pre-click confidence between participants using interfaces with the syntactic component and participants using interfaces without the syntactic component, $F(1,456)=0.682$, $p>0.05$. Interfaces with the syntactic component had an average pre-click confidence of 4.271 and interfaces without the syntactic component had an average pre-click confidence of 4.175 (see Figure 9).

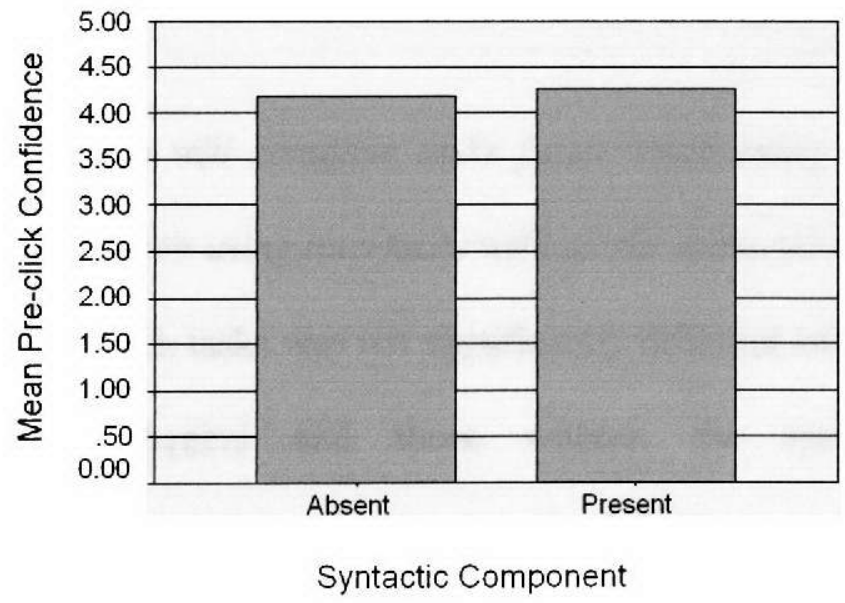

Figure 9. Average pre-click confidence in the 2 levels of the syntactic component 
Hypothesis 2c: Participants will report higher satisfaction when using interfaces with the syntactic component than when using interfaces without the syntactic component.

There was no significant difference in the level of satisfaction reported between participants using interfaces with the syntactic component and participants using interfaces without the syntactic component, $F(1,456)=0.194, p>0.05$. On the SUS scale, participants using interfaces with the syntactic component reported an average satisfaction rating of 78.9 while those using interfaces without the syntactic component reported an average satisfaction rating of 78.4 (see Figure 10).

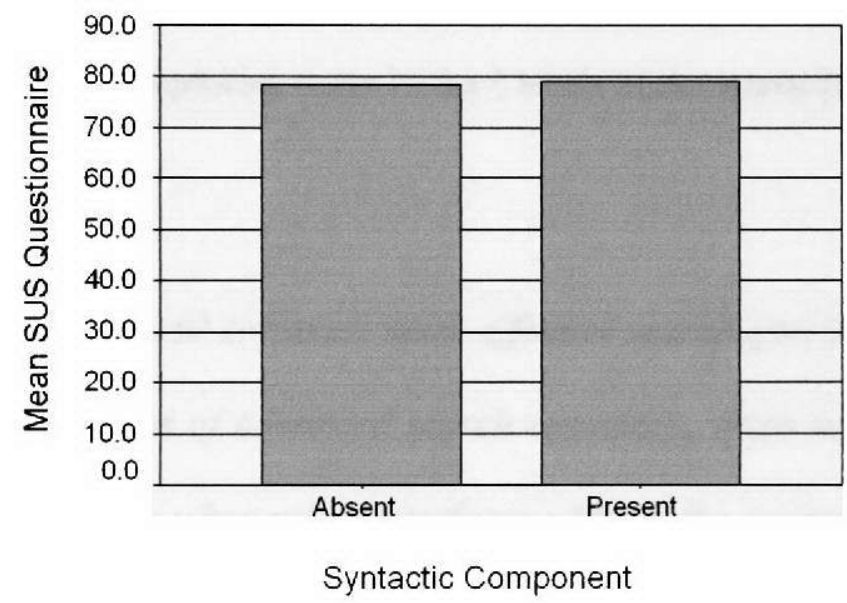

Figure 10. Average satisfaction ratings in the 2 levels of the syntactic component

Hypothesis 2d: Participants will complete tasks faster when using interfaces with the syntactic component than when using interfaces without the syntactic component.

Completion time of the search tasks was not significantly different between the interfaces with the syntactic component and those without the syntactic component, $\mathrm{F}(1,456)=0.158, \mathrm{p}>0.05$. Participants using interfaces with the syntactic component completed the search tasks in an average of 28.710 seconds while participants using 
interfaces without the syntactic component had an average completion time of 27.740 seconds (see Figure 11).

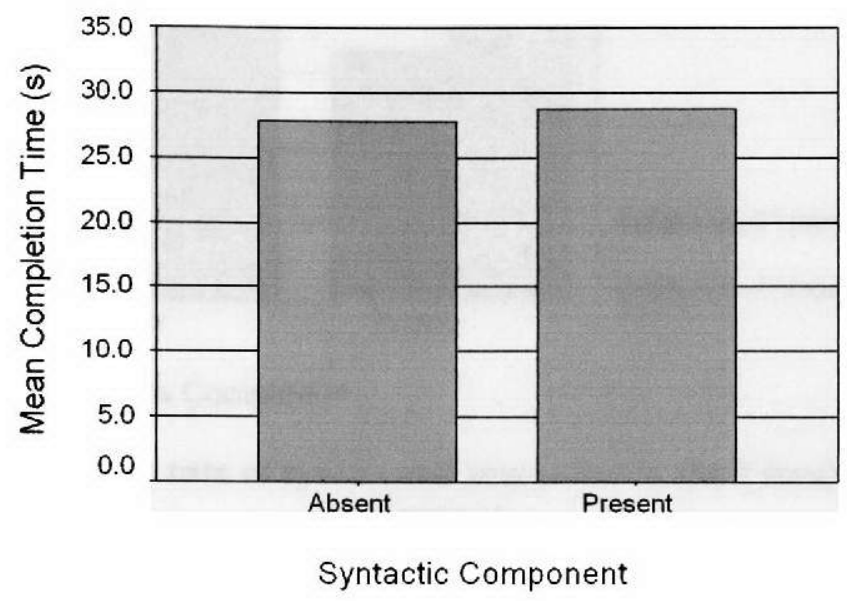

Figure 11. Average completion times in the 2 levels of the syntactic component

\section{Examples Component}

Hypothesis 3a: Participants will construct more effective search queries, measured by the presence and appropriateness of advanced search operators, when using interfaces with the examples component than when using interfaces without the examples component.

Participants using interfaces with the examples component constructed significantly more effective search queries, in terms of the correct usage of semantics, than participants using interfaces without the examples component, $\mathrm{F}(1,456)=7.448, \mathrm{p}<0.05$. Participants interacting with interfaces with the examples component had an average success rate of 0.579 while those interacting with interfaces without the examples component had an average success rate of 0.463 (see Figure 12). 


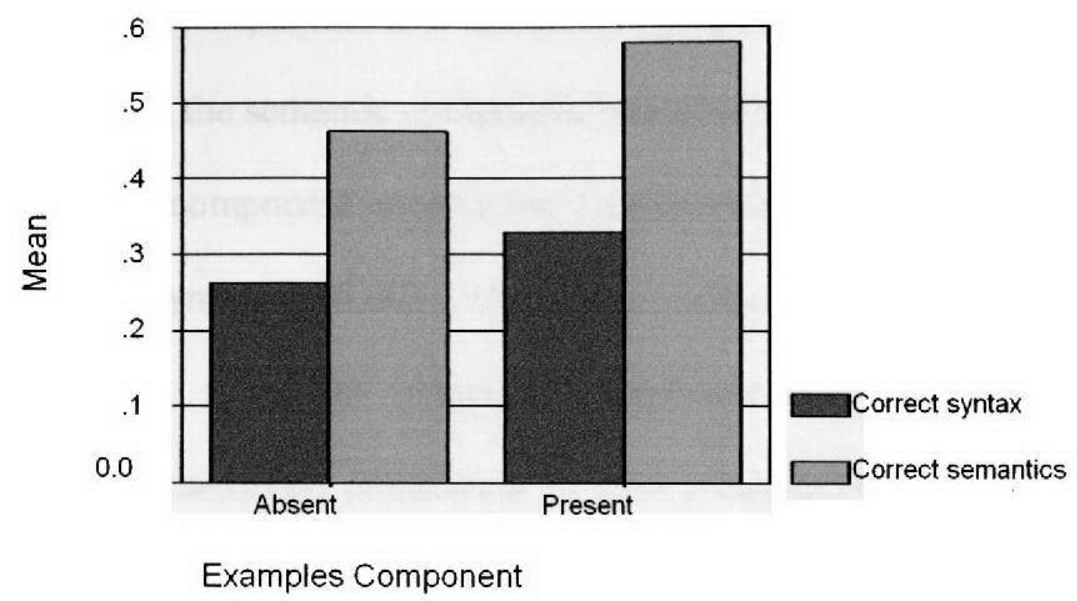

Figure 12. Average success rate of syntax and semantics in the 2 levels of the examples component

The presence of the examples component did not have any significant effect on the correct usage of syntax, $F(1,456)=2.764, p>0.05$. However, the interaction between the syntactic component and examples component was significant, $F(1,456)=13.991$, $\mathrm{p}<0.001$, in terms of the correct usage of syntax. A pairwise comparison indicated that when the examples component was absent, participants who were presented with the syntactic component constructed significantly more effective search queries in terms of correct syntax $(\mathrm{p}<0.001)$, than those using interfaces without the syntactic component. Also, when the syntactic component was absent, participants using interfaces with the examples component constructed significantly more effective search queries in terms of syntax $(\mathrm{p}<0.001)$, than those interacting with interfaces without the examples component.

Furthermore, as previously stated, neither the semantic component or examples component had a significant effect on the correct usage of syntax, however, the interaction between the semantic component and examples component was significant, 
$\mathrm{F}(1,456)=6.218, \mathrm{p}<0.05$, in terms of the correct usage of syntax. A pairwise comparison indicated that when the semantic component was absent, participants who were presented with the examples component constructed significantly more effective search queries in terms of correct syntax $(\mathrm{p}<0.001)$, than those using interfaces without the examples component. Also, when the examples component was present, participants using interfaces with the semantic component as well constructed significantly less effective search queries in terms of syntax $(p<0.05)$, than those using interfaces without the semantic component.

Hypothesis 3b: Participants will have higher pre-click confidence when using interfaces with the examples component than when using interfaces without the examples component.

Participants interacting with interfaces without the examples component were significantly more confident about their search queries than those interacting with interfaces with the examples component, $F(1,456)=8.042, \mathrm{p}<0.05$. Interfaces with the examples component had an average pre-click confidence of 4.058 and interfaces without the examples component had an average pre-click confidence of 4.388 (see Figure 13). 


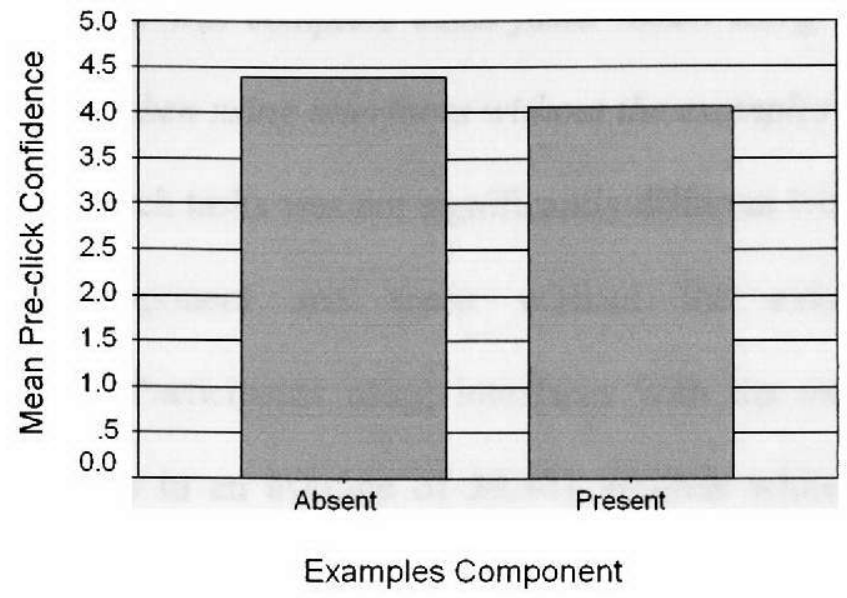

Figure 13. Average pre-click confidence in the 2 levels of the examples component

Hypothesis 3c: Participants will report higher satisfaction when using interfaces with the examples component than when using interfaces without the examples component.

Interfaces without the examples component were given significantly higher ratings than the interfaces with the examples component, $\mathrm{F}(1,456)=9.513, \mathrm{p}<0.005$. On the SUS scale, participants using interfaces with the examples component reported an average satisfaction rating of 76.9 and participants using interfaces without the examples component reported an average satisfaction rating of 80.4 (see Figure 14).

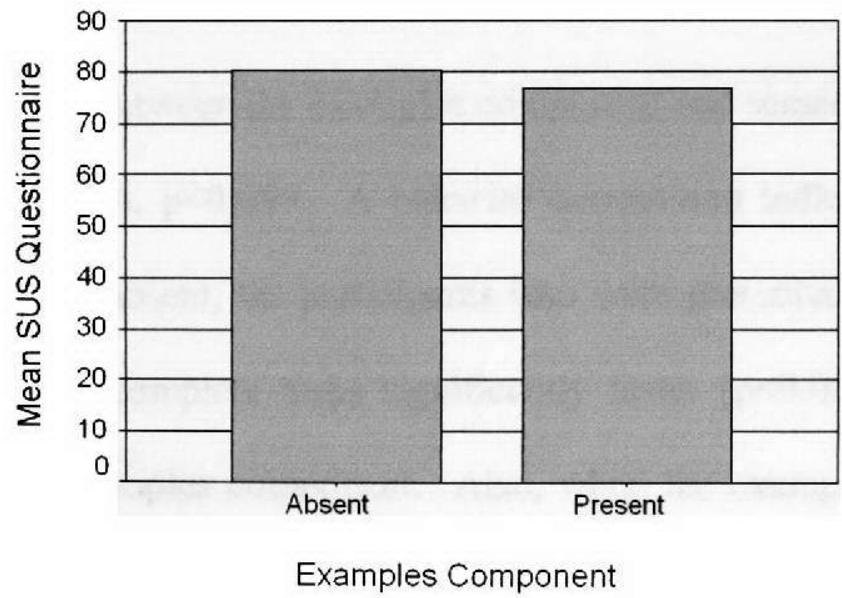

Figure 14. Average satisfaction ratings in the 2 levels of the examples component 
Hypothesis 3d: Participants will complete tasks faster when using interfaces with the examples component than when using interfaces without the examples component.

Completion time of the search tasks was not significantly different between the interfaces with the examples component and those without the examples component, $\mathrm{F}(1,456)=0.778, \mathrm{p}>0.05$. Participants using interfaces with the examples component completed the search tasks in an average of 29.301 seconds while participants using interfaces without the examples component had an average completion time of 27.149 seconds (see Figure 15).

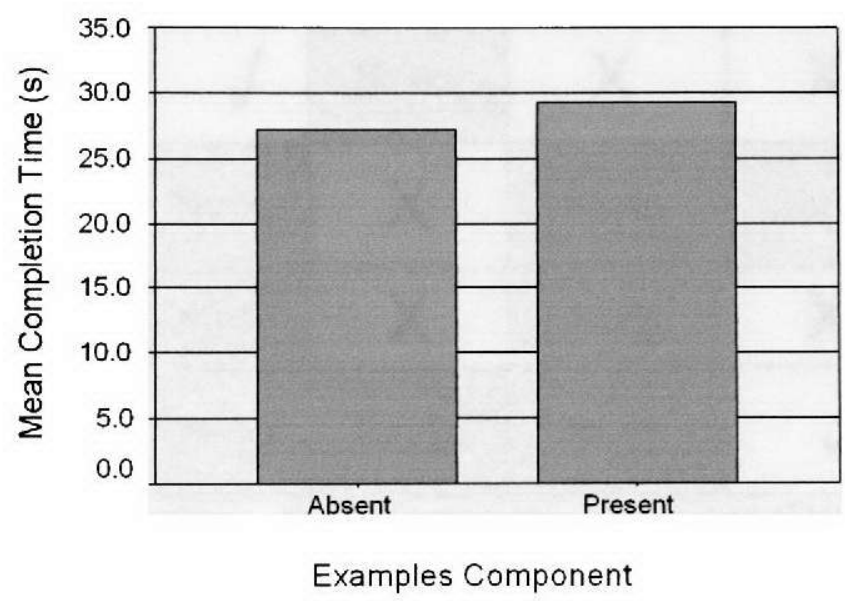

Figure 15. Average completion times in the 2 levels of the examples component

However, the interaction between the examples component and semantic component was significant, $F(1,456)=9.554, p<0.005$. A pairwise comparison indicated that when the semantic component was absent, the participants who were presented with the examples component were able to complete tasks significantly faster $(\mathrm{p}<0.05)$ than those using interfaces without the examples component. Also, when the examples component was absent, participants using interfaces with the semantic component were able to complete 
tasks significantly faster $(\mathrm{p}<0.001)$ than those interacting with interfaces without the semantic component.

The outcome of statistical results, including main effects and interactions, for hypotheses 1 through 3 are summarized in Table 3.

Table 3. Summary of results for hypotheses 1-3

\begin{tabular}{|c|c|c|c|c|c|c|}
\hline & Semantic & Syntax & Examples & $\begin{array}{c}\text { Semantics/ } \\
\text { Syntax }\end{array}$ & $\begin{array}{l}\text { Semantics/ } \\
\text { Examples }\end{array}$ & $\begin{array}{c}\text { Syntaxl } \\
\text { Examples }\end{array}$ \\
\hline $\begin{array}{c}\text { More effective } \\
\text { queries } \\
\text { (Semantics) }\end{array}$ & $\sqrt{ }$ & No sig. & $\sqrt{ }$ & No sig. & $x^{2}$ & $\sqrt{ }$ \\
\hline $\begin{array}{c}\text { More effective } \\
\text { queries } \\
\text { (Syntax) }\end{array}$ & No sig. & $\sqrt{ }$ & No sig. & $X$ & $X$ & $\sqrt{ }$ \\
\hline $\begin{array}{c}\text { Higher pre- } \\
\text { click } \\
\text { confidence } \\
\end{array}$ & $\sqrt{ }$ & No sig. & $X$ & No sig. & No sig. & No sig. \\
\hline $\begin{array}{c}\text { Greater } \\
\text { satisfaction }\end{array}$ & No sig. & No sig. & $X$ & No sig. & $X$ & No sig. \\
\hline $\begin{array}{c}\text { Reduced } \\
\text { completion } \\
\text { time }\end{array}$ & $X$ & No sig. & No sig. & No sig. & $\sqrt{ }$ & No sig. \\
\hline
\end{tabular}

: significant and supports hỵpothesis: $\mathbf{X}$ : significant in opposite direction of hypothesis

Hypothesis 4: As the number of search hint components displayed on the interface increases, the incremental magnitude of effect on all dependent variables will decrease.

There was no difference in the magnitude of effect on the dependent variables as the number of search hint components displayed on the interface increased.

\section{Boolean Operators}

The following results are based on analyses across the three search hint components. 


\section{Performance - Semantic}

The correct use of semantics was significantly different among the three Boolean operators, $\mathrm{F}(2,456)=15.656, \mathrm{p}<0.001$. The average success rate, in terms of semantics, was 0.413 for the AND operator, 0.688 for the NOT operator and 0.463 for the OR operator (see Figure 16). After running a post hoc analysis, it was noted that participants used the correct form of semantics for the NOT operator significantly more than the AND operator $(\mathrm{p}<0.001)$ or the OR operator $(\mathrm{p}<0.001)$. No significance was found between the AND operator and the NOT operator $(\mathrm{p}>0.05)$.

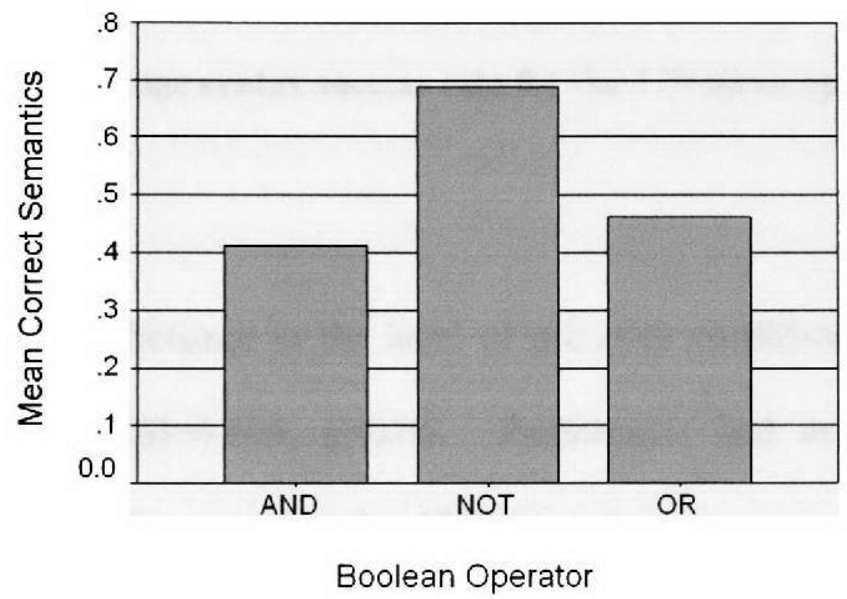

Figure 16. Average semantic success rate for the 3 Boolean operators

\section{Performance - Syntax}

The correct use of syntax was significantly different among the three Boolean operators, $F(2,456)=4.351, p<0.05$. The average success rate, in terms of syntax, was 0.212 for the AND operator, 0.344 for the NOT operator and 0.331 for the OR operator (see Figure 17). After running a post hoc analysis, it was noted that participants were significantly less successful in using the correct form of syntax for the AND operator than the NOT 
operator $(\mathrm{p}<0.05)$ or the OR operator $(\mathrm{p}<0.05)$. No significance was found between the operators NOT and OR ( $>0.05)$.

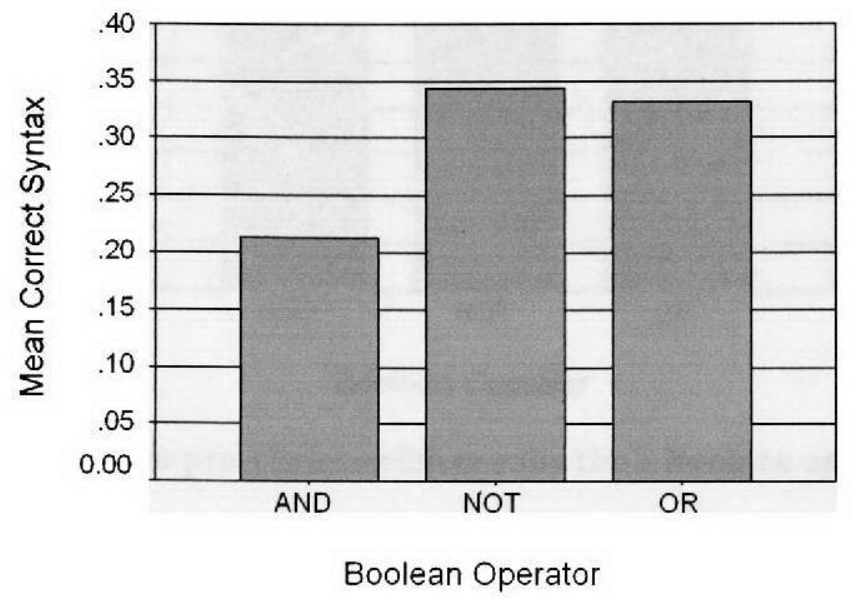

Figure 17. Average syntax success rate for the 3 Boolean operators

\section{Pre-click Confidence}

There was a significant difference in the level of pre-click confidence among the three Boolean operators, $\mathrm{F}(2,456)=4.694, \mathrm{p}<0.05$. Participants had an average pre-click confidence of 4.025 for tasks requiring the AND operator, an average of 4.456 for tasks requiring the NOT operator and an average of 4.187 for tasks requiring the OR operator (see Figure 18). After running a post hoc analysis, it was noted that participants were significantly more confident about their search query when the NOT operator was required than when the AND operator was required $(\mathrm{p}<0.05)$. There was no significant difference between the OR operator and the AND operator $(\mathrm{p}>0.05)$ or the NOT operator $(p>0.05)$. 


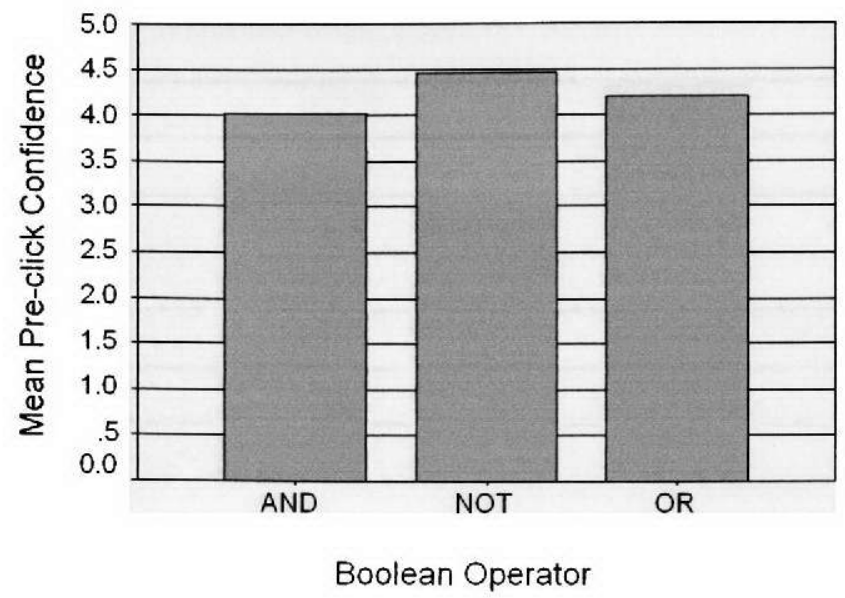

Figure 18. Average pre-click confidence for the 3 Boolean operators

\section{Completion Time}

There was a significant time difference in completing the search tasks among the three Boolean operators, $\mathrm{F}(2,456)=6.905, \mathrm{p}<0.005$. Participants completed the search tasks in an average of 26.396 seconds when the AND operator was required, 23.819 seconds when the NOT operator was required and 34.460 seconds when the OR operator was required (see Figure 19). After running a post hoc analysis, it was noted that participants took a significantly longer amount of time completing tasks that required the OR operator than tasks that required the AND operator $(\mathrm{p}<0.05)$ or the NOT operator $(\mathrm{p}<0.005)$. No significant difference was found between the operators AND and NOT ( $\mathrm{p}>0.05)$. 


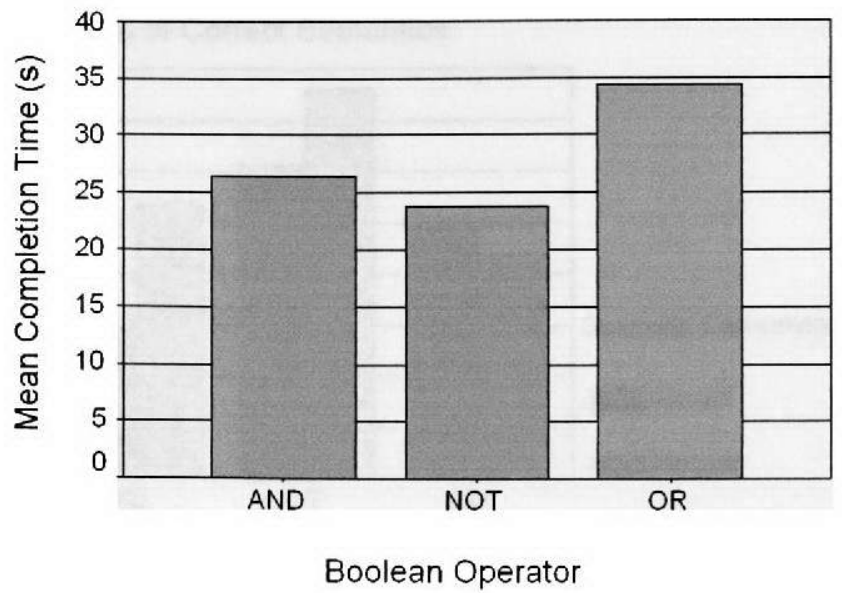

Figure 19. Average completion time for the 3 Boolean operators

\section{Boolean Operators \& Search Hint Components}

The following results are partitioned according to the three search hint components.

\section{Performance - Semantics}

The presence of the semantic component had a significant effect on the semantic success rate among the Boolean operators, $\mathrm{F}(2,456)=4.256, \mathrm{p}<0.05$. When comparing the average success rate of each operator in the absence of the semantic component versus its presence, the operator AND had an average semantic success rate of 0.29 versus 0.54 , the operator NOT had an average of 0.61 versus 0.76 and the operator OR had an average success rate of 0.49 versus 0.44 (see Figure 20). By conducting a pairwise comparison, it was noted that there was a significant increase in the semantic success rate of the operators AND $(\mathrm{p}<0.005)$ and NOT $(\mathrm{p}<0.05)$ with the presence of the semantic component. However, the presence of the semantic component did not a have a significant effect on the semantic success rate of the operator OR $(p>0.05)$. 


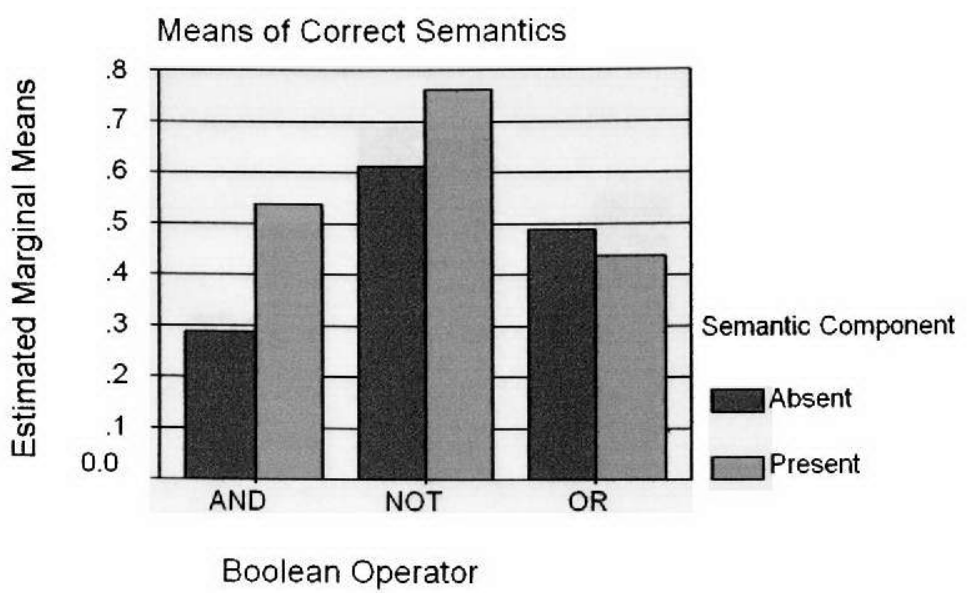

Figure 20. Average semantic success rate for the 3 Boolean operators in the 2 levels of the semantic component

The presence of the syntactic component did not have a significant effect on the semantic success rate among the Boolean operators, $F(2,456)=0, p>0.05$.

The presence of the examples component had a marginally significant effect on the semantic success rate among the Boolean operators, $F(2,456)=2.774, p=0.06$. When comparing the average success rate of each operator in the absence of the examples component versus its presence, the operator AND had an average of 0.33 versus 0.50 , the operator NOT had an average of 0.70 versus 0.67 and the operator OR had an average of 0.36 versus 0.56 (see Figure 21). By conducting a pairwise comparison, it was noted that there was a significant increase in the semantic success rate of the operators AND $(\mathrm{p}<0.05)$ and $\mathrm{OR}(\mathrm{p}<0.05)$ with the presence of the examples component. However, the presence of the examples component did not a have a significant effect on the semantic success rate of the operator NOT $(\mathrm{p}>0.05)$. 


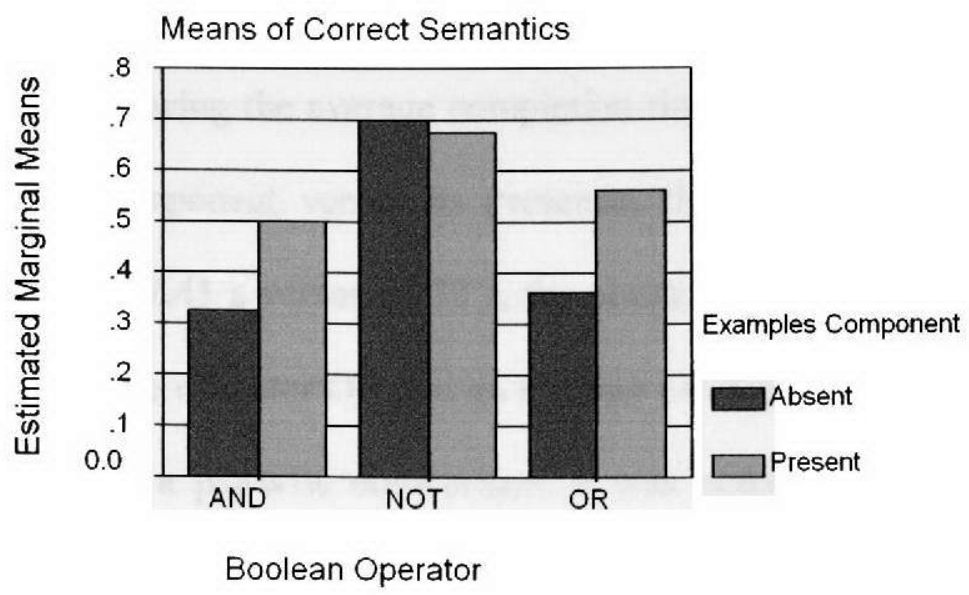

Figure 21. Average semantic success rate for the 3 Boolean operators in the 2 levels of the examples component

Performance - Syntax

In terms of the correct use of syntax, there was no significant interaction between Boolean operator and semantic component $[\mathrm{F}(2,456)=0.291, \mathrm{p}>0.05]$, syntactic component $[\mathrm{F}(2,456)=0.205, \mathrm{p}>0.05]$ or examples component $[\mathrm{F}(2,456)=1.112, \mathrm{p}>0.05]$.

Pre-click Confidence

In terms of pre-click confidence, there was no significant interaction between Boolean operator and semantic component $\mathrm{F}(2,456)=0.465, \mathrm{p}>0.05$, syntactic component $\mathrm{F}(2,456)=0.542, \mathrm{p}>0.05$ or examples component $\mathrm{F}(2,456)=0.682, \mathrm{p}>0.05$.

\section{Completion Time}

There was no significant interaction between Boolean operator and semantic component $\mathrm{F}(2,456)=0.563, \mathrm{p}>0.05$ or syntactic component $\mathrm{F}(2,456)=1.414, \mathrm{p}>0.05$, in terms of completion time. However, the presence of the examples component did have a 
significant effect on the completion time among the Boolean operators, $F(2,456)=3.850$, $\mathrm{p}<0.05$. When comparing the average completion time for each operator in the absence of the examples component versus its presence, the operator AND had an average completion time of $27.41 \mathrm{~s}$ versus $25.38 \mathrm{~s}$, the operator NOT had an average of $25.43 \mathrm{~s}$ versus $22.21 \mathrm{~s}$ and the operator OR had an average of $28.61 \mathrm{~s}$ versus $40.31 \mathrm{~s}$ (see Figure 22). By conducting a pairwise comparison, it was noted that there was a significant increase in the completion time for the operator OR $(p<0.05)$ with the presence of the examples component. However, the presence of the examples component did not a have a significant effect on the completion times of the operators AND $(\mathrm{p}<0.05)$ or NOT $(\mathrm{p}>0.05)$.

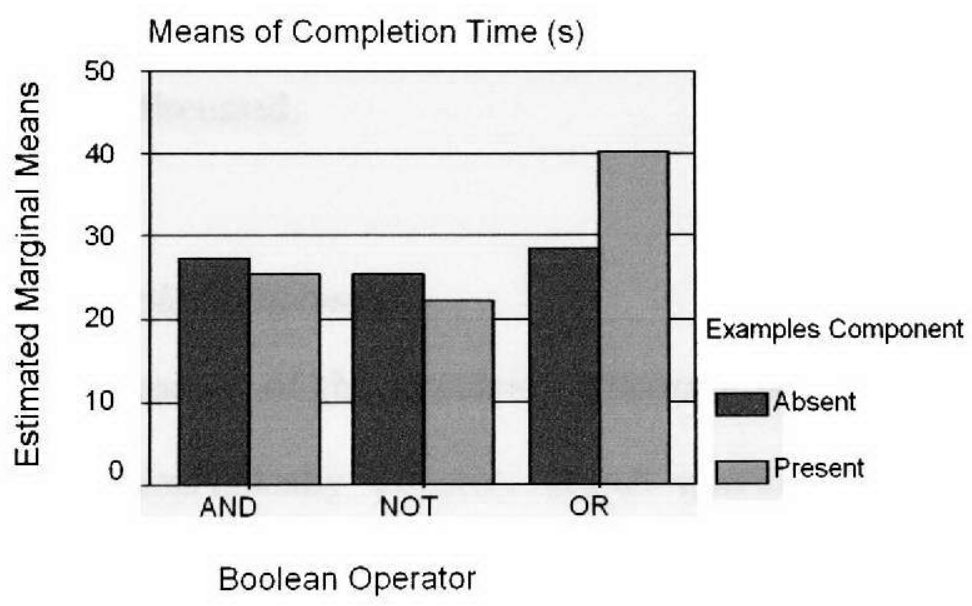

Figure 22. Average completion time for the 3 Boolean operators in the 2 levels of the examples component 


\section{DISCUSSION}

The results of this study add a great deal of insight to current practices in search user interface design. Field studies have shown that most users do not use advanced search features and previous empirical results suggest that the presence of query instructions would not significantly improve performance. However, the design of the search hints used here was specifically formulated to be simple and intuitive, thus balancing the users' need for speed and assistance.

The componential nature of the search hints also elucidates their effects on user behavior. Each type of search hint created differential effects on performance, improving performance specifically related to the type of information contained in the hint. Each of these factors will be discussed.

\section{Effects of the Semantic Component}

As expected, the presence of the semantic component resulted in the formulation of significantly more semantically effective search queries. However, the semantic component had no effect on syntax. The semantic component did not specify the proper syntax to employ, but rather focused on the logic behind the Boolean operators. Therefore it follows that its presence would not significantly affect syntactic performance. The presence of the semantic component also increased users' confidence (4.1 to 4.3 on the PCC scale) in the search queries that they constructed, suggesting that users appreciated and valued the assistance provided. However, this increase was very small. 
The presence of the semantic component did not, however, have the effect on completion time that was expected. The presence of this component resulted in significantly longer completion times ( $25.8 \mathrm{~s}$ to $30.6 \mathrm{~s})$. This is likely due to the additional reading time that is required by the extra text the semantic component adds to the user interface. The timing for each search query began just as the participant was presented with the search engine interface and stopped at the moment the participant clicked on the Search button of that interface. Therefore, the time it took for the participant to read the content displayed on the interface is included in the time it took for them to complete a search task. Since the semantic component contained more material for the participants to read than the syntactic or examples components, extended completion times resulted. This is another positive indication that the search hints were read by the user before constructing his/her query.

\section{Effects of the Syntactic Component}

Analogous to the results with the semantic component, the presence of the syntactic component resulted in the construction of significantly more syntactically effective search queries, but had no effect on semantic performance. This was expected because the syntactic component provided relevant information about syntax, but not about semantics.

Although the syntactic component had a significant effect on the correct usage of syntax, there was an unexpected and adverse interaction with the semantic component that resulted in less effective search queries. When participants were presented with an 
interface containing both the syntactic and semantic components, they constructed significantly less effective search queries in terms of syntactic performance. It is possible that the compound hint was too long and the participants were not willing to read it. Again, the presence of a powerful tradeoff between time and effectiveness is evident. Although a few extra seconds of reading time may have considerably increased the effectiveness of the search query, participants may have felt overwhelmed by the amount of information and not taken the time to read all of the content displayed on the interface. Therefore, displaying too much content may result in the overlooking of some important details within the overall search hints or perhaps the avoidance of the search hints as a whole, thus resulting in less effective search queries. This supports the findings of Jin and Fine (1996) who reported that too much information may overwhelm a potential user and discourage him/her from utilizing the system; therefore the amount of content displayed on the search engine interface is of utmost importance. This is further supported by the lack of significance in performance time with the syntactic hints. The lack of an increase in performance time for these hints suggests that participants did not read them.

A similar rationale can explain the interaction between the examples component and the semantic component. This interaction showed that when presented with a compound hint of semantic information and examples, participants constructed significantly less effective search queries in terms of syntax, than those using interfaces with just the examples. Once again, the addition of the semantic component displayed on the search engine interface resulted in significantly less effective search queries. Curiously though, 
the decrement was in syntactic performance. There was also no effect of the presence of examples on performance time.

\section{Effects of the Examples Component}

The presence of the examples component did not have any significant effect on the correct usage of syntax, but did significantly improve the semantic quality of the search queries. Because the examples contained both semantic and syntactic information, it was expected that examples would improve both types of performance. However, this was not the case. Since semantics are application independent, participants were likely able to utilize the examples component and apply the general knowledge they had regarding search query formulation to construct semantically correct queries. However, it appears that the syntactic information was not sufficiently clear to affect performance. Perhaps examples could provide this benefit if constructed differently.

There was no effect of the examples component on the time required to construct queries. Considered in combination with the improved semantic performance, it appears that users were able to read and benefit from the examples component very quickly. From a practical perspective this is a powerful result in light of the recurring tradeoff between time and effectiveness. Any design that improves performance without costing the user time is likely to be used and valued.

The presence of the examples component had the opposite effect on confidence and satisfaction than was expected, significantly lowering both measures. It is possible that 
despite the insight that the examples conveyed, their relevance to query construction on the existing interface was not consciously clear. This could lead to reduced confidence and satisfaction, despite the improved performance. If a participant is unsure about the inner workings of a particular interface and is not given precise directions on how to successfully make use of it, lower levels of confidence can result. These divergent findings can be caused by the fact that users' awareness of their performance is not perfectly correlated with their actual performance (Andre and Wickens, 1995). This contradiction must be considered in any interface design. It is important to note, however, that the magnitude of the decrement on both confidence (4.4 to 4.1 on the PCC scale) and satisfaction ( 80 to 77 on the SUS scale) was quite small. And $83 \%$ of those participants using interfaces with the examples component reported to be in favor of using that search interface when completing their routine searches.

\section{Boolean Operators}

Participants used the correct form of semantics for the NOT operator significantly more than the AND operator or the OR operator. One credible reason for this occurrence is that the NOT operator is not easily confused with the AND or OR operators, but the AND and OR operators are easily confused with each other. In many instances, participants mistakenly used the AND operator in their search queries when the OR operator was required. This supports the findings of a field study described in Jansen, Spink and Saracevic (2000) that also found more user errors with AND and OR than with NOT. 
Another explanation is that when participants were presented with a search query that required the NOT operator, in other words explicitly asking them to exclude certain keywords from the search results, perhaps a significant amount of them did not know how to successfully complete this task. A study conducted by Spink et al. (2001), which analyzed over one million search queries, found that the NOT operator was used in only $0.0003 \%$ of the queries. This was less than either the AND or OR operators. Perhaps this lack of knowledge encouraged participants to carefully read the content displayed on the search engine interface and therefore resulted in the correct semantic use of the NOT operator. This did not, however, have significant affects on the completion time of the NOT operator. Since the tasks requiring the NOT operator were the easiest to distinguish, participants likely knew precisely what type of information they needed to look for within the search hints to effectively tackle the task. Therefore, they were able to construct an effective search query, without affecting completion time. This may also be the reason that participants were significantly more confident about their search query when the NOT operator was required than when the AND operator was required. If participants are presented with a task whose means of execution are uncertain but subsequently come to find the answer they were in search of, then they are likely to feel more confident that their search query will return the desired results.

Participants were significantly less successful in using the correct form of syntax for the AND operator than the NOT operator or the OR operator. The main reason for this occurrence is not that participants necessarily used the wrong syntax for the AND operator, but rather that few participants incorporated the AND operator into their search 
queries at all (operator absence was considered an incorrect response). This contradicts most studies which found that search users use the AND operator more than any other Boolean operator. The lack of the AND operator's utilization in this study is most likely due to the fact that some search engines, such as Google and Yahoo, use AND as the default operator, thus allowing users to omit the term from the query. Since $87.5 \%$ of participants listed either Google or Yahoo as the search engine they use most often, perhaps knowledge of this web retrieving feature caused participants to omit its use, even when they knew it was relevant.

Participants took a significantly longer amount of time completing tasks that required the OR operator than tasks that required the AND or NOT operator ( $34.5 \mathrm{~s}$ versus $26.4 \mathrm{~s}$ or $23.8 \mathrm{~s}$ ). Studies have shown that very few search users make use of the OR operator when constructing search queries or are even aware of this Boolean operator's existence, therefore participants may not have been familiar with its use. In the study performed by Spink et al. (2001), only $1 \%$ of all the search queries analyzed contained some form of the OR operator. The unfamiliarity associated with this Boolean operator is likely the cause for the extended completion times. When presented with a search task requiring the OR operator, participants perhaps needed extra time to seek out help within the search hint components and/or deliberate how to construct the query. 


\section{WEB DESIGN GUIDELINES}

It is of utmost importance to obtain a solid understanding of the tradeoff between quality and quantity when providing instructional material on any interface. The results of this study strongly indicated that the quality of the content displayed on a search interface can have significant effects on the quality of performance. It was determined that the search hints displayed on the search engine interfaces had significant effects on all of the independent variables examined in this study. The information that is conveyed in instructional material can lead to a significant improvement in user performance, but only if it is exceptionally clear and understandable, and provides information that is directly related to the user's needs. Negative consequences such as increased performance time can also occur.

The results of this study also found that displaying too much information on an interface can overwhelm users and cause them to completely disregard instructional material. Therefore, the key to designing effective interfaces is to reduce the amount of content displayed without adversely affecting the quality of the content. An interface should contain minimal content, but of the highest quality. This is a daunting challenge for interface designers but one that must be managed effectively to support user performance and satisfaction with the system. 


\section{RECOMMENDATIONS FOR FUTURE RESEARCH}

While this study provides some insight into the relationship between the time users spend reading instructional material and the benefits to their performance, a more detailed analysis would provide designers specific guidelines for designing instructional material for interfaces. It would be beneficial to have an understanding of how much time users are willing to give up in order to improve their performance under different kinds of task objectives and environments.

The results of this study also identified a complex relationship between the type and amount of instructional material and users' willingness to read it. Therefore, investigating exactly how much information can be presented on an interface without having users disregard it will allow for more effective, efficient and usable systems.

Some unexpected results were observed in the relative performance with each of the Boolean operators. A further analysis of the effects that the operators NOT and AND had on performance may provide additional insight into search user behavior. It would be useful to verify that search users' performance was significantly better when completing tasks requiring the NOT operator because the unfamiliarity associated with this operator led them to read the instructions displayed. It would also be valuable to confirm that the AND operator was seldom used within the search queries because many popular search engines use AND as the default operator, thus allowing users to omit the term from the search query. These results would provide valuable insights into the relationships between prior use, knowledge and experience on behavior when using domain-specific 
terminology. In this case, Boolean operators use common language, but with usage that is much more specific than common parlance. It would be useful to determine if these effects can be reproduced with other terminologies. 


\section{CONCLUSION}

The outcome of this study demonstrated the importance of displaying targeted instructional hints to improve search. The results showed the positive effects that semantic, syntactic and exemplar search hints can have on the effectiveness of search queries when displayed on a search interface. However, they also show the costs of including too much information. The study's results can provide designers with valuable guidance concerning the content and amount of information to be displayed on the interface of any search tool. This study will allow for more effective, efficient and usable search tools as well as improved and finer decisions regarding the overall design of search user interfaces. 


\section{LIST OF REFERENCES}

Alexa (2000). Alexa research finds "sex" popular on the Web, many people inefficient at reaching their online destinations. Alexa Research Technical Report. Retrieved from the World Wide Web on 30 September 2000 from www.alexaresearch.com/clientdir/news/ report.php?id=23.

Alexa Insider Page (2000). Alexa Insider Side Bar. Retrieved from the World Wide Web on 30 March 2000 from http://insider.alexa.com/insider?cli=10.

Andre A.D. and Wickens C.D. (1995). When users want what's not best for them. Ergonomics in Design, 3(4), 10-14.

Atkinson, R.K. (2002). Optimizing Learning From Examples Using Animated Pedagogical Agents. Journal of Educational Psychology, 94(2), 416-427.

Bandos, J. and Resnick, M.L. (2002). Understanding Query Formation in the Use of Internet Search Engines. Proceedings of the $46^{\text {th }}$ HFES Annual Meeting, Human Factors and Ergonomics Society, Baltimore, MA.

Brooke, J. (1996). SUS: A ‘Quick and Dirty' Usability Scale. From Usability Evaluation in Industry, Taylor and Francis, Bristol, PA.

Catrambone, R. (1995). Following Instructions: Effects of Principles and Examples. Journal of Experimental Psychology: Applied, 1(3), 227-244.

Chiang, R.H.L., Chua, C.E.H., and Storey, V.C. (2001). A Smart Web Query Method for Semantic Retrieval of Web Data. Data \& Knowledge Engineering, 38, 63-84.

Crouch, C.J., Crouch, D.B., Chen, Q., and Holtz, S.J. (2002). Improving the Retrieval Effectiveness of Very Short Queries. Information Processing and Management, 38, 1-36.

Ford, N., Miller, D., and Moss, N. (2001). The Role of Individual Differences in Internet Searching: An Empirical Study. Journal of the American Society for Information Science and Technology, 52(12), 1049-1066.

Frants, V.I., Shapiro, J., Taksa, I., and Voiskunskii, V.G. (1999). Boolean Search:

Current State and Perspectives. Journal of the American Society for Information Science, 50(1), 86-95.

Gordon, M., \& Pathak, P. (1999). Finding information on the World Wide Web: the retrieval effectiveness of search engines. Information Processing and Management, $35(2), 141-180$. 
Hagan, P.R., Manning, H., and Paul, Y. (2000). Must Search Stink? Technical Report. Forrester Research, Inc. Cambridge, MA.

Harman, D. (1992). User-Friendly Systems Instead of User Friendly Front-Ends. Journal of American Society for Information Science, 34(2), 164-174.

Herring, S.D. (1999). The Value of Interdisciplinarity: A Study Based on the Design of Internet Search Engines. Journal of the American Society for Information Science, 50(4), 358-365.

Hou, L. and Cercone, N. (2001). Extracting Meaningful Semantic Information with EMATISE: An HPSG-based Internet Search Engine Parser, 2001 IEEE International Conference on Systems, Man \& Cybernetics, 5, 2858-2866.

Hu, P.J., Ma, P. and Chau, P.Y.K. (1999). Evaluation of User Interface Designs for Information Retrieval Systems: A Computer-Based Experiment. Decision Support Systems, 27, 125-143.

Internet Domain Survey (2000). Retrieved from the World Wide Web on 24 February 2003 from http://www.isc.org/ ds/WWW-200001/report.html.

Jansen, B.J. and Pooch, U. (2000). Web user studies: A Review and Framework for Future Work. Journal of the American Society of Information Science and Technology, 52(3), 235-246.

Jansen, B.J., Spink, A., and Saracevic, T. (1998). Failure Analysis in Query Construction: Data and Analysis from a Large Sample of Web Queries. The $3^{\text {rd }}$ ACM Conference on Digital Libraries. Pittsburgh, PA., 289-290.

Jansen, B.J., Spink, A., and Saracevic, T. (2000). Real life, real users, and real needs: A study and analysis of user queries on the web. Information Processing and Management. $36(2), 207-227$.

Jin, Z. and Fine, S. (1996). The Effect of Human Behavior on the Design of an Information Retrieval System Interface. International Information \& Library Review, 28, 249-260.

Jupiter Research. (1999). Go Network Announces New INFOSEEK Search: 30 Percent Faster, 50 Percent Larger. Retrieved on from the World Wide Web on 24 February 2003 from http://info.go.com/press/ search.html.

Kowalski, G. (1997). Information Retrieval Systems: Theory and Implementation. Kluwer Academic Publishers, Amherst, MA.

Lancaster, F.W. and Warner, A.J. (1993). Information Retrieval Today. Information Resources Press, Arlington, VA, IT-enabled IT a norm. 
Lazonder, A.W., Biemans, H.J.A., and Wopereis, I.G.J.H. (2000). Differences between Novice and Experienced Users in Searching Information on the World Wide Web. Journal of the American Society for Information Science, 51(6), 576-581.

Lee, A.Y. and Hutchison, L. (1998). Improving Learning from Examples Through Reflection. Journal of Experimental Psychology: Applied, 4(3), 187-210.

LeFevre, J., \& Dixon, P. (1986). Do written instructions need examples? Cognition and Instruction, 3(1), 1-30.

Lergier, R. and Resnick, M.L. (2001). Task Based Analysis of Internet Search Output Fields. Usability Evaluation and Interface Design Volume 1. M.J. Smith, G. Salvendy, D. Harris, and R.J. Koubek (eds). Lawrence Erlbaum Associates: Mahwah, NJ.

Mead, S.E., Sit, R.A., Rogers, W.A., Jamieson, B.A., and Rousseau, G.K. (2000). Influences of general computer experience and age on library database search performance. Behaviour \& Information Technology, 19(2), 107-123.

Monaghan, M.L. and Andre, A.D. (2000). Evaluating the transparency of web search engines. Proceedings of the 2000 HFES/IEA Congress, Human Factors and Ergonomics Society, Santa Monica, CA. 1.487.

Nicholson, S. (2000). Raising Reliability of Web Search Tool Research through Replication and Chaos Theory. Journal of the American Society for Information Science, 51(8), 724-729.

Nielsen, J. (2000). Designing Web Usability: The Practice of Simplicity, New Riders Publishing, Indianapolis, IN.

Reynolds, D. (1985). Library Automation: Issues and Applications, Bowker, New York.

Savoy, J. and Picard, J. (2001). Retrieval Effectiveness on the Web. Information Processing and Management, 37, 543-569.

Schwartz, C. (1998). Web Search Engines. Journal of the American Society for Information Science, 49(11), 973-982.

Search Engine Watch (2000). NPD Search and Portal Site Study. Retrieved from the World Wide Web on 24 February 2003 from http://www.searchenginewatch.com/ sereport/00/07-npd.html.

Search Engine Watch (2000). The Search Engine Report. Search Satisfaction and Behavior Results Released. Retrieved from the World Wide Web on 24 February 2003 from http://www.search enginewatch.com/sereport/00/04-npd.html. 
Search Engine Watch (2000). Survey Reveals Search Habits. Commissioned by RealNames. Retrieved from the World Wide Web on 24 February 2003 from http://www.searchenginewatch.com/ sereport/00/06-realnames.html.

Search Engine Watch (2001). WebTop Search Rage Study. Roper Starch Worldwide. Retrieved from the World Wide Web on 24 February 2003 from http://www.searchengine watch.com/sereport/01/02-searchrage.html.

Spink, A., Wolfram, D., Jansen, B.J., and Saracevic, T. (2001). Searching the Web: The Public and Their Queries. Journal of the American Society for Information Science and Technology, 52(3), 226-234.

Wang, P., Hawk, W.B., and Tenopir, C. (2000). Users' Interaction with World Wide Web Resources: An Exploratory Study Using a Holistic Approach. Information Processing and Management, 36, 229-251.

Willett, P. (1988). Document Retrieval System. London: Taylor Graham. 


\section{LIST OF APPENDICES}

Appendix A. Search Engine Interfaces

Appendix B. SUS Questionnaire

Appendix C. Demographic Information Questionnaire

Appendix D. Boolean Quiz

Appendix E. Consent Form

Appendix F. Data Collection Sheet

Appendix G. Statistical Output 
APPENDICES 


\section{APPENDIX A: Search Engine Interfaces}

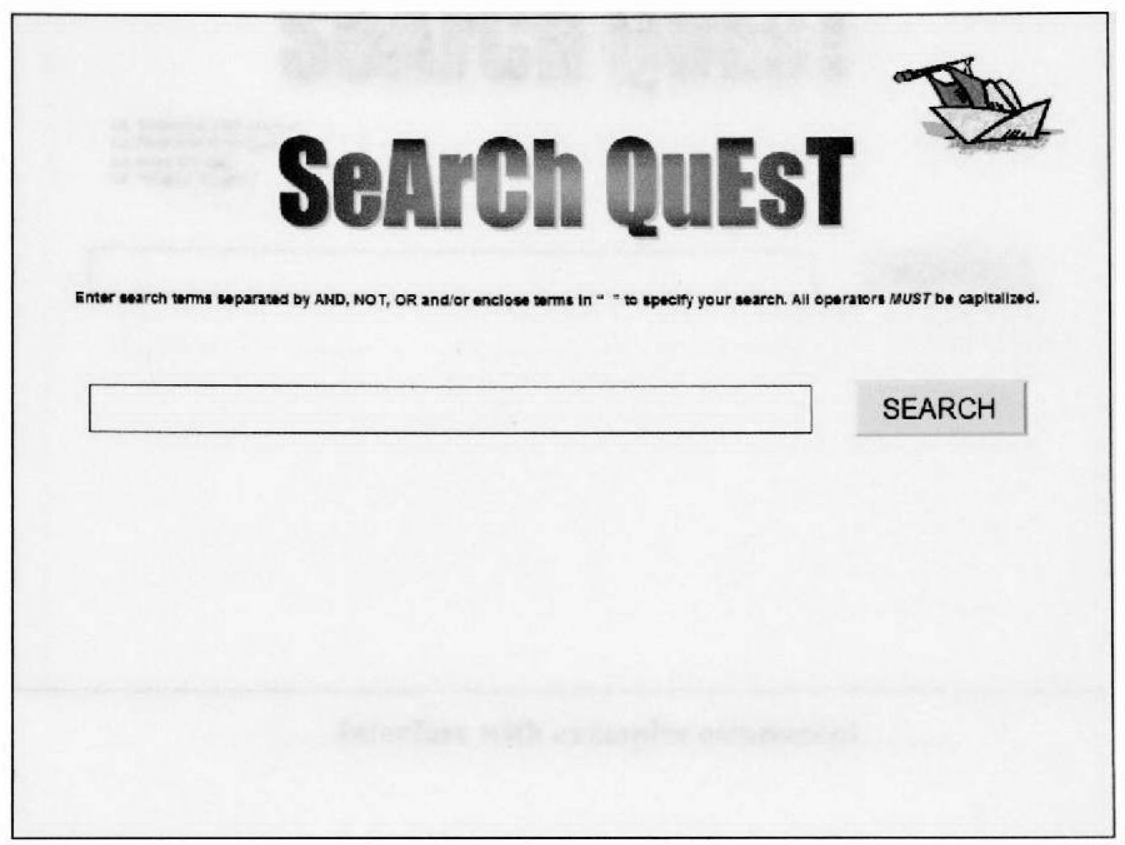

Interface with syntactic component

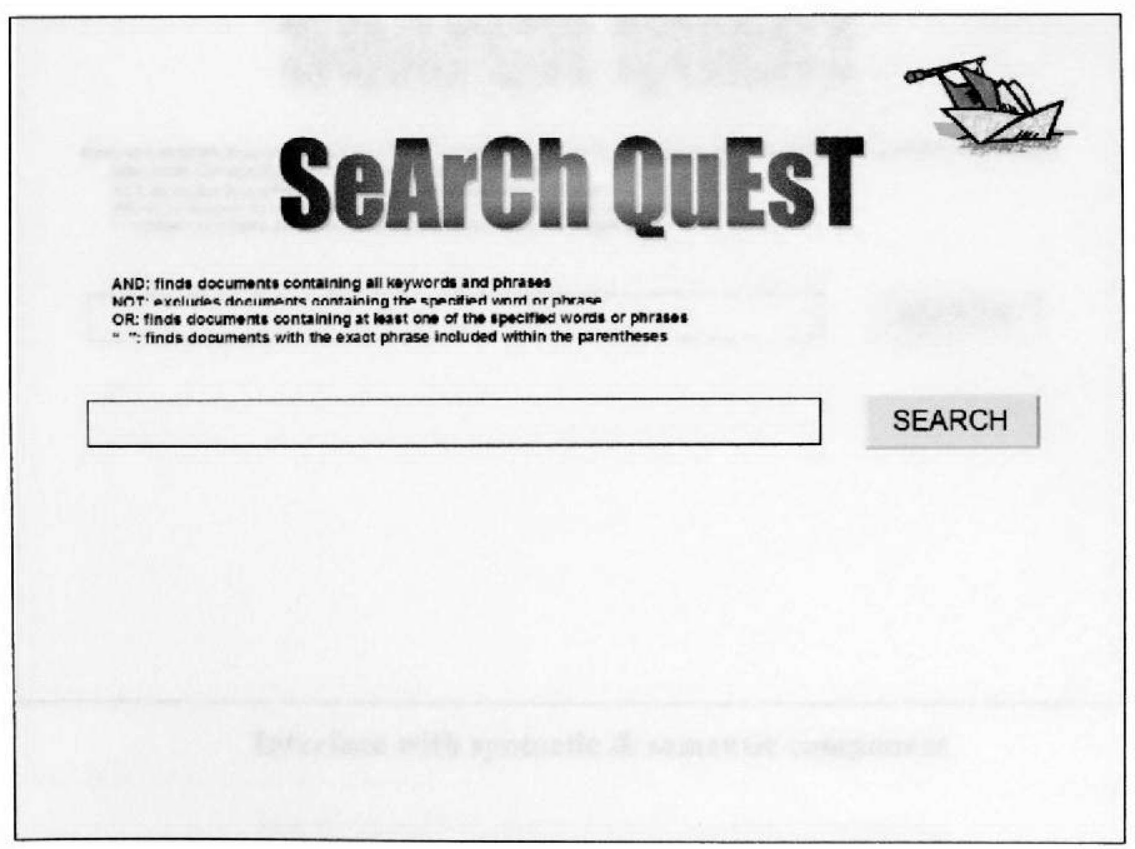

Interface with semantic component 


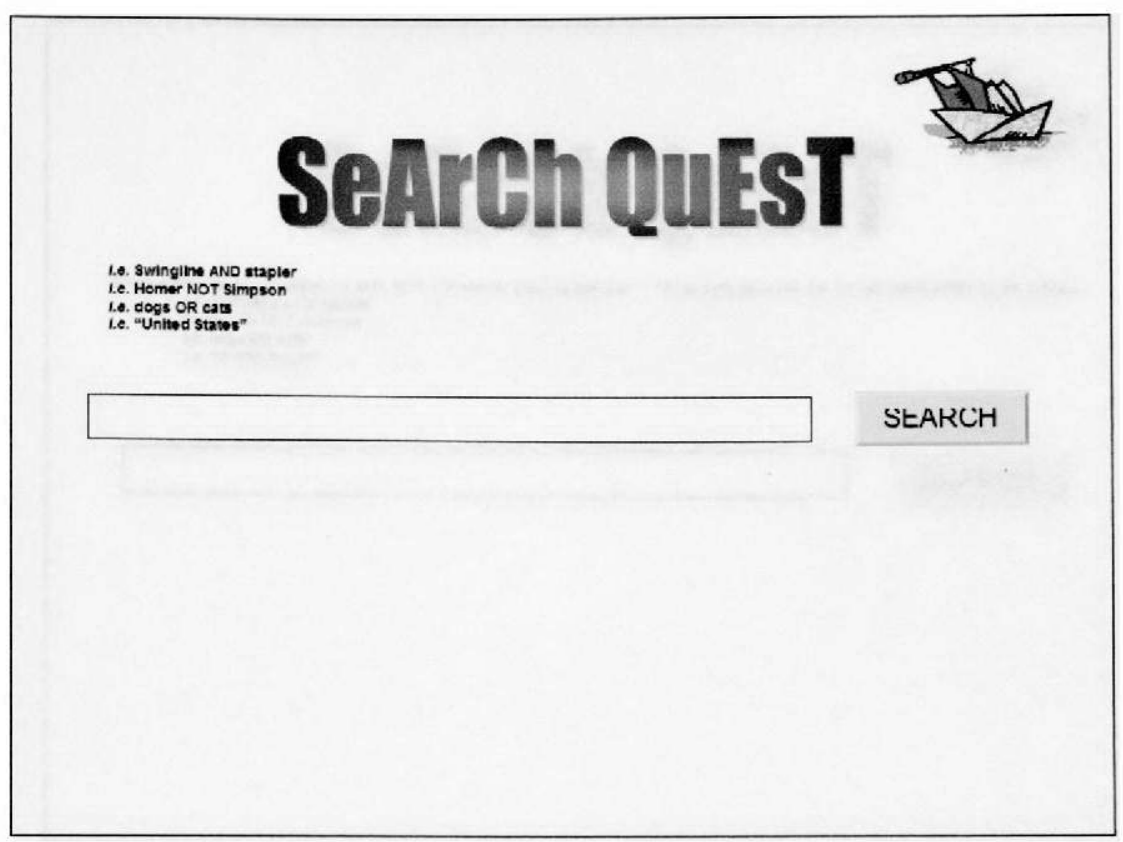

Interface with examples component

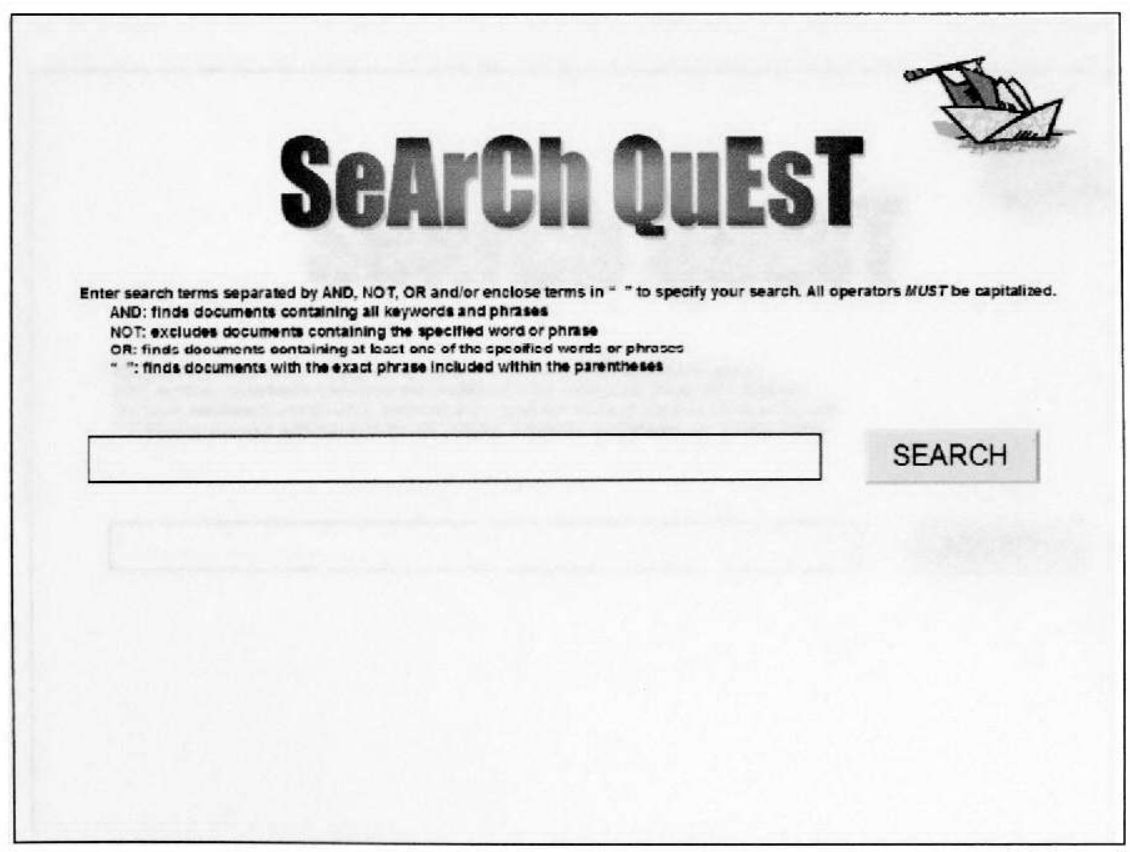

Interface with syntactic \& semantic component 


\section{SeArCh QuEsT

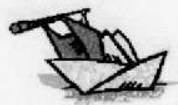

Enter search terms separated by AND, NOT, OR andior enciose terms in " " to specify your search. All operators MUST be capitalized. 1.e. Swingline AND stapior

1.e. dogu OR cas

1.0. "United states"

\section{SEARCH}

Interface with syntactic $\&$ examples component
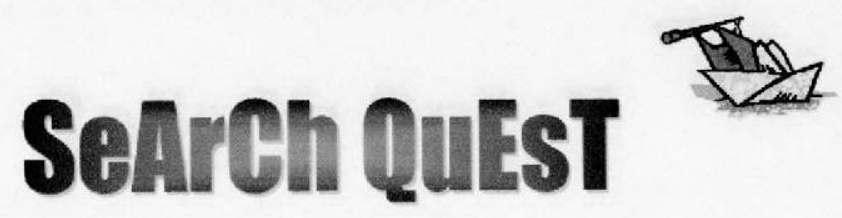

AND: finds documents comtaining all keywords and phrases; i.e. Swingline ANO stapier

OR: finds documents comaining at least one of the specified words or phrases; 1,e. dogs OR cats

" ": finds documents with the exact phrane ineluded within the parentheses: i.e. "United States"

Interface with semantic $\&$ examples component 


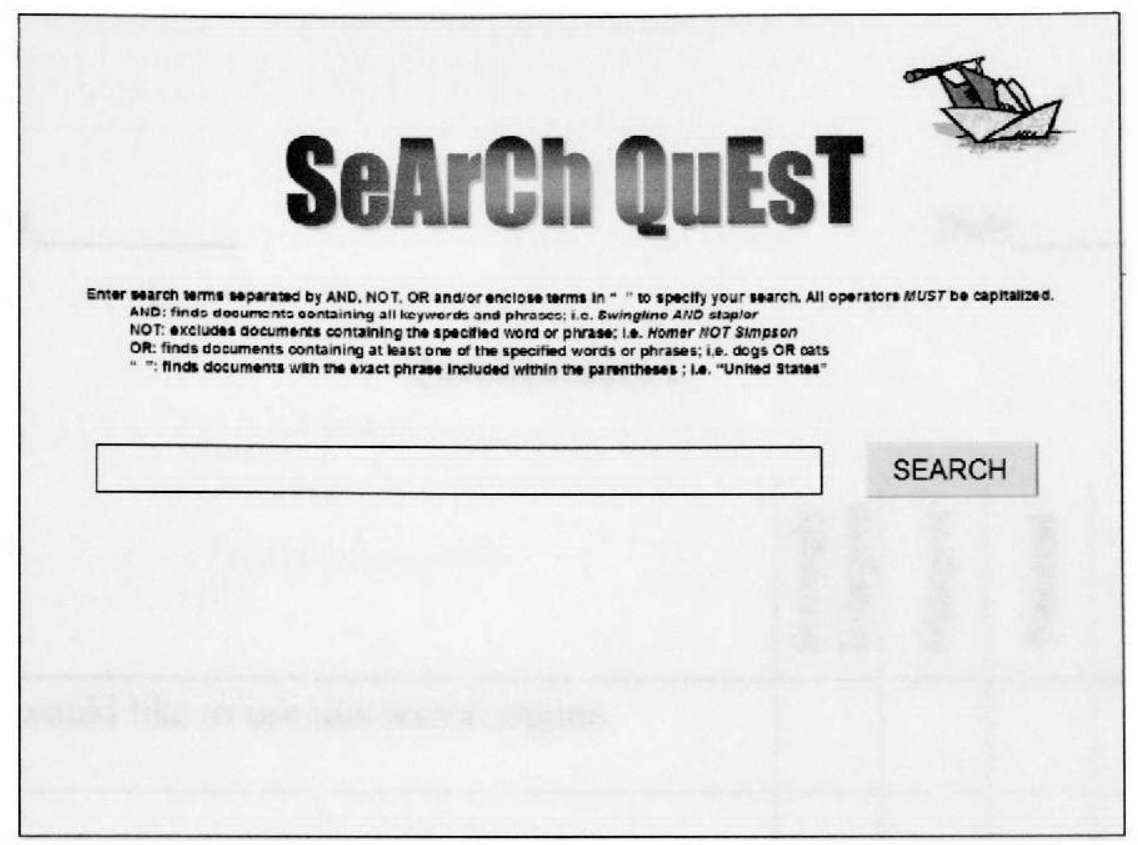

Interface with syntactic, semantic \& examples component

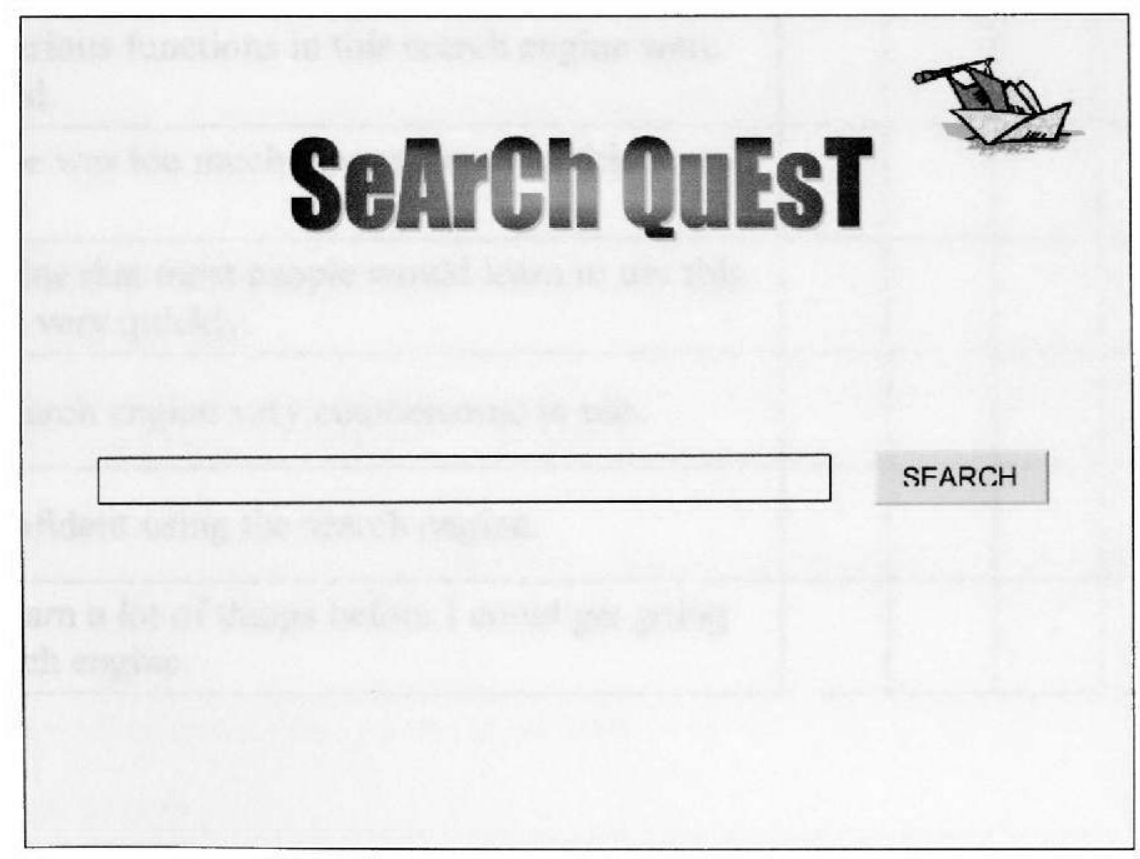

Control group interface 


\section{APPENDIX B: SUS Questionnaire}

\section{Participant \#}

Date

\section{Questionnaire 1}

\begin{tabular}{|c|c|c|c|c|c|}
\hline & 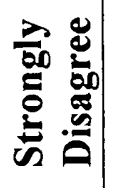 & 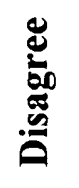 & $\frac{\bar{E}}{\overline{0}}$ & 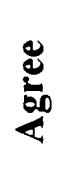 & 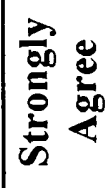 \\
\hline \multicolumn{6}{|l|}{$\begin{array}{l}\text { I think that I would like to use this search engine } \\
\text { frequently. }\end{array}$} \\
\hline \multicolumn{6}{|l|}{ I found the search engine unnecessarily complex. } \\
\hline \multicolumn{6}{|l|}{ I thought the search engine was easy to use. } \\
\hline \multicolumn{6}{|l|}{$\begin{array}{l}\text { I think that I would need the support of a technical person } \\
\text { to be able to use this search engine. }\end{array}$} \\
\hline \multicolumn{6}{|l|}{$\begin{array}{l}\text { I found the various functions in this search engine were } \\
\text { well integrated. }\end{array}$} \\
\hline \multicolumn{6}{|l|}{$\begin{array}{l}\text { I thought there was too much inconsistency in this search } \\
\text { engine. }\end{array}$} \\
\hline \multicolumn{6}{|l|}{$\begin{array}{l}\text { I would imagine that most people would learn to use this } \\
\text { search engine very quickly. }\end{array}$} \\
\hline \multicolumn{6}{|l|}{ I found the search engine very cumbersome to use. } \\
\hline \multicolumn{6}{|l|}{ I felt very confident using the search engine. } \\
\hline $\begin{array}{l}\text { I needed to learn a lot of things before I could get going } \\
\text { with this search engine. }\end{array}$ & & & & & \\
\hline
\end{tabular}




\section{APPENDIX C: Demographic Information Questionnaire}

Participant \#

Date

\section{Questionnaire 2}

Age

Gender

Male

Female

How often do you use computers to search?

$\square$ Several times a day.

$\square$ Once a day

$\square$ Twice a week

Once a week

Once a month

$\square$ Never

When you use computers to search, how successful are you?

$\begin{array}{llllll}1 & 2 & 3 & 4 & 5\end{array}$

Not successful Somewhat

at all successful

Very successful

Would you be in favor of using the search engine interface used in this study? पYes $\quad$ No

Which search engine do you use most often?

Would you prefer using the interface used in this study over the interface of the search engine you use most often? $\square$ Yes $\square$ No

Do you typically use advanced search operators while performing routine searches?

口Yes $\quad$ No

If so, which type of operators do you use most often?

$\square$ AND, NOT, OR

$\square+,-$

$\square$ other 


\section{APPENDIX D: Boolean Quiz}

Participant \#

Date

Please answer the following questions based on your knowledge of Boolean logic BEFORE taking part in this study. Select the single best possible answer.

1. Searching for python AND snake will retrieve web pages containing a passage like:

...a snake is a reptile without legs...

...pythons are very large constricting snakes that have caused serious injury in many cases...

...there is a significant variation in the care and housing arrangements between the different species, for example tree pythons and boas tend to have stricter needs for housing...

$\square$...Python is an object oriented interpreted programming language...

2. Searching for college $O R$ university will retrieve web pages containing the following passages EXCEPT:

$\square$...the University of Georgia is the oldest state-chartered university in the United States...

...there will be information on college scholarships and financial aid available for all students...

....a private, nondenominational, coeducational institution of higher learning and research...

$\square$...organization geared to the prevention of college and university campus crime, as well as counseling resources for victims of crime on college

3. Searching for dolphins NOT Miami will retrieve web pages containing a passage like:

....research on Pacific Bottle-nose dolphins under Navy contracts...

...the Miami Dolphins have traded linebacker Derrick Rodgers...

... according to the Dolphins team page, Miami may not be interested in bringing back veteran WR Cris Carter...

...downtown driving in Miami could be reshaped today by city commissioners...

4. Searching for "heart disease" will retrieve web pages containing a passage like:

...science immediately went to work studying the disease, consequently the field of cardiology has grown tremendously to meet the demands of the disease...

... overall, a total of 114,975 women in Florida died from diseases of the heart during the five-year study period...

...the Atlas includes more than 200 national and state maps of heart disease mortality...

...congenital heart information network suggests that families of children with congenital heart defects... 


\section{APPENDIX E: Consent Form}

\section{THE EFFECTS OF SEMANTIC AND SYNTACTIC INSTRUCTION ON USER PERFORMANCE AND SATISFACTION IN SEARCH USER INTERFACE DESIGN}

You are being asked to be in a research study entitled "The Effects of Semantic and Syntactic Instruction on User Performance and Satisfaction in Search User Interface Design". Syntactic instruction refers to the grammatical rules pertaining to individual search engines and semantic instruction refers to the logic and understanding of these rules. The study will be conducted at Florida International University with Jennifer Bandos as principal investigator. Your participation will require 15 minutes of your time. You will be one of about 80 subjects participating in the study. We will be testing the effectiveness and efficiency of an Internet search engine interface.

If you decide to be a part of the study, you will be presented with a generic search engine interface, similar to that of Google, and will be given seven search tasks to complete using this interface. You will be asked to try to complete each task to the best of your abilities. At the completion of the final task, you will be asked to complete 2 questionnaires. The first questionnaire evaluates the satisfaction of your interaction with the search engine interface. The second questionnaire consists of a set of questions intended to gather basic demographics, as well as system experience and expertise. The time it takes you to accomplish the tasks will be recorded. However, this time is only being taken to measure the ease of use of the interface.

Your participation in this study will be similar to performing a standard search on the computer for information and the completion of an ordinary questionnaire similar to one you might receive in the mail. We do not expect any harm to you by being in the study. There is no cost or payment to you as a subject. You will not get any direct benefit from being in the study. However, your help will give us information about the design of search user interfaces. You will receive a small gift as a token for your participation in the study. Your responses will be kept strictly confidential. Only a code number will identify all data, and your individual performance will not be shared with anyone unless required by law.

You may withdraw your consent and discontinue participation in this research project at any time with no negative consequences. Even if you do not complete the study you will get the gift. You have the right to ask questions concerning the procedure, and all your questions have been answered to your satisfaction. If any new findings are developed during the time that you are in this study, which may affect your willingness to continue to be in the study, you will be informed as soon as possible.

If you would like more information about this research after you are done, you can contact Dr. Marc Resnick at 305-348-3537. If you would like to talk with someone about being a subject in this study you may contact Dr. Bernard Gerstman, the Chairperson of the FIU Institutional Review Board at 305-3483115 or 305-348-2494. You will be offered a copy of this informed consent form.

Your signature below indicates that all questions have been answered to your liking. You are aware of your rights and you would like to be in the study.

Signature of Participant

Printed Name

$\overline{\text { Date }}$

I have explained the research procedure, subject rights and answered questions asked by the participant. I have offered him/her a copy of this informed consent form.

Signature of Witness

Date 
Participant \#

Date

Interface

\begin{tabular}{|l|c|c|c|}
\cline { 2 - 4 } \multicolumn{1}{c|}{} & Time & Correct Syntax & Correct Semantics \\
\hline 1) Task \# & & YES / NO & YES / NO \\
\hline 3) Task \# & & YES / NO & YES / NO \\
\hline 4) Task \# & & YES / NO & YES / NO \\
\hline 5) Task \# & & YES / NO & YES / NO \\
\hline 6) Task \# & & YES / NO & YES / NO \\
\hline
\end{tabular}




\section{APPENDIX G: Statistical Output}

\section{PERFORMANCE (SEMANTICS)}

\section{Univariate Analysis of Variance}

\section{Between-Subjects Factors}

\begin{tabular}{|ll|l|l|}
\hline & & Value Label & N \\
\hline Semantic Component & 0 & Absent & 240 \\
& 1 & Present & 240 \\
Syntactic Component & 0 & Absent & 240 \\
& 1 & Present & 240 \\
Examples Component & 0 & Absent & 240 \\
Boolean operator & 1 & Present & 240 \\
& 1 & AND & 160 \\
& 2 & NOT & 160 \\
& 3 & OR & 160 \\
\hline
\end{tabular}

Tests of Between-Subjects Effects

Dependent Variable: Correct Semantics

\begin{tabular}{|c|c|c|c|c|c|}
\hline Source & $\begin{array}{l}\text { Type III Sum } \\
\text { of Squares }\end{array}$ & df & Mean Square & $\mathrm{F}$ & Sig. \\
\hline Corrected Model & $19.792^{\mathrm{a}}$ & 23 & .861 & 3.924 & .000 \\
\hline Intercept & 130.208 & 1 & 130.208 & 593.750 & .000 \\
\hline SEMANTIC & 1.633 & 1 & 1.633 & 7.448 & .007 \\
\hline SYNTAX & .675 & 1 & .675 & 3.078 & .080 \\
\hline EXAMPLES & 1.633 & 1 & 1.633 & 7.448 & .007 \\
\hline OPERATOR & 6.867 & 2 & 3.433 & 15.656 & .000 \\
\hline SEMANTIC * SYNTAX & .300 & 1 & .300 & 1.368 & .243 \\
\hline SEMANTIC * EXAMPLES & 2.408 & 1 & 2.408 & 10.982 & .001 \\
\hline SYNTAX * EXAMPLES & 1.200 & 1 & 1.200 & 5.472 & .020 \\
\hline $\begin{array}{l}\text { SEMANTIC * SYNTAX * } \\
\text { EXAMPLES }\end{array}$ & .675 & 1 & .675 & 3.078 & .080 \\
\hline SEMANTIC * OPERATOR & 1.867 & 2 & .933 & 4.256 & .015 \\
\hline SYNTAX * OPERATOR & .000 & 2 & .000 & .000 & 1.000 \\
\hline $\begin{array}{l}\text { SEMANTIC * SYNTAX * } \\
\text { OPERATOR }\end{array}$ & .200 & 2 & .100 & .456 & .634 \\
\hline EXAMPLES * OPERATOR & 1.217 & 2 & .608 & 2.774 & .063 \\
\hline $\begin{array}{l}\text { SEMANTIC * EXAMPLES } \\
\text { OPERATOR }\end{array}$ & .317 & 2 & .158 & .722 & .486 \\
\hline $\begin{array}{l}\text { SYNTAX * EXAMPLES * } \\
\text { OPERATOR }\end{array}$ & .150 & 2 & .075 & .342 & .711 \\
\hline $\begin{array}{l}\text { SEMANTIC * SYNTAX * } \\
\text { EXAMPLES * OPERATOR }\end{array}$ & .650 & 2 & .325 & 1.482 & .228 \\
\hline Error & 100.000 & 456 & .219 & & \\
\hline Total & 250.000 & 480 & & & \\
\hline Corrected Total & 119.792 & 479 & & & \\
\hline
\end{tabular}

a. R Squared $=.165$ (Adjusted R Squared $=.123$ ) 


\section{Estimated Marginal Means}

\section{Semantic Component}

Dependent Variable: Correct Semantics

\begin{tabular}{|l|r|r|r|r|}
\hline & & & \multicolumn{2}{|c|}{$95 \%$ Confidence Interval } \\
\cline { 4 - 5 } Semantic Component & Mean & Std. Error & Lower Bound & Upper Bound \\
\hline Absent & .463 & .030 & .403 & .522 \\
Present & .579 & .030 & .520 & .639 \\
\hline
\end{tabular}

\section{Syntactic Component}

Dependent Variable: Correct Semantics

\begin{tabular}{|l|r|r|r|r|}
\hline & & & \multicolumn{2}{|c|}{$95 \%$ Confidence Interval } \\
\cline { 4 - 5 } Syntactic Component & Mean & Std. Error & Lower Bound & Upper Bound \\
\hline Absent & .483 & .030 & .424 & .543 \\
Present & .558 & .030 & .499 & .618 \\
\hline
\end{tabular}

\section{Examples Component}

Dependent Variable: Correct Semantics

\begin{tabular}{|c|c|c|c|c|}
\hline \multirow[b]{2}{*}{ Examples Component } & \multirow[b]{2}{*}{ Mean } & \multirow[b]{2}{*}{ Std. Error } & \multicolumn{2}{|c|}{$95 \%$ Confidence Interval } \\
\hline & & & Lower Bound & Upper Bound \\
\hline Absent & .463 & .030 & .403 & .522 \\
\hline Present & .579 & .030 & .520 & .639 \\
\hline
\end{tabular}

\section{Boolean operator}

Dependent Variable: Correct Semantics

\begin{tabular}{|l|r|r|r|r|}
\hline & & & \multicolumn{2}{|c|}{$95 \%$ Confidence Interval } \\
\cline { 4 - 5 } Boolean operator & Mean & Std. Error & Lower Bound & Upper Bound \\
\hline AND & .413 & .037 & .340 & .485 \\
NOT & .688 & .037 & .615 & .760 \\
OR & .463 & .037 & .390 & .535 \\
\hline
\end{tabular}

\section{Semantic Component * Boolean operator}

Dependent Variable: Correct Semantics

\begin{tabular}{|c|c|c|c|c|c|}
\hline \multirow{2}{*}{\multicolumn{2}{|c|}{ Semantic Component Boolean operator }} & \multirow[b]{2}{*}{ Mean } & \multirow[b]{2}{*}{ Std. Error } & \multicolumn{2}{|c|}{$95 \%$ Confidence Interval } \\
\hline & & & & Lower Bound & Upper Bound \\
\hline \multirow[t]{3}{*}{ Absent } & AND & .288 & .052 & .185 & .390 \\
\hline & NOT & 613 & .052 & .510 & .715 \\
\hline & OR & .488 & .052 & .385 & .590 \\
\hline \multirow[t]{3}{*}{ Present } & AND & .538 & .052 & .435 & .640 \\
\hline & NOT & .763 & .052 & 660 & .865 \\
\hline & OR & .438 & .052 & .335 & .540 \\
\hline
\end{tabular}




\section{Syntactic Component * Boolean operator}

Dependent Variable: Correct Semantics

\begin{tabular}{|ll|r|r|r|r|}
\hline \multirow{2}{*}{ Syntactic Component } & & \multirow{2}{*}{$95 \%$ Confidence Interval } \\
\cline { 5 - 6 } & Boolean operator & Mean & Std. Error & Lower Bound & Upper Bound \\
\hline Absent & AND & .375 & .052 & .272 & .478 \\
& NOT & .650 & .052 & .547 & .753 \\
& OR & .425 & .052 & .322 & .528 \\
\hline Present & AND & .450 & .052 & .347 & .553 \\
& NOT & .725 & .052 & .622 & .828 \\
& OR & .500 & .052 & .397 & .603 \\
\hline
\end{tabular}

\section{Examples Component * Boolean operator}

Dependent Variable: Correct Semantics

\begin{tabular}{|ll|r|r|r|r|}
\hline \multirow{2}{*}{ Examples Component } & & & \multicolumn{3}{|c|}{$95 \%$ Confidence Interval } \\
\cline { 5 - 6 } & Boolean operator & Mean & Std. Error & Lower Bound & Upper Bound \\
\hline Absent & AND & .325 & .052 & .222 & .428 \\
& NOT & .700 & .052 & .597 & .803 \\
& OR & .363 & .052 & .260 & .465 \\
\hline Present & AND & .500 & .052 & .397 & .603 \\
& NOT & .675 & .052 & .572 & .778 \\
& OR & .563 & .052 & .460 & .665 \\
\hline
\end{tabular}

\section{Semantic Component * Syntactic Component}

Dependent Variable: Correct Semantics

\begin{tabular}{|ll|r|r|r|r|}
\hline & & & \multicolumn{2}{|c|}{$95 \%$ Confidence Interval } \\
\cline { 5 - 7 } Semantic Component & Syntactic Component & Mean & Std. Error & Lower Bound & Upper Bound \\
\hline Absent & Absent & .400 & .043 & .316 & .484 \\
& Present & .525 & .043 & .441 & .609 \\
\hline Present & Absent & .567 & .043 & .483 & .651 \\
& Present & .592 & .043 & .508 & .676 \\
\hline
\end{tabular}

\section{Semantic Component * Examples Component}

Dependent Variable: Correct Semantics

\begin{tabular}{|ll|r|r|r|r|}
\hline \multirow{2}{*}{ Semantic Component } & & & \multicolumn{2}{|c|}{$95 \%$ Confidence Interval } \\
\cline { 5 - 6 } & Examples Component & Mean & Std. Error & Lower Bound & Upper Bound \\
\hline Absent & Absent & .333 & .043 & .249 & .417 \\
& Present & .592 & .043 & .508 & .676 \\
\hline Present & Absent & .592 & .043 & .508 & .676 \\
& Present & .567 & .043 & .483 & .651 \\
\hline
\end{tabular}

\section{Syntactic Component * Examples Component}

Dependent Variable: Correct Semantics

\begin{tabular}{|ll|r|r|r|r|}
\hline \multirow{2}{*}{ Syntactic Component } & & & \multicolumn{2}{|c|}{$95 \%$ Confidence Interval } \\
\cline { 5 - 7 } & Examples Component & Mean & Std. Error & Lower Bound & Upper Bound \\
\hline Absent & Absent & .375 & .043 & .291 & .459 \\
& Present & .592 & .043 & .508 & .676 \\
\hline Present & Absent & .550 & .043 & .466 & .634 \\
& Present & .567 & .043 & .483 & .651 \\
\hline
\end{tabular}




\section{Boolean operator * Semantic Component}

Palrwise Comparisons

Dependent Variable: Correct Semantics

\begin{tabular}{|c|c|c|c|c|c|}
\hline Semantic Component & (I) Boolean operator & (J) Boolean operator & $\begin{array}{c}\text { Mean } \\
\text { Difference } \\
(\mathrm{I}-\mathrm{J})\end{array}$ & Std. Error & Sig. ${ }^{a}$ \\
\hline \multirow[t]{6}{*}{ Absent } & \multirow[t]{2}{*}{ AND } & NOT & $-.325^{\star}$ & .076 & .000 \\
\hline & & OR & $-.200^{\star}$ & .076 & .026 \\
\hline & \multirow[t]{2}{*}{ NOT } & AND & $.325^{\star}$ & .076 & .000 \\
\hline & & OR & .125 & .076 & .302 \\
\hline & \multirow[t]{2}{*}{ OR } & AND & $.200^{\star}$ & .076 & .026 \\
\hline & & NOT & -.125 & .076 & .302 \\
\hline \multirow[t]{6}{*}{ Present } & \multirow[t]{2}{*}{ AND } & NOT & $-.225^{\star}$ & .076 & .010 \\
\hline & & OR & .100 & .076 & .566 \\
\hline & \multirow[t]{2}{*}{ NOT } & AND & $.225^{\star}$ & .076 & .010 \\
\hline & & OR & $.325^{\star}$ & .076 & .000 \\
\hline & \multirow[t]{2}{*}{ OR } & AND & -.100 & .076 & .566 \\
\hline & & NOT & $-.325^{\star}$ & .076 & .000 \\
\hline
\end{tabular}

Based on estimated marginal means

*. The mean difference is significant at the .05 level.

a. Adjustment for multiple comparisons: Bonferroni.

\section{Boolean operator * Semantic Component}

Pairwise Comparisons

Dependent Variable: Correct Semantics

\begin{tabular}{|c|c|c|c|c|c|}
\hline Boolean operator & (I) Semantic Component & (J) Semantic Component & $\begin{array}{c}\text { Mean } \\
\text { Difference } \\
(1-J)\end{array}$ & Std. Error & Sig. $^{a}$ \\
\hline \multirow[t]{2}{*}{ AND } & Absent & Present & $-.250^{\star}$ & .076 & .001 \\
\hline & Present & Absent & $.250^{\star}$ & .076 & .001 \\
\hline \multirow[t]{2}{*}{ NOT } & Absent & Present & $-.150^{\star}$ & .076 & .049 \\
\hline & Present & Absent & $.150^{\star}$ & .076 & .049 \\
\hline \multirow[t]{2}{*}{ OR } & Absent & Present & .050 & .076 & .511 \\
\hline & Present & Absent & -.050 & .076 & .511 \\
\hline
\end{tabular}

Based on estimated marginal means

*. The mean difference is significant at the .05 level.

a. Adjustment for multiple comparisons: Bonferroni. 


\section{Boolean operator * Syntactic Component}

Pairwise Comparisons

Dependent Variable: Correct Semantics

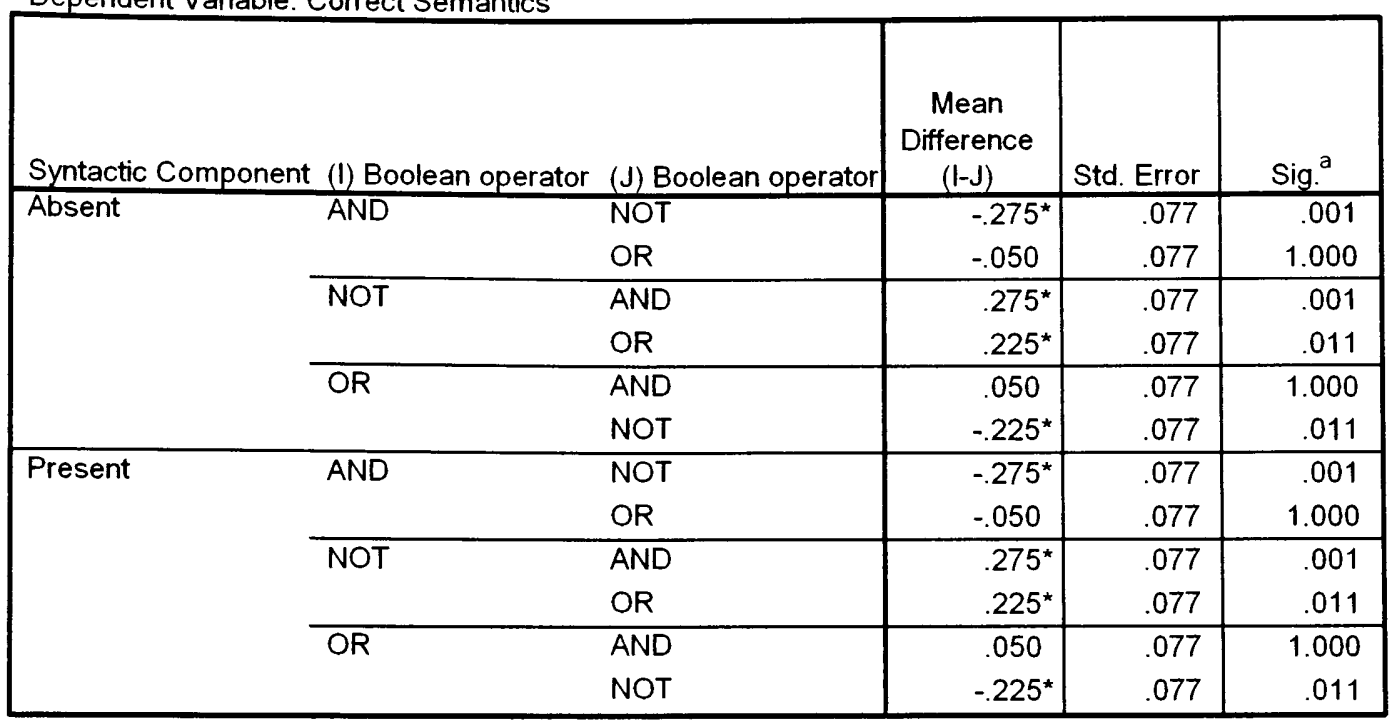

Based on estimated marginal means

*. The mean difference is significant at the .05 level.

a. Adjustment for multiple comparisons: Bonferroni.

\section{Boolean operator * Syntactic Component}

\section{Pairwise Comparisons}

Dependent Variable: Correct Semantics

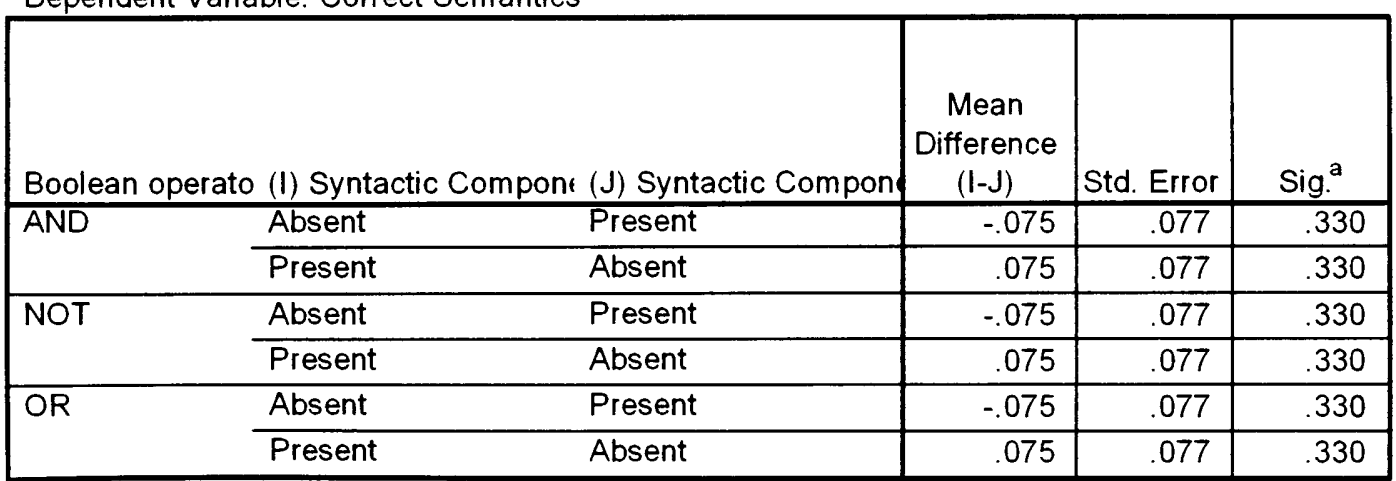

a. Adjustment for multiple comparisons: Bonferroni. 


\section{Boolean operator * Examples Component}

\section{Pairwise Comparisons}

Dependent Variable: Correct Semantics

\begin{tabular}{|c|c|c|c|c|c|}
\hline Examples Componen & (1) Boolean operator & (J) Boolean operator & $\begin{array}{c}\text { Mean } \\
\text { Difference } \\
(1-J)\end{array}$ & Std. Error & Sig. ${ }^{a}$ \\
\hline \multirow[t]{6}{*}{ Absent } & \multirow[t]{2}{*}{ AND } & NOT & $-.375^{\star}$ & .076 & .000 \\
\hline & & OR & -.037 & .076 & 1.000 \\
\hline & \multirow[t]{2}{*}{ NOT } & AND & $.375^{\star}$ & .076 & .000 \\
\hline & & OR & $.338^{\star}$ & .076 & .000 \\
\hline & \multirow[t]{2}{*}{ OR } & AND & .037 & .076 & 1.000 \\
\hline & & NOT & $-.338^{\star}$ & .076 & .000 \\
\hline \multirow[t]{6}{*}{ Present } & \multirow[t]{2}{*}{ AND } & NOT & -.175 & .076 & .066 \\
\hline & & OR & -.062 & .076 & 1.000 \\
\hline & \multirow[t]{2}{*}{ NOT } & AND & .175 & .076 & .066 \\
\hline & & OR & .113 & .076 & .421 \\
\hline & \multirow[t]{2}{*}{ OR } & AND & .062 & .076 & 1.000 \\
\hline & & NOT & -.113 & .076 & .421 \\
\hline
\end{tabular}

Based on estimated marginal means

${ }^{*}$. The mean difference is significant at the .05 level.

a. Adjustment for multiple comparisons: Bonferroni.

\section{Boolean operator * Examples Component}

\section{Pairwise Comparisons}

Dependent Variable: Correct Semantics

\begin{tabular}{|c|c|c|c|c|c|}
\hline Boolean operato & (I) Examples Componer & (J) Examples Compone & $\begin{array}{c}\text { Mean } \\
\text { Difference } \\
(\mathrm{I}-\mathrm{J})\end{array}$ & Std. Error & Sig. $^{a}$ \\
\hline \multirow[t]{2}{*}{ AND } & Absent & Present & $-.175^{\star}$ & .076 & .022 \\
\hline & Present & Absent & $.175^{\star}$ & .076 & .022 \\
\hline \multirow[t]{2}{*}{ NOT } & Absent & Present & .025 & .076 & .743 \\
\hline & Present & Absent & -.025 & .076 & .743 \\
\hline \multirow[t]{2}{*}{ OR } & Absent & Present & $-.200^{\star}$ & .076 & .009 \\
\hline & Present & Absent & $.200^{\star}$ & .076 & .009 \\
\hline
\end{tabular}

Based on estimated marginal means

*. The mean difference is significant at the .05 level.

a. Adjustment for multiple comparisons: Bonferroni. 


\section{Post Hoc Tests}

Boolean operator

\section{Multiple Comparisons}

Dependent Variable: Correct Semantics

Bonferroni

\begin{tabular}{|ll|r|r|r|}
\hline & $\begin{array}{c}\text { Mean } \\
\text { Difference } \\
(\mathrm{I}-\mathrm{J})\end{array}$ & Std. Error & \multicolumn{1}{c|}{ Sig. } \\
\hline (I) Boolean operator & $(\mathrm{J})$ Boolean operator & $-.28^{*}$ & .052 & .000 \\
& NOT & -.05 & .052 & 1.000 \\
\hline OROT & AND & $.28^{*}$ & .052 & .000 \\
& OR & $.22^{*}$ & .052 & .000 \\
\hline OR & AND & .05 & .052 & 1.000 \\
& NOT & $-.22^{*}$ & .052 & .000 \\
\hline
\end{tabular}

Based on observed means.

${ }^{*}$. The mean difference is significant at the .05 level. 


\section{PERFORMANCE (SYNTAX)}

\section{Univariate Analysis of Variance}

\section{Between-Subjects Factors}

\begin{tabular}{|ll|l|r|}
\hline & & Value Label & N \\
\hline Semantic Component & 0 & Absent & 240 \\
& 1 & Present & 240 \\
Syntactic Component & 0 & Absent & 240 \\
& 1 & Present & 240 \\
Examples Component & 0 & Absent & 240 \\
& 1 & Present & 240 \\
Boolean operator & 1 & AND & 160 \\
& 2 & NOT & 160 \\
& 3 & OR & 160 \\
\hline
\end{tabular}

Tests of Between-Subjects Effects

Dependent Variable: Correct Syntax

\begin{tabular}{|c|c|c|c|c|c|}
\hline Source & $\begin{array}{l}\text { Type III Sum } \\
\text { of Squares } \\
\end{array}$ & df & Mean Square & $\mathrm{F}$ & Sig. \\
\hline Corrected Model & $11.992^{\mathbf{a}}$ & 23 & .521 & 2.702 & .000 \\
\hline Intercept & 42.008 & 1 & 42.008 & 217.680 & .000 \\
\hline SEMANTIC & .075 & 1 & .075 & .389 & .533 \\
\hline SYNTAX & 1.408 & 1 & 1.408 & 7.298 & .007 \\
\hline EXAMPLES & .533 & 1 & .533 & 2.764 & .097 \\
\hline OPERATOR & 1.679 & 2 & .840 & 4.351 & .013 \\
\hline SEMANTIC * SYNTAX & 1.408 & 1 & 1.408 & 7.298 & .007 \\
\hline SEMANTIC * EXAMPLES & 1.200 & 1 & 1.200 & 6.218 & .013 \\
\hline SYNTAX * EXAMPLES & 2.700 & 1 & 2.700 & 13.991 & .000 \\
\hline $\begin{array}{l}\text { SEMANTIC * SYNTAX * } \\
\text { EXAMPLES }\end{array}$ & .833 & 1 & .833 & 4.318 & .038 \\
\hline SEMANTIC * OPERATOR & .113 & 2 & .056 & .291 & .747 \\
\hline SYNTAX * OPERATOR & .079 & 2 & .040 & .205 & .815 \\
\hline $\begin{array}{l}\text { SEMANTIC * SYNTAX * } \\
\text { OPERATOR }\end{array}$ & .179 & 2 & .090 & .464 & .629 \\
\hline EXAMPLES * OPERATOR & .429 & 2 & .215 & 1.112 & .330 \\
\hline $\begin{array}{l}\text { SEMANTIC * EXAMPLES * } \\
\text { OPERATOR }\end{array}$ & .112 & 2 & .056 & .291 & .747 \\
\hline $\begin{array}{l}\text { SYNTAX * EXAMPLES * } \\
\text { OPERATOR }\end{array}$ & .163 & 2 & .081 & .421 & .657 \\
\hline $\begin{array}{l}\text { SEMANTIC * SYNTAX * } \\
\text { EXAMPLES * OPERATOR }\end{array}$ & 1.079 & 2 & .540 & 2.796 & .062 \\
\hline Error & 88.000 & 456 & .193 & & \\
\hline Total & 142.000 & 480 & & & \\
\hline Corrected Total & 99.992 & 479 & & & \\
\hline
\end{tabular}

a. $\mathrm{R}$ Squared $=.120$ (Adjusted R Squared $=.076$ ) 


\section{Estimated Marginal Means}

\section{Semantic Component}

Dependent Variable: Correct Syntax

\begin{tabular}{|l|r|r|r|r|}
\hline & & \multirow{2}{*}{$95 \%$ Confidence Interval } \\
\cline { 4 - 5 } Semantic Component & Mean & Std. Error & Lower Bound & Upper Bound \\
\hline Absent & .308 & .028 & .253 & .364 \\
Present & .283 & .028 & .228 & .339 \\
\hline
\end{tabular}

\section{Syntactic Component}

Dependent Variable: Correct Syntax

\begin{tabular}{|l|r|r|r|r|}
\hline & & & \multicolumn{2}{|c|}{$95 \%$ Confidence Interval } \\
\cline { 4 - 6 } Syntactic Component & Mean & Std. Error & Lower Bound & Upper Bound \\
\hline Absent & .242 & .028 & .186 & .297 \\
Present & .350 & .028 & .294 & .406 \\
\hline
\end{tabular}

\section{Examples Component}

Dependent Variable: Correct Syntax

\begin{tabular}{|l|r|r|r|r|}
\hline & & \multirow{2}{*}{ Ex\% Confidence Interval } \\
\cline { 4 - 5 } & Mean & Std. Error & Lower Bound & Upper Bound \\
\hline Absent & .262 & .028 & .207 & .318 \\
Present & .329 & .028 & .273 & .385 \\
\hline
\end{tabular}

\section{Boolean operator}

Dependent Variable: Correct Syntax

\begin{tabular}{|l|r|r|r|r|}
\hline & & & \multicolumn{2}{|c|}{$95 \%$ Confidence Interval } \\
\cline { 4 - 5 } Boolean operator & Mean & Std. Error & Lower Bound & Upper Bound \\
\hline AND & .212 & .035 & .144 & .281 \\
NOT & .344 & .035 & .276 & .412 \\
OR & .331 & .035 & .263 & .399 \\
\hline
\end{tabular}

\section{Semantic Component * Boolean operator}

Dependent Variable: Correct Syntax

\begin{tabular}{|c|c|c|c|c|c|}
\hline \multirow[b]{2}{*}{ Semantic Component } & \multirow[b]{2}{*}{ Boolean operator } & \multirow[b]{2}{*}{ Mean } & \multirow[b]{2}{*}{ Std. Error } & \multicolumn{2}{|c|}{$95 \%$ Confidence Interval } \\
\hline & & & & Lower Bound & Upper Bound \\
\hline \multirow[t]{3}{*}{ Absent } & AND & .225 & .049 & .128 & .322 \\
\hline & NOT & 338 & .049 & 241 & 434 \\
\hline & OR & .362 & .049 & 266 & 459 \\
\hline \multirow[t]{3}{*}{ Present } & AND & 200 & .049 & 103 & 297 \\
\hline & NOT & 350 & .049 & .253 & .447 \\
\hline & OR & .300 & .049 & 203 & .397 \\
\hline
\end{tabular}




\section{Syntactic Component * Boolean operator}

Dependent Variable: Correct Syntax

\begin{tabular}{|c|c|c|c|c|c|}
\hline \multirow[b]{2}{*}{ Syntactic Component } & \multirow[b]{2}{*}{ Boolean operator } & \multirow[b]{2}{*}{ Mean } & \multirow[b]{2}{*}{ Std. Error } & \multicolumn{2}{|c|}{ 95\% Confidence Interval } \\
\hline & & & & Lower Bound & Upper Bound \\
\hline \multirow[t]{3}{*}{ Absent } & AND & .175 & .049 & .078 & .272 \\
\hline & NOT & .288 & .049 & 191 & .384 \\
\hline & OR & .262 & .049 & .166 & .359 \\
\hline \multirow[t]{3}{*}{ Present } & AND & .250 & .049 & .153 & .347 \\
\hline & NOT & .400 & .049 & .303 & .497 \\
\hline & OR & .400 & .049 & .303 & .497 \\
\hline
\end{tabular}

\section{Examples Component * Boolean operator}

Dependent Variable: Correct Syntax

\begin{tabular}{|ll|r|r|r|r|}
\hline & & & & \multicolumn{2}{|c|}{$95 \%$ Confidence Interval } \\
\cline { 5 - 6 } Examples Component & Boolean operator & Mean & Std. Error & Lower Bound & Upper Bound \\
\hline Absent & AND & .137 & .049 & .041 & .234 \\
& NOT & .337 & .049 & .241 & .434 \\
& OR & .312 & .049 & .216 & .409 \\
\hline Present & AND & .288 & .049 & .191 & .384 \\
& NOT & .350 & .049 & .253 & .447 \\
& OR & .350 & .049 & .253 & .447 \\
\hline
\end{tabular}

\section{Semantic Component * Syntactic Component}

Dependent Variable: Correct Syntax

\begin{tabular}{|ll|r|r|r|r|}
\hline & & & & \multicolumn{2}{|c|}{$95 \%$ Confidence Interval } \\
\cline { 5 - 6 } Semantic Component & Syntactic Component & Mean & Std. Error & Lower Bound & Upper Bound \\
\hline Absent & Absent & .200 & .040 & .121 & .279 \\
& Present & .417 & .040 & .338 & .495 \\
\hline Present & Absent & .283 & .040 & .205 & .362 \\
& Present & .283 & .040 & .205 & .362 \\
\hline
\end{tabular}

\section{Semantic Component * Examples Component}

Dependent Variable: Correct Syntax

\begin{tabular}{|ll|r|r|r|r|}
\hline & & & & \multicolumn{2}{|c|}{ 95\% Confidence Interval } \\
\cline { 5 - 6 } Semantic Component & Examples Component & Mean & Std. Error & Lower Bound & Upper Bound \\
\hline Absent & Absent & .225 & .040 & .146 & .304 \\
& Present & .392 & .040 & .313 & .470 \\
\hline Present & Absent & .300 & .040 & .221 & .379 \\
& Present & .267 & .040 & .188 & .345 \\
\hline
\end{tabular}

\section{Syntactic Component * Examples Component}

Dependent Variable: Correct Syntax

\begin{tabular}{|ll|r|r|r|r|}
\hline \multirow{2}{*}{ Syntactic Component } & & & \multicolumn{2}{|c|}{$95 \%$ Confidence Interval } \\
\cline { 4 - 6 } & Examples Component & Mean & Std. Error & Lower Bound & Upper Bound \\
\hline Absent & Absent & .133 & .040 & .055 & .212 \\
& Present & .350 & .040 & .271 & .429 \\
\hline Present & Absent & .392 & .040 & .313 & .470 \\
& Present & .308 & .040 & .230 & .387 \\
\hline
\end{tabular}




\section{Boolean operator * Semantic Component}

Pairwise Comparisons

Dependent Variable: Correct Syntax

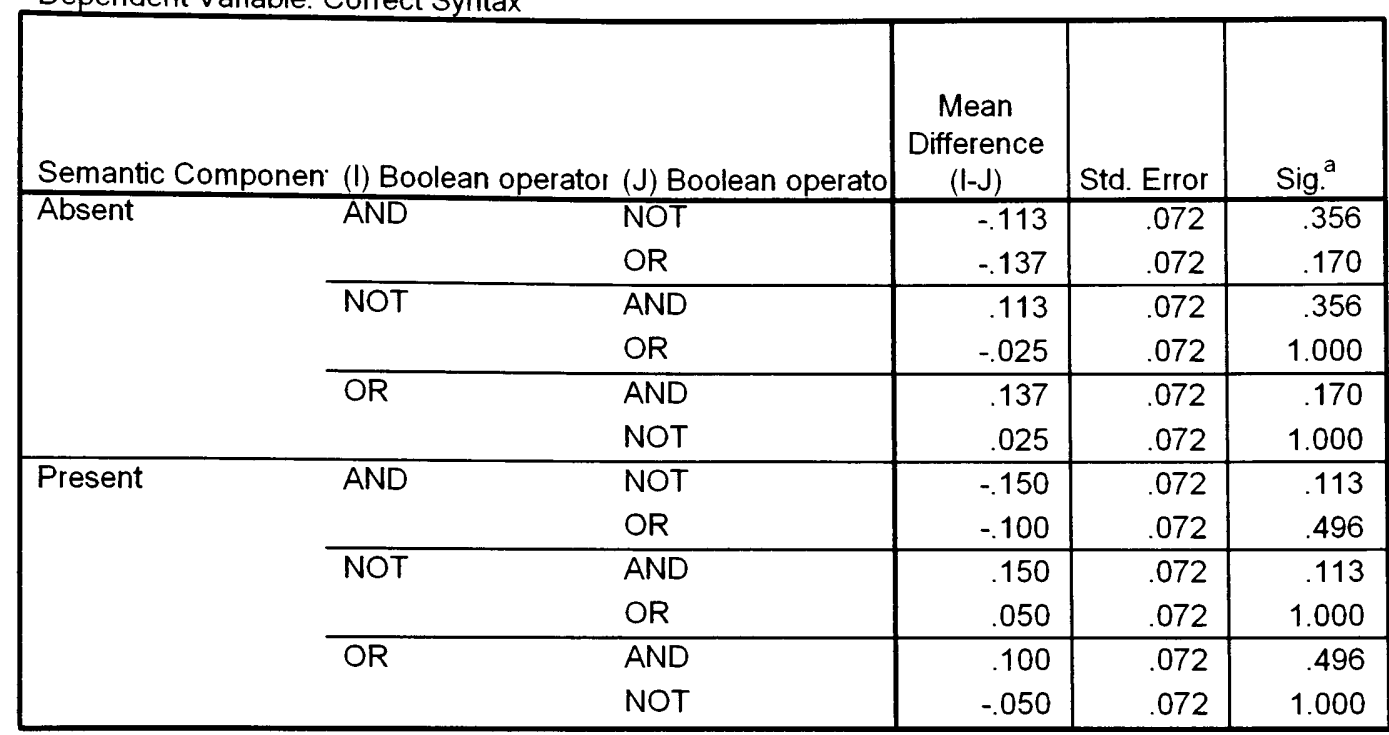

Based on estimated marginal means

a. Adjustment for multiple comparisons: Bonferroni.

\section{Boolean operator * Semantic Component}

\section{Pairwise Comparisons}

Dependent Variable: Correct Syntax

\begin{tabular}{|c|c|c|c|c|c|}
\hline Boolean operator & (I) Semantic Componer & (J) Semantic Componer & $\begin{array}{c}\text { Mean } \\
\text { Difference } \\
(1-J)\end{array}$ & Std. Error & Sig. $^{a}$ \\
\hline \multirow[t]{2}{*}{ AND } & Absent & Present & .025 & .072 & .728 \\
\hline & Present & Absent & -.025 & .072 & .728 \\
\hline \multirow[t]{2}{*}{ NOT } & Absent & Present & -.012 & .072 & .862 \\
\hline & Present & Absent & .012 & .072 & .862 \\
\hline \multirow[t]{2}{*}{ OR } & Absent & Present & .062 & .072 & .385 \\
\hline & Present & Absent & -.062 & .072 & .385 \\
\hline
\end{tabular}

Based on estimated marginal means

a. Adjustment for multiple comparisons: Bonferroni. 


\section{Boolean operator * Syntactic Component}

\section{Pairwise Comparisons}

Dependent Variable: Correct Syntax

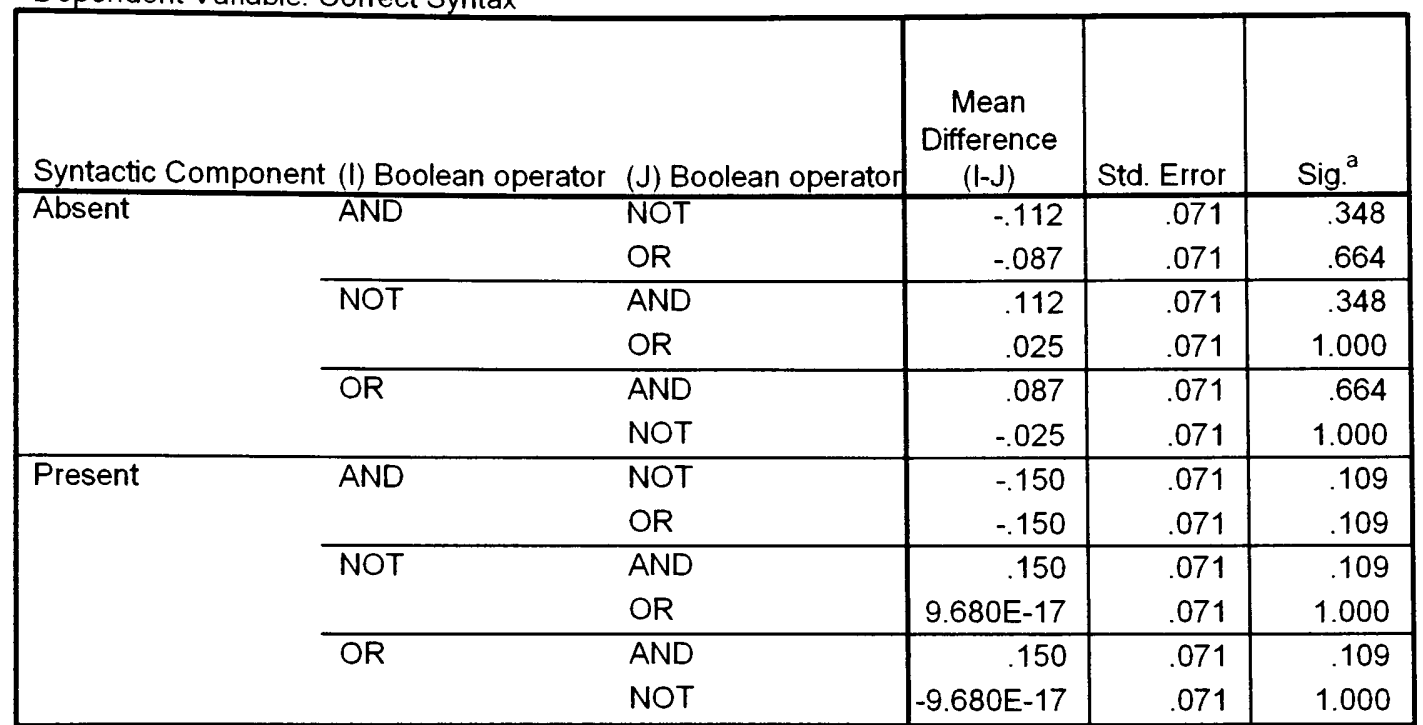

Based on estimated marginal means

a. Adjustment for multiple comparisons: Bonferroni.

\section{Boolean operator * Syntactic Component}

\section{Pairwise Comparisons}

Dependent Variable: Correct Syntax

\begin{tabular}{|c|c|c|c|c|c|}
\hline Boolean operator & (l) Syntactic Componen & (J) Syntactic Componen & $\begin{array}{c}\text { Mean } \\
\text { Difference } \\
(\mathrm{I}-\mathrm{J})\end{array}$ & Std. Error & Sig. $^{a}$ \\
\hline \multirow[t]{2}{*}{ AND } & Absent & Present & -.075 & .071 & .294 \\
\hline & Present & Absent & .075 & .071 & .294 \\
\hline \multirow[t]{2}{*}{ NOT } & Absent & Present & -.113 & .071 & .116 \\
\hline & Present & Absent & .113 & .071 & .116 \\
\hline \multirow[t]{2}{*}{$\overline{O R}$} & Absent & Present & -.137 & .071 & .055 \\
\hline & Present & Absent & .137 & .071 & .055 \\
\hline
\end{tabular}

Based on estimated marginal means

a. Adjustment for multiple comparisons: Bonferroni. 


\section{Boolean operator * Examples Component}

Pairwise Comparisons

Dependent Variable: Correct Syntax

\begin{tabular}{|c|c|c|c|c|c|}
\hline Examples Component & (I) Boolean operator & (J) Boolean operator & $\begin{array}{c}\text { Mean } \\
\text { Difference } \\
(I-J)\end{array}$ & Std. Error & Sig. ${ }^{a}$ \\
\hline \multirow[t]{6}{*}{ Absent } & \multirow[t]{2}{*}{ AND } & NOT & $-.200^{\star}$ & .072 & .016 \\
\hline & & OR & $-.175^{\star}$ & .072 & .045 \\
\hline & \multirow[t]{2}{*}{ NOT } & AND & $.200^{\star}$ & .072 & .016 \\
\hline & & OR & .025 & .072 & 1.000 \\
\hline & \multirow[t]{2}{*}{ OR } & AND & $.175^{\star}$ & .072 & .045 \\
\hline & & NOT & -.025 & .072 & 1.000 \\
\hline \multirow[t]{6}{*}{ Present } & \multirow[t]{2}{*}{ AND } & NOT & -.062 & .072 & 1.000 \\
\hline & & OR & -.062 & .072 & 1.000 \\
\hline & \multirow[t]{2}{*}{ NOT } & AND & .062 & .072 & 1.000 \\
\hline & & OR & $9.680 \mathrm{E}-17$ & .072 & 1.000 \\
\hline & \multirow[t]{2}{*}{ OR } & AND & .062 & .072 & 1.000 \\
\hline & & NOT & $-9.680 \mathrm{E}-17$ & .072 & 1.000 \\
\hline
\end{tabular}

Based on estimated marginal means

${ }^{\star}$. The mean difference is significant at the .05 level.

a. Adjustment for multiple comparisons: Bonferroni.

\section{Boolean operator * Examples Component}

Pairwise Comparisons

Dependent Variable: Correct Syntax

\begin{tabular}{|c|c|c|c|c|c|}
\hline Boolean operator & (I) Examples Componen & (J) Examples Componen & $\begin{array}{c}\text { Mean } \\
\text { Difference } \\
(1-J)\end{array}$ & Std. Error & Sig. ${ }^{a}$ \\
\hline \multirow[t]{2}{*}{ AND } & Absent & Present & $-.150^{\star}$ & .072 & .037 \\
\hline & Present & Absent & $.150^{*}$ & .072 & .037 \\
\hline \multirow[t]{2}{*}{ NOT } & Absent & Present & -.013 & .072 & .862 \\
\hline & Present & Absent & .013 & .072 & .862 \\
\hline \multirow[t]{2}{*}{ OR } & Absent & Present & -.037 & .072 & .601 \\
\hline & Present & Absent & .037 & .072 & 601 \\
\hline
\end{tabular}

Based on estimated marginal means

*. The mean difference is significant at the .05 level.

a. Adjustment for multiple comparisons: Bonferroni. 


\section{Post Hoc Tests}

Boolean operator

\section{Multiple Comparisons}

Dependent Variable: Correct Syntax

Bonferroni

\begin{tabular}{|ll|r|r|r|}
\hline & $\begin{array}{c}\text { Mean } \\
\text { Difference } \\
(\text { I-J) }\end{array}$ & Std. Error & \multicolumn{1}{c|}{ Sig. } \\
\hline (1) Boolean operator & (J) Boolean operator & $-.13^{*}$ & .049 & .023 \\
& NOT & $-.12^{\star}$ & .049 & .048 \\
\hline NOT & OR & $.13^{\star}$ & .049 & .023 \\
& AND & .01 & .049 & 1.000 \\
\hline OR & OR & $.12^{\star}$ & .049 & .048 \\
& AND & -.01 & .049 & 1.000 \\
\hline
\end{tabular}

Based on observed means.

*. The mean difference is significant at the .05 level. 


\section{PRE-CLICK CONFIDENCE}

\section{Univariate Analysis of Variance}

\section{Between-Subjects Factors}

\begin{tabular}{|ll|l|r|}
\hline & & Value Label & N \\
\hline Semantic Component & 0 & Absent & 240 \\
& 1 & Present & 240 \\
Syntactic Component & 0 & Absent & 240 \\
& 1 & Present & 240 \\
Examples Component & 0 & Absent & 240 \\
& 1 & Present & 240 \\
Boolean operator & 1 & AND & 160 \\
& 2 & NOT & 160 \\
& 3 & OR & 160 \\
\hline
\end{tabular}

Tests of Between-Subjects Effects

Dependent Variable: Pre-click Confidence

\begin{tabular}{|c|c|c|c|c|c|}
\hline Source & $\begin{array}{l}\text { Type III Sum } \\
\text { of Squares }\end{array}$ & df & Mean Square & $\mathrm{F}$ & Sig. \\
\hline Corrected Model & $47.898^{\mathrm{a}}$ & 23 & 2.083 & 1.288 & .169 \\
\hline Intercept & 8559.852 & 1 & 8559.852 & 5294.395 & .000 \\
\hline SEMANTIC & 6.302 & 1 & 6.302 & 3.898 & .049 \\
\hline SYNTAX & 1.102 & 1 & 1.102 & .682 & .409 \\
\hline EXAMPLES & 13.002 & 1 & 13.002 & 8.042 & .005 \\
\hline OPERATOR & 15.179 & 2 & 7.590 & 4.694 & .010 \\
\hline SEMANTIC * SYNTAX & .102 & 1 & .102 & .063 & .802 \\
\hline SEMANTIC * EXAMPLES & 1.519 & 1 & 1.519 & .939 & .333 \\
\hline SYNTAX * EXAMPLES & .019 & 1 & .019 & .012 & .914 \\
\hline $\begin{array}{l}\text { SEMANTIC * SYNTAX * } \\
\text { EXAMPLES }\end{array}$ & .052 & 1 & .052 & .032 & .858 \\
\hline SEMANTIC * OPERATOR & 1.504 & 2 & .752 & .465 & .628 \\
\hline SYNTAX * OPERATOR & 1.754 & 2 & .877 & .542 & .582 \\
\hline $\begin{array}{l}\text { SEMANTIC * SYNTAX * } \\
\text { OPERATOR }\end{array}$ & 1.779 & 2 & .890 & .550 & .577 \\
\hline EXAMPLES * OPERATOR & 2.204 & 2 & 1.102 & .682 & .506 \\
\hline $\begin{array}{l}\text { SEMANTIC * EXAMPLES } \\
\text { OPERATOR }\end{array}$ & .613 & 2 & .306 & .189 & .828 \\
\hline $\begin{array}{l}\text { SYNTAX * EXAMPLES * } \\
\text { OPERATOR }\end{array}$ & 1.363 & 2 & 681 & .421 & .656 \\
\hline $\begin{array}{l}\text { SEMANTIC * SYNTAX * } \\
\text { EXAMPLES * OPERATOR }\end{array}$ & 1.404 & 2 & .702 & .434 & 648 \\
\hline Error & 737.250 & 456 & 1.617 & & \\
\hline Total & 9345.000 & 480 & & & \\
\hline Corrected Total & 785.148 & 479 & & & \\
\hline
\end{tabular}

a. R Squared $=.061$ (Adjusted R Squared $=.014$ ) 


\section{Estimated Marginal Means}

\section{Semantic Component}

Dependent Variable: Pre-click Confidence

\begin{tabular}{|l|r|r|r|r|}
\hline & & & \multicolumn{2}{|c|}{$95 \%$ Confidence Interval } \\
\cline { 4 - 5 } Semantic Component & Mean & Std. Error & Lower Bound & Upper Bound \\
\hline Absent & 4.108 & .082 & 3.947 & 4.270 \\
Present & 4.337 & .082 & 4.176 & 4.499 \\
\hline
\end{tabular}

\section{Syntactic Component}

Dependent Variable: Pre-click Confidence

\begin{tabular}{|l|r|r|r|r|}
\hline & & & \multicolumn{2}{|c|}{$95 \%$ Confidence Interval } \\
\cline { 4 - 5 } Syntactic Component & Mean & Std. Error & Lower Bound & Upper Bound \\
\hline Absent & 4.175 & .082 & 4.014 & 4.336 \\
Present & 4.271 & .082 & 4.110 & 4.432 \\
\hline
\end{tabular}

\section{Examples Component}

Dependent Variable: Pre-click Confidence

\begin{tabular}{|c|c|c|c|c|}
\hline \multirow[b]{2}{*}{ Examples Component } & \multirow[b]{2}{*}{ Mean } & \multirow[b]{2}{*}{ Std. Error } & \multicolumn{2}{|c|}{$95 \%$ Confidence Interval } \\
\hline & & & Lower Bound & Upper Bound \\
\hline Absent & 4.387 & .082 & 4.226 & 4.549 \\
\hline Present & 4.058 & .082 & 3.897 & 4.220 \\
\hline
\end{tabular}

\section{Boolean operator}

Dependent Variable: Pre-click Confidence

\begin{tabular}{|l|r|r|r|r|}
\hline \multirow{2}{*}{ Boolean operator } & & & \multicolumn{2}{|c|}{$95 \%$ Confidence Interval } \\
\cline { 4 - 5 } & Mean & Std. Error & Lower Bound & Upper Bound \\
\hline AND & 4.025 & .101 & 3.827 & 4.223 \\
NOT & 4.456 & .101 & 4.259 & 4.654 \\
OR & 4.187 & .101 & 3.990 & 4.385 \\
\hline
\end{tabular}

\section{Semantic Component * Boolean operator}

Dependent Variable: Pre-click Confidence

\begin{tabular}{|c|c|c|c|c|c|}
\hline \multirow{2}{*}{\multicolumn{2}{|c|}{ Semantic Component Boolean operator }} & \multirow[b]{2}{*}{ Mean } & \multirow[b]{2}{*}{ Std. Error } & \multicolumn{2}{|c|}{$95 \%$ Confidence Interval } \\
\hline & & & & Lower Bound & Upper Bound \\
\hline \multirow[t]{3}{*}{ Absent } & AND & 3.950 & .142 & 3.671 & 4.229 \\
\hline & NOT & 4.262 & .142 & 3.983 & 4.542 \\
\hline & OR & 4.112 & .142 & 3.833 & 4.392 \\
\hline \multirow[t]{3}{*}{ Present } & $\overline{\text { AND }}$ & 4.100 & 142 & 3.821 & 4.379 \\
\hline & NOT & 4.650 & .142 & 4.371 & 4.929 \\
\hline & OR & 4.262 & .142 & 3.983 & 4.542 \\
\hline
\end{tabular}




\section{Syntactic Component * Boolean operator}

Dependent Variable: Pre-click Confidence

\begin{tabular}{|ll|r|r|r|r|}
\hline & & & & \multicolumn{2}{|c|}{$95 \%$ Confidence Interval } \\
\cline { 5 - 6 } Syntactic Component & Boolean operator & Mean & Std. Error & Lower Bound & Upper Bound \\
\hline Absent & AND & 3.937 & .142 & 3.658 & 4.217 \\
& NOT & 4.363 & .142 & 4.083 & 4.642 \\
& OR & 4.225 & .142 & 3.946 & 4.504 \\
\hline Present & AND & 4.113 & .142 & 3.833 & 4.392 \\
& NOT & 4.550 & .142 & 4.271 & 4.829 \\
& OR & 4.150 & .142 & 3.871 & 4.429 \\
\hline
\end{tabular}

\section{Examples Component * Boolean operator}

Dependent Variable: Pre-click Confidence

\begin{tabular}{|ll|r|r|r|r|}
\hline & & & & \multicolumn{2}{|c|}{$95 \%$ Confidence Interval } \\
\cline { 5 - 6 } Examples Component & Boolean operator & Mean & Std. Error & Lower Bound & Upper Bound \\
\hline Absent & AND & 4.237 & .142 & 3.958 & 4.517 \\
& NOT & 4.525 & .142 & 4.246 & 4.804 \\
& OR & 4.400 & .142 & 4.121 & 4.679 \\
\hline Present & AND & 3.812 & .142 & 3.533 & 4.092 \\
& NOT & 4.387 & .142 & 4.108 & 4.667 \\
& OR & 3.975 & .142 & 3.696 & 4.254 \\
\hline
\end{tabular}

\section{Semantic Component * Syntactic Component}

Dependent Variable: Pre-click Confidence

\begin{tabular}{|ll|r|r|r|r|}
\hline & & & & \multicolumn{2}{|c|}{$95 \%$ Confidence Interval } \\
\cline { 5 - 6 } Semantic Component & Syntactic Component & Mean & Std. Error & Lower Bound & Upper Bound \\
\hline Absent & Absent & 4.075 & .116 & 3.847 & 4.303 \\
& Present & 4.142 & .116 & 3.914 & 4.370 \\
\hline Present & Absent & 4.275 & .116 & 4.047 & 4.503 \\
& Present & 4.400 & .116 & 4.172 & 4.628 \\
\hline
\end{tabular}

\section{Semantic Component * Examples Component}

Dependent Variable: Pre-click Confidence

\begin{tabular}{|ll|r|r|r|r|}
\hline & & & & \multicolumn{2}{|c|}{$95 \%$ Confidence Interval } \\
\cline { 5 - 6 } Semantic Component & Examples Component & Mean & Std. Error & Lower Bound & Upper Bound \\
\hline Absent & Absent & 4.217 & .116 & 3.989 & 4.445 \\
& Present & 4.000 & .116 & 3.772 & 4.228 \\
\hline Present & Absent & 4.558 & .116 & 4.330 & 4.786 \\
& Present & 4.117 & .116 & 3.889 & 4.345 \\
\hline
\end{tabular}

\section{Syntactic Component * Examples Component}

Dependent Variable: Pre-click Confidence

\begin{tabular}{|ll|r|r|r|r|}
\hline & & & \multicolumn{2}{|c|}{$95 \%$ Confidence Interval } \\
\cline { 5 - 6 } Syntactic Component & Examples Component & Mean & Std. Error & Lower Bound & Upper Bound \\
\hline Absent & Absent & 4.333 & .116 & 4.105 & 4.561 \\
& Present & 4.017 & .116 & 3.789 & 4.245 \\
\hline Present & Absent & 4.442 & .116 & 4.214 & 4.670 \\
& Present & 4.100 & .116 & 3.872 & 4.328 \\
\hline
\end{tabular}




\section{Boolean operator * Semantic Component}

Pairwise Comparisons

Dependent Variable: Pre-click Confidence

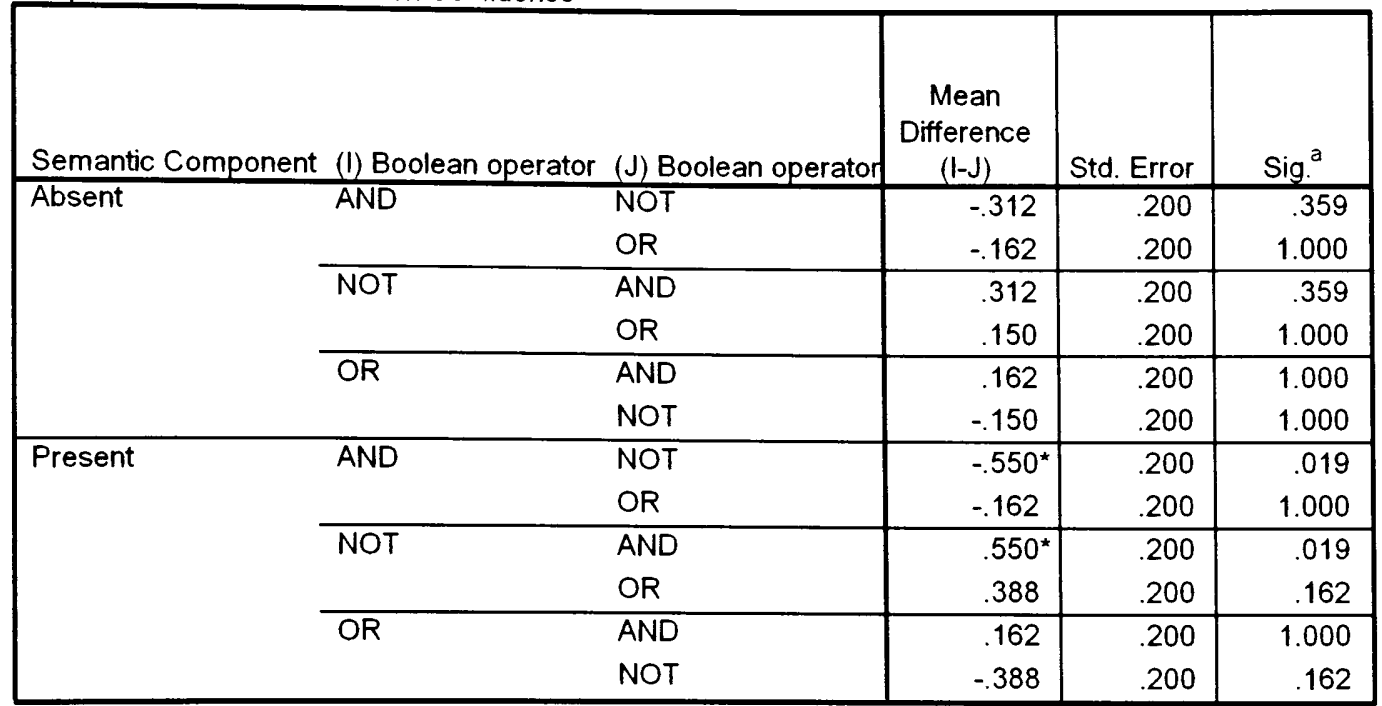

Based on estimated marginal means

*. The mean difference is significant at the .05 level.

a. Adjustment for multiple comparisons: Bonferroni.

\section{Boolean operator * Semantic Component}

\section{Pairwise Comparisons}

Dependent Variable: Pre-click Confidence

\begin{tabular}{|c|c|c|c|c|c|}
\hline Boolean operato & (1) Semantic Componer & (J) Semantic Componer & $\begin{array}{c}\text { Mean } \\
\text { Difference } \\
(1-J)\end{array}$ & Std. Error & Sig. $^{a}$ \\
\hline \multirow[t]{2}{*}{ AND } & Absent & Present & -.150 & .200 & .455 \\
\hline & Present & Absent & .150 & .200 & .455 \\
\hline \multirow[t]{2}{*}{ NOT } & Absent & Present & -.388 & .200 & .054 \\
\hline & Present & Absent & .388 & 200 & .054 \\
\hline \multirow[t]{2}{*}{$\overline{O R}$} & Absent & Present & -.150 & .200 & .455 \\
\hline & Present & Absent & .150 & .200 & .455 \\
\hline
\end{tabular}

Based on estimated marginal means

a. Adjustment for multiple comparisons: Bonferroni. 


\section{Boolean operator * Syntactic Component}

Pairwise Comparisons

Dependent Variable: Pre-click Confidence

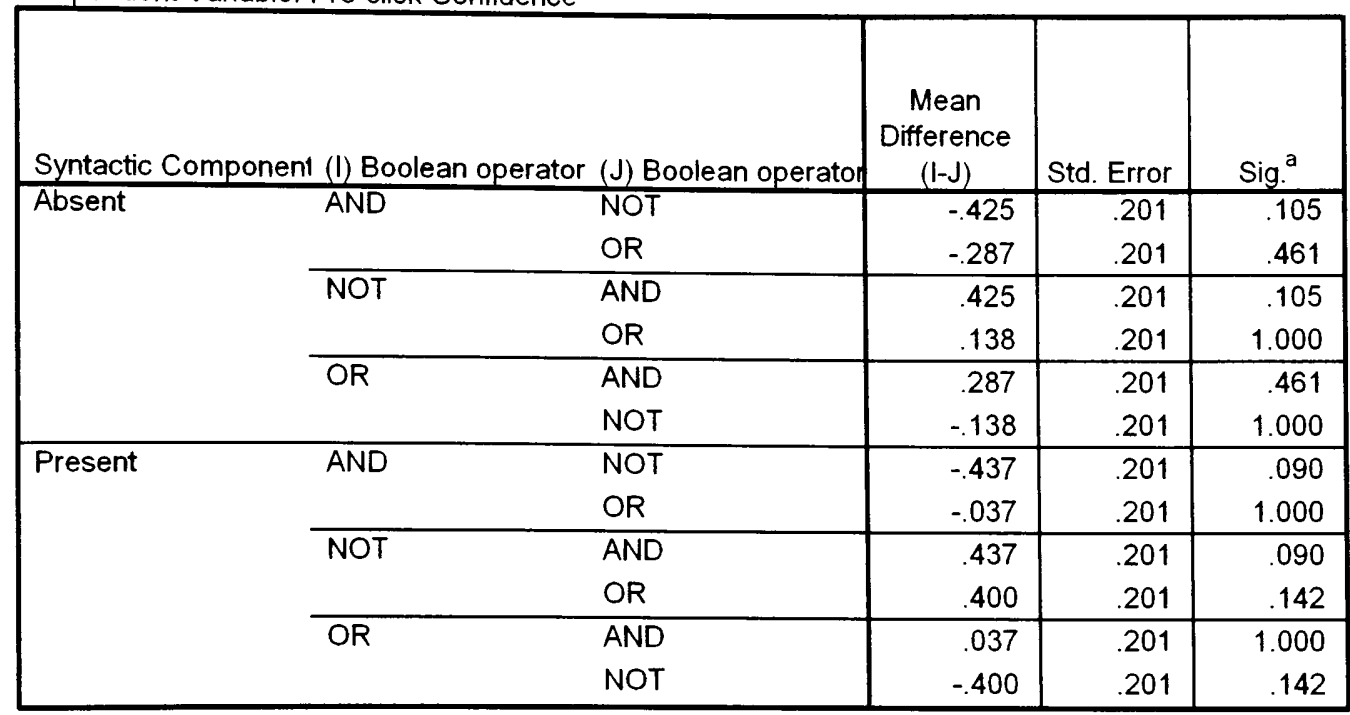

Based on estimated marginal means

a. Adjustment for multiple comparisons: Bonferroni.

\section{Boolean operator * Syntactic Component}

\section{Pairwise Comparisons}

Dep endent Variable: Pre-click Confidence

\begin{tabular}{|c|c|c|c|c|c|}
\hline \multicolumn{3}{|c|}{ Boolean op erator ( $) S$ ntactic Componer $(J) S$ ntactic Com pone } & $\begin{array}{c}\text { Mean } \\
\text { Difference } \\
(1-J)\end{array}$ & Std. Error & Sig. $^{a}$ \\
\hline \multirow[t]{2}{*}{ AND } & Absent & Present & -.175 & .201 & .385 \\
\hline & Present & Absent & .175 & .201 & .385 \\
\hline \multirow[t]{2}{*}{ NOT } & Absent & Present & -.187 & .201 & .352 \\
\hline & Present & Absent & .187 & 201 & .352 \\
\hline \multirow[t]{2}{*}{ OR } & Absent & Present & .075 & .201 & .709 \\
\hline & Present & Absent & -.075 & .201 & .709 \\
\hline
\end{tabular}

Based on estimated marginal means

a. Adjustment for multiple comparisons: Bonferroni. 


\section{Boolean operator * Examples Component}

\section{Pairwise Comparisons}

Dependent Variable: Pre-click Confidence

\begin{tabular}{|c|c|c|c|c|c|}
\hline Examples Component & (1) Boolean operator & (J) Boolean operator & $\begin{array}{c}\text { Mean } \\
\text { Difference } \\
(1-J)\end{array}$ & Std. Error & Sig. ${ }^{a}$ \\
\hline \multirow[t]{6}{*}{ Ábsent } & \multirow[t]{2}{*}{ AND } & NOT & -.288 & .200 & .451 \\
\hline & & OR & -.162 & .200 & 1.000 \\
\hline & \multirow[t]{2}{*}{ NOT } & AND & .288 & .200 & .451 \\
\hline & & OR & .125 & .200 & 1.000 \\
\hline & \multirow[t]{2}{*}{ OR } & AND & .162 & .200 & 1.000 \\
\hline & & NOT & -.125 & .200 & 1.000 \\
\hline \multirow[t]{6}{*}{ Present } & \multirow[t]{2}{*}{ AND } & NOT & $-.575^{\star}$ & 200 & .012 \\
\hline & & OR & -.162 & .200 & 1.000 \\
\hline & \multirow[t]{2}{*}{ NOT } & AND & $.575^{\star}$ & .200 & .012 \\
\hline & & OR & .413 & .200 & .118 \\
\hline & \multirow[t]{2}{*}{ OR } & AND & .162 & 200 & 1.000 \\
\hline & & NOT & -.413 & .200 & 118 \\
\hline
\end{tabular}

Based on estimated marginal means

*. The mean difference is significant at the .05 level.

a. Adjustment for multiple comparisons: Bonferroni.

\section{Boolean operator * Examples Component}

Pairwise Comparisons

Dependent Variable: Pre-click Confidence

\begin{tabular}{|c|c|c|c|c|c|}
\hline Boolean operator & (I) Examples Componer & (J) Examples Componer & $\begin{array}{c}\text { Mean } \\
\text { Difference } \\
(1-J)\end{array}$ & Std. Error & Sig. $^{a}$ \\
\hline \multirow[t]{2}{*}{ AND } & Absent & Present & $.425^{\star}$ & .200 & .034 \\
\hline & Present & Absent & $-.425^{\star}$ & .200 & .034 \\
\hline \multirow[t]{2}{*}{ NOT } & Absent & Present & .138 & .200 & .491 \\
\hline & Present & Absent & -.138 & .200 & .491 \\
\hline \multirow[t]{2}{*}{ OR } & Absent & Present & $.425^{\star}$ & .200 & .034 \\
\hline & Present & Absent & $-.425^{\star}$ & .200 & .034 \\
\hline
\end{tabular}

Based on estimated marginal means

* . The mean difference is significant at the .05 level.

a. Adjustment for multiple comparisons: Bonferroni. 


\section{Post Hoc Tests}

Boolean operator

Multiple Comparisons

Dependent Variable: Pre-click Confidence

Bonferroni

\begin{tabular}{|ll|r|r|r|}
\hline & $\begin{array}{c}\text { Mean } \\
\text { Difference } \\
(\mathrm{I}-\mathrm{J})\end{array}$ & Std. Error & \multicolumn{1}{c|}{ Sig. } \\
\hline (I) Boolean operator & $(\mathrm{J})$ Boolean operator & $-.43^{*}$ & .142 & .008 \\
& NOT & -.16 & .142 & .761 \\
\hline NOT & OR & $.43^{\star}$ & .142 & .008 \\
& AND & .27 & .142 & .178 \\
\hline OR & OR & .16 & .142 & .761 \\
& AND & -.27 & .142 & .178 \\
\hline
\end{tabular}

Based on observed means.

*. The mean difference is significant at the .05 level. 


\section{SATISFACTION (SUS)}

\section{Univariate Analysis of Variance}

Between-Subjects Factors

\begin{tabular}{|ll|l|r|}
\hline & & Value Label & N \\
\hline Semantic Component & 0 & Absent & 240 \\
& 1 & Present & 240 \\
Syntactic Component & 0 & Absent & 240 \\
& 1 & Present & 240 \\
Examples Component & 0 & Absent & 240 \\
& 1 & Present & 240 \\
Boolean operator & 1 & AND & 160 \\
& 2 & NOT & 160 \\
& 3 & OR & 160 \\
\hline
\end{tabular}

Tests of Between-Subjects Effects

Dependent Variable: SUS Questionnaire

\begin{tabular}{|c|c|c|c|c|c|}
\hline Source & $\begin{array}{l}\text { Type III Sum } \\
\text { of Squares }\end{array}$ & df & Mean Square & $\mathrm{F}$ & Sig. \\
\hline Corrected Model & $3630.000^{\mathbf{a}}$ & 23 & 157.826 & 1.021 & .436 \\
\hline Intercept & 2967307.500 & 1 & 2967307.500 & 19203.012 & .000 \\
\hline SEMANTIC & 226.875 & 1 & 226.875 & 1.468 & .226 \\
\hline SYNTAX & 30.000 & 1 & 30.000 & .194 & .660 \\
\hline EXAMPLES & 1470.000 & 1 & 1470.000 & 9.513 & .002 \\
\hline OPERATOR & .000 & 2 & .000 & .000 & 1.000 \\
\hline SEMANTIC * SYNTAX & 226.875 & 1 & 226.875 & 1.468 & .226 \\
\hline SEMANTIC * EXAMPLES & 676.875 & 1 & 676.875 & 4.380 & .037 \\
\hline SYNTAX * EXAMPLES & 7.500 & 1 & 7.500 & .049 & .826 \\
\hline $\begin{array}{l}\text { SEMANTIC * SYNTAX * } \\
\text { EXAMPLES }\end{array}$ & 991.875 & 1 & 991.875 & 6.419 & .012 \\
\hline SEMANTIC * OPERATOR & .000 & 2 & .000 & .000 & 1.000 \\
\hline SYNTAX * OPERATOR & .000 & 2 & .000 & .000 & 1.000 \\
\hline $\begin{array}{l}\text { SEMANTIC * SYNTAX * } \\
\text { OPERATOR }\end{array}$ & .000 & 2 & .000 & .000 & 1.000 \\
\hline EXAMPLES * OPERATOR & .000 & 2 & .000 & .000 & 1.000 \\
\hline $\begin{array}{l}\text { SEMANTIC * EXAMPLES } \\
\text { OPERATOR }\end{array}$ & .000 & 2 & .000 & .000 & 1.000 \\
\hline $\begin{array}{l}\text { SYNTAX * EXAMPLES * } \\
\text { OPERATOR }\end{array}$ & .000 & 2 & .000 & .000 & 1.000 \\
\hline $\begin{array}{l}\text { SEMANTIC * SYNTAX * } \\
\text { EXAMPLES * OPERATOR }\end{array}$ & .000 & 2 & .000 & .000 & 1.000 \\
\hline Error & 70462.500 & 456 & 154.523 & & \\
\hline Total & 3041400.000 & 480 & & & \\
\hline Corrected Total & 74092.500 & 479 & & & \\
\hline
\end{tabular}

a. R Squared $=.049$ (Adjusted R Squared $=.001$ ) 


\section{Estimated Marginal Means}

\section{Semantic Component}

Dependent Variable: sUS Questionnaire

\begin{tabular}{|l|c|r|r|r|}
\hline & & & \multicolumn{2}{|c|}{$95 \%$ Confidence Interval } \\
\cline { 4 - 5 } Semantic Component & Mean & Std. Error & Lower Bound & Upper Bound \\
\hline Absent & 79.313 & .802 & 77.736 & 80.889 \\
Present & 77.938 & .802 & 76.361 & 79.514 \\
\hline
\end{tabular}

\section{Syntactic Component}

Dependent Variable: SUS Questionnaire

\begin{tabular}{|l|r|r|r|r|}
\hline & & \multicolumn{3}{|c|}{$95 \%$ Confidence Interval } \\
\cline { 4 - 5 } Syntactic Component & Mean & Std. Error & Lower Bound & Upper Bound \\
\hline Absent & 78.375 & .802 & 76.798 & 79.952 \\
Present & 78.875 & .802 & 77.298 & 80.452 \\
\hline
\end{tabular}

\section{Examples Component}

Dependent Variable: SUS Questionnaire

\begin{tabular}{|l|r|r|r|r|}
\hline & & & \multicolumn{2}{|c|}{$95 \%$ Confidence Interval } \\
\cline { 4 - 5 } Examples Component & Mean & Std. Error & Lower Bound & Upper Bound \\
\hline Absent & 80.375 & .802 & 78.798 & 81.952 \\
Present & 76.875 & .802 & 75.298 & 78.452 \\
\hline
\end{tabular}

\section{Semantic Component * Syntactic Component}

Dependent Variable: SUS Questionnaire

\begin{tabular}{|ll|r|r|r|r|}
\hline \multirow{2}{*}{ Semantic Component } & & & \multicolumn{2}{|c|}{$95 \%$ Confidence Interval } \\
\cline { 5 - 6 } & Syntactic Component & Mean & Std. Error & Lower Bound & Upper Bound \\
\hline Absent & Absent & 78.375 & 1.135 & 76.145 & 80.605 \\
& Present & 80.250 & 1.135 & 78.020 & 82.480 \\
\hline Present & Absent & 78.375 & 1.135 & 76.145 & 80.605 \\
& Present & 77.500 & 1.135 & 75.270 & 79.730 \\
\hline
\end{tabular}

\section{Semantic Component * Examples Component}

Dependent Variable: SUS Questionnaire

\begin{tabular}{|ll|r|r|r|r|}
\hline \multirow{2}{*}{ Semantic Component } & & & \multicolumn{2}{|c|}{ 95\% Confidence Interval } \\
\cline { 5 - 6 } & Examples Component & Mean & Std. Error & Lower Bound & Upper Bound \\
\hline Absent & Absent & 79.875 & 1.135 & 77.645 & 82.105 \\
& Present & 78.750 & 1.135 & 76.520 & 80.980 \\
\hline Present & Absent & 80.875 & 1.135 & 78.645 & 83.105 \\
& Present & 75.000 & 1.135 & 72.770 & 77.230 \\
\hline
\end{tabular}

\section{Syntactic Component * Examples Component}

Dependent Variable: SUS Questionnaire

\begin{tabular}{|ll|r|r|r|r|}
\hline \multirow{2}{*}{ Syntactic Component } & & \multicolumn{2}{|c|}{$95 \%$ Confidence Interval } \\
\cline { 5 - 6 } & Examples Component & Mean & Std. Error & Lower Bound & Upper Bound \\
\hline Absent & Absent & 80.000 & 1.135 & 77.770 & 82.230 \\
& Present & 76.750 & 1.135 & 74.520 & 78.980 \\
\hline Present & Absent & 80.750 & 1.135 & 78.520 & 82.980 \\
& Present & 77.000 & 1.135 & 74.770 & 79.230 \\
\hline
\end{tabular}




\section{TIME}

\section{Univariate Analysis of Variance}

Between-Subjects Factors

\begin{tabular}{|ll|l|r|}
\hline & & Value Label & N \\
\hline Semantic Component & 0 & Absent & 240 \\
& 1 & Present & 240 \\
Syntactic Component & 0 & Absent & 240 \\
Examples Component & 1 & Present & 240 \\
& 0 & Absent & 240 \\
Boolean operator & 1 & Present & 240 \\
& 1 & AND & 160 \\
& 2 & NOT & 160 \\
& 3 & OR & 160 \\
\hline
\end{tabular}

Tests of Between-Subjects Effects

Dependent Variable: Completion Time (s)

\begin{tabular}{|c|c|c|c|c|c|}
\hline Source & $\begin{array}{l}\text { Type III Sum } \\
\text { of Squares }\end{array}$ & df & Mean Square & $\mathrm{F}$ & Sig. \\
\hline Corrected Model & $37649.581^{a}$ & 23 & 1636.938 & 2.293 & .001 \\
\hline Intercept & 382396.252 & 1 & 382396.252 & 535.571 & .000 \\
\hline SEMANTIC & 2791.890 & 1 & 2791.890 & 3.910 & .049 \\
\hline SYNTAX & 113.034 & 1 & 113.034 & .158 & 691 \\
\hline EXAMPLES & 555.539 & 1 & 555.539 & .778 & 378 \\
\hline OPERATOR & 9860.331 & 2 & 4930.165 & 6.905 & .001 \\
\hline SEMANTIC * SYNTAX & 82.759 & 1 & 82.759 & .116 & .734 \\
\hline SEMANTIC * EXAMPLES & 6821.363 & 1 & 6821.363 & 9.554 & .002 \\
\hline SYNTAX * EXAMPLES & 299.173 & 1 & 299.173 & .419 & .518 \\
\hline $\begin{array}{l}\text { SEMANTIC * SYNTAX * } \\
\text { EXAMPLES }\end{array}$ & 2712.014 & 1 & 2712.014 & 3.798 & .052 \\
\hline SEMANTIC * OPERATOR & 804.220 & 2 & 402.110 & .563 & .570 \\
\hline SYNTAX * OPERATOR & 2018.897 & 2 & 1009.449 & 1.414 & .244 \\
\hline $\begin{array}{l}\text { SEMANTIC * SYNTAX * } \\
\text { OPERATOR }\end{array}$ & 1207.110 & 2 & 603.555 & .845 & .430 \\
\hline EXAMPLES * OPERATOR & 5497.703 & 2 & 2748.851 & 3.850 & .022 \\
\hline $\begin{array}{l}\text { SEMANTIC * EXAMPLES } \\
\text { OPERATOR }\end{array}$ & 3125.932 & 2 & 1562.966 & 2.189 & .113 \\
\hline $\begin{array}{l}\text { SYNTAX * EXAMPLES * } \\
\text { OPERATOR }\end{array}$ & 16.629 & 2 & 8.314 & .012 & .988 \\
\hline $\begin{array}{l}\text { SEMANTIC * SYNTAX * } \\
\text { EXAMPLES * OPERATOR }\end{array}$ & 1742.987 & 2 & 871.493 & 1.221 & .296 \\
\hline Error & 325582.769 & 456 & 713.997 & & \\
\hline Total & 745628.602 & 480 & & & \\
\hline Corrected Total & 363232.350 & 479 & & & \\
\hline
\end{tabular}

a. R Squared $=.104$ (Adjusted R Squared $=.058$ ) 


\section{Estimated Marginal Means}

\section{Semantic Component}

Dependent Variable: Completion Time (s)

\begin{tabular}{|l|r|r|r|r|}
\hline & & & \multicolumn{2}{|c|}{$95 \%$ Confidence Interval } \\
\cline { 4 - 5 } Semantic Component & Mean & Std. Error & Lower Bound & Upper Bound \\
\hline Absent & 25.813 & 1.725 & 22.424 & 29.203 \\
Present & 30.637 & 1.725 & 27.247 & 34.026 \\
\hline
\end{tabular}

\section{Syntactic Component}

Dependent Variable: Completion Time (s)

\begin{tabular}{|l|r|r|r|r|}
\hline & & & \multicolumn{2}{|c|}{$95 \%$ Confidence Interval } \\
\cline { 4 - 5 } Syntactic Component & Mean & Std. Error & Lower Bound & Upper Bound \\
\hline Absent & 27.740 & 1.725 & 24.350 & 31.129 \\
Present & 28.710 & 1.725 & 25.321 & 32.100 \\
\hline
\end{tabular}

\section{Examples Component}

Dependent Variable: Completion Time (s)

\begin{tabular}{|c|c|c|c|c|}
\hline \multirow[b]{2}{*}{ Examples Component } & \multirow[b]{2}{*}{ Mean } & \multirow[b]{2}{*}{ Std. Error } & \multicolumn{2}{|c|}{$95 \%$ Confidence Interval } \\
\hline & & & Lower Bound & Upper Bound \\
\hline Absent & 27.149 & 1.725 & 23.760 & 30.539 \\
\hline Present & 29.301 & 1.725 & 25.911 & 32.691 \\
\hline
\end{tabular}

\section{Boolean operator}

Dependent Variable: Completion Time (s)

\begin{tabular}{|l|r|r|r|r|}
\hline & & & \multicolumn{2}{|c|}{$95 \%$ Confidence Interval } \\
\cline { 4 - 5 } Boolean operator & Mean & Std. Error & Lower Bound & Upper Bound \\
\hline AND & 26.396 & 2.112 & 22.245 & 30.548 \\
NOT & 23.819 & 2.112 & 19.668 & 27.971 \\
OR & 34.460 & 2.112 & 30.308 & 38.611 \\
\hline
\end{tabular}

\section{Semantic Component * Boolean operator}

Dependent Variable: Completion Time (s)

\begin{tabular}{|c|c|c|c|c|c|}
\hline \multirow[b]{2}{*}{ Semantic Component } & \multirow[b]{2}{*}{ Boolean operator } & \multirow[b]{2}{*}{ Mean } & \multirow[b]{2}{*}{ Std. Error } & \multicolumn{2}{|c|}{$95 \%$ Confidence Interval } \\
\hline & & & & Lower Bound & Upper Bound \\
\hline \multirow[t]{3}{*}{ Absent } & AND & 22.436 & 2.987 & 16.565 & 28.307 \\
\hline & NOT & 21.337 & 2.987 & 15.466 & 27.208 \\
\hline & OR & 33.668 & 2.987 & 27.797 & 39.538 \\
\hline \multirow[t]{3}{*}{ Present } & AND & 30.357 & 2.987 & 24.486 & 36.228 \\
\hline & NOT & 26.302 & 2.987 & 20.431 & 32.173 \\
\hline & OR & 35.252 & 2.987 & 29.381 & 41.123 \\
\hline
\end{tabular}




\section{Syntactic Component * Boolean operator}

Dependent Variable: Completion Time (s)

\begin{tabular}{|c|c|c|c|c|c|}
\hline \multirow[b]{2}{*}{ Syntactic Component } & \multirow[b]{2}{*}{ Boolean operator } & \multirow[b]{2}{*}{ Mean } & \multirow[b]{2}{*}{ Std. Error } & \multicolumn{2}{|c|}{$95 \%$ Confidence Interval } \\
\hline & & & & Lower Bound & Upper Bound \\
\hline \multirow[t]{3}{*}{ Absent } & AND & 26.193 & 2.987 & 20.322 & 32.064 \\
\hline & NOT & 25.693 & 2.987 & 19.822 & 31.564 \\
\hline & OR & 31.334 & 2.987 & 25.463 & 37.205 \\
\hline \multirow[t]{3}{*}{ Present } & AND & 26.600 & 2.987 & 20.729 & 32.470 \\
\hline & NOT & 21.946 & 2.987 & 16.075 & 27.817 \\
\hline & OR & 37.586 & 2.987 & 31.715 & 43.457 \\
\hline
\end{tabular}

\section{Examples Component * Boolean operator}

Dependent Variable: Completion Time (s)

\begin{tabular}{|c|c|c|c|c|c|}
\hline \multirow[b]{2}{*}{ Examples Component } & \multirow[b]{2}{*}{ Boolean operator } & \multirow[b]{2}{*}{ Mean } & \multirow[b]{2}{*}{ Std. Error } & \multicolumn{2}{|c|}{$95 \%$ Confidence Interval } \\
\hline & & & & Lower Bound & Upper Bound \\
\hline \multirow[t]{3}{*}{ Absent } & AND & 27.409 & 2.987 & 21.538 & 33.280 \\
\hline & NOT & 25.428 & 2.987 & 19.557 & 31.299 \\
\hline & OR & 28.610 & 2.987 & 22.739 & 34.481 \\
\hline \multirow[t]{3}{*}{ Present } & AND & 25.383 & 2.987 & 19.512 & 31.254 \\
\hline & NOT & 22.210 & 2.987 & 16.339 & 28.081 \\
\hline & OR & 40.309 & 2.987 & 34.438 & 46.180 \\
\hline
\end{tabular}

\section{Semantic Component * Syntactic Component}

Dependent Variable: Completion Time (s)

\begin{tabular}{|ll|r|r|r|r|}
\hline \multirow{2}{*}{ Semantic Component } & & & \multicolumn{2}{|c|}{$95 \%$ Confidence Interval } \\
\cline { 5 - 6 } & Syntactic Component & Mean & Std. Error & Lower Bound & Upper Bound \\
\hline Absent & Absent & 24.913 & 2.439 & 20.119 & 29.706 \\
& Present & 26.714 & 2.439 & 21.920 & 31.507 \\
\hline Present & Absent & 30.567 & 2.439 & 25.773 & 35.360 \\
& Present & 30.707 & 2.439 & 25.913 & 35.500 \\
\hline
\end{tabular}

\section{Semantic Component * Examples Component}

Dependent Variable: Completion Time (s)

\begin{tabular}{|ll|r|r|r|r|}
\hline \multirow{2}{*}{ Semantic Component } & & & \multicolumn{2}{|c|}{$95 \%$ Confidence Interval } \\
\cline { 4 - 6 } & Examples Component & Mean & Std. Error & Lower Bound & Upper Bound \\
\hline Absent & Absent & 20.968 & 2.439 & 16.174 & 25.761 \\
& Present & 30.659 & 2.439 & 25.865 & 35.453 \\
\hline Present & Absent & 33.331 & 2.439 & 28.537 & 38.124 \\
& Present & 27.943 & 2.439 & 23.149 & 32.736 \\
\hline
\end{tabular}

\section{Syntactic Component * Examples Component}

Dependent Variable: Completion Time (s)

\begin{tabular}{|ll|r|r|r|r|}
\hline \multirow{2}{*}{ Syntactic Component } & & & \multicolumn{2}{|c|}{$95 \%$ Confidence Interval } \\
\cline { 4 - 6 } & Examples Component & Mean & Std. Error & Lower Bound & Upper Bound \\
\hline Absent & Absent & 25.875 & 2.439 & 21.081 & 30.668 \\
& Present & 29.605 & 2.439 & 24.812 & 34.399 \\
\hline Present & Absent & 28.424 & 2.439 & 23.631 & 33.218 \\
& Present & 28.997 & 2.439 & 24.203 & 33.790 \\
\hline
\end{tabular}




\section{Boolean operator * Semantic Component}

Pairwise Comparisons

Dependent Variable: Completion Time (s)

\begin{tabular}{|c|c|c|c|c|c|}
\hline Semantic Component & (I) Boolean operator & (J) Boolean operator & $\begin{array}{c}\text { Mean } \\
\text { Difference } \\
(1-J)\end{array}$ & Std. Error & Sig. ${ }^{\mathrm{a}}$ \\
\hline \multirow[t]{6}{*}{ Absent } & \multirow[t]{2}{*}{ AND } & NOT & 1.099 & 4.295 & 1.000 \\
\hline & & OR & $-11.232^{\star}$ & 4.295 & .028 \\
\hline & \multirow[t]{2}{*}{ NOT } & AND & -1.099 & 4.295 & 1.000 \\
\hline & & OR & $-12.330^{\star}$ & 4.295 & .013 \\
\hline & \multirow[t]{2}{*}{ OR } & AND & $11.232^{\star}$ & 4.295 & .028 \\
\hline & & NOT & $12.330^{\star}$ & 4.295 & .013 \\
\hline \multirow[t]{6}{*}{ Present } & \multirow[t]{2}{*}{ AND } & NOT & 4.055 & 4.295 & 1.000 \\
\hline & & OR & -4.895 & 4.295 & .765 \\
\hline & \multirow[t]{2}{*}{ NOT } & AND & -4.055 & 4.295 & 1.000 \\
\hline & & OR & -8.950 & 4.295 & .113 \\
\hline & \multirow[t]{2}{*}{ OR } & AND & 4.895 & 4.295 & .765 \\
\hline & & NOT & 8.950 & 4.295 & .113 \\
\hline
\end{tabular}

Based on estimated marginal means

*. The mean difference is significant at the .05 level.

a. Adjustment for multiple comparisons: Bonferroni.

\section{Boolean operator * Semantic Component}

\section{Pairwise Comparisons}

Dependent Variable: Completion Time (s)

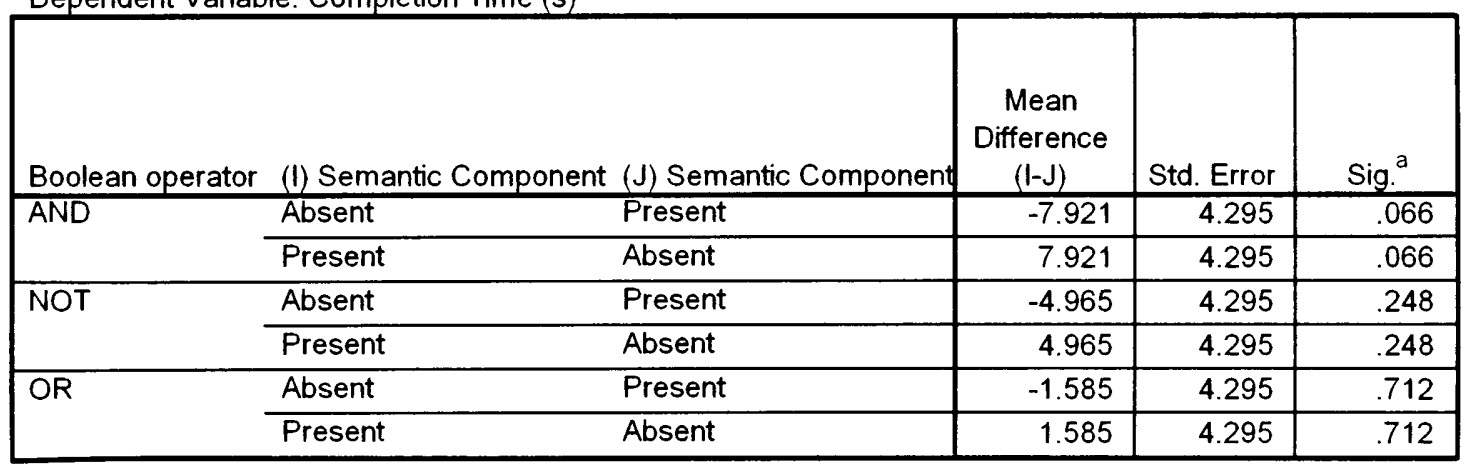

Based on estimated marginal means

a. Adjustment for multiple comparisons: Bonferroni. 


\section{Boolean operator * Syntactic Component}

\section{Pairwise Comparisons}

Dependent Variable: Completion Time (s)

\begin{tabular}{|c|c|c|c|c|c|}
\hline Syntactic Component & (1) Boolean operator & (J) Boolean operator & $\begin{array}{c}\text { Mean } \\
\text { Difference } \\
(1-J)\end{array}$ & Std. Error & Sig. $^{a}$ \\
\hline \multirow[t]{6}{*}{ Absent } & \multirow[t]{2}{*}{ AND } & NOT & .500 & 4.304 & 1.000 \\
\hline & & OR & -5.140 & 4.304 & .699 \\
\hline & \multirow[t]{2}{*}{ NOT } & AND & -.500 & 4.304 & 1.000 \\
\hline & & OR & -5.641 & 4.304 & .572 \\
\hline & \multirow[t]{2}{*}{ OR } & AND & 5.140 & 4.304 & .699 \\
\hline & & NOT & 5.641 & 4.304 & .572 \\
\hline \multirow[t]{6}{*}{ Present } & \multirow[t]{2}{*}{ AND } & NOT & 4.654 & 4.304 & .840 \\
\hline & & OR & $-10.986^{\star}$ & 4.304 & .033 \\
\hline & \multirow[t]{2}{*}{ NOT } & AND & -4.654 & 4.304 & .840 \\
\hline & & OR & $-15.640^{*}$ & 4.304 & .001 \\
\hline & \multirow[t]{2}{*}{ OR } & AND & $10.986^{\star}$ & 4.304 & .033 \\
\hline & & NOT & $15.640^{*}$ & 4.304 & .001 \\
\hline
\end{tabular}

Based on estimated marginal means

*. The mean difference is significant at the .05 level.

a. Adjustment for multiple comparisons: Bonferroni.

\section{Boolean operator * Syntactic Component}

\section{Pairwise Comparisons}

Dependent Variable: Completion Time (s)

\begin{tabular}{|c|c|c|c|c|}
\hline Boolean operator & (I) Syntactic Componen (J) Syntactic Componen & $\begin{array}{c}\text { Mean } \\
\text { Difference } \\
(\mid-J)\end{array}$ & Std. Error & Sig. ${ }^{a}$ \\
\hline \multirow[t]{2}{*}{ AND } & Absent $\quad$ Present & -.406 & 4.304 & .925 \\
\hline & Present & .406 & 4.304 & .925 \\
\hline \multirow[t]{2}{*}{ NOT } & Present & 3.747 & 4.304 & .384 \\
\hline & Present & -3.747 & 4.304 & .384 \\
\hline \multirow[t]{2}{*}{ OR } & Present & -6.252 & 4.304 & .147 \\
\hline & Present & 6.252 & 4.304 & .147 \\
\hline
\end{tabular}

Based on estimated marginal means

a. Adjustment for multiple comparisons: Bonferroni. 


\section{Boolean operator * Examples Component}

Pairwise Comparisons

Dependent Variable: Completion Time (s)

\begin{tabular}{|c|c|c|c|c|c|}
\hline Examples Component & (I) Boolean operator & (J) Boolean operator & $\begin{array}{c}\text { Mean } \\
\text { Difference } \\
(1-J)\end{array}$ & Std. Error & Sig. ${ }^{a}$ \\
\hline \multirow[t]{6}{*}{ Absent } & \multirow[t]{2}{*}{ AND } & NOT & 1.981 & 4.280 & 1.000 \\
\hline & & OR & -1.201 & 4.280 & 1.000 \\
\hline & \multirow[t]{2}{*}{ NOT } & AND & -1.981 & 4.280 & 1.000 \\
\hline & & OR & -3.182 & 4.280 & 1.000 \\
\hline & \multirow[t]{2}{*}{ OR } & AND & 1.201 & 4.280 & 1.000 \\
\hline & & NOT & 3.182 & 4.280 & 1.000 \\
\hline \multirow[t]{6}{*}{ Present } & \multirow[t]{2}{*}{ AND } & NOT & 3.173 & 4.280 & 1.000 \\
\hline & & OR & $-14.926^{\star}$ & 4.280 & .002 \\
\hline & \multirow[t]{2}{*}{ NOT } & $\overline{\text { AND }}$ & -3.173 & 4.280 & 1.000 \\
\hline & & OR & $-18.099^{\star}$ & 4.280 & .000 \\
\hline & \multirow[t]{2}{*}{ OR } & AND & $14.926^{\star}$ & 4.280 & .002 \\
\hline & & NOT & $18.099^{*}$ & 4.280 & .000 \\
\hline
\end{tabular}

Based on estimated marginal means

*. The mean difference is significant at the .05 level.

a. Adjustment for multiple comparisons: Bonferroni.

\section{Boolean operator * Examples Component}

\section{Pairwise Comparisons}

Dependent Variable: Completion Time (s)

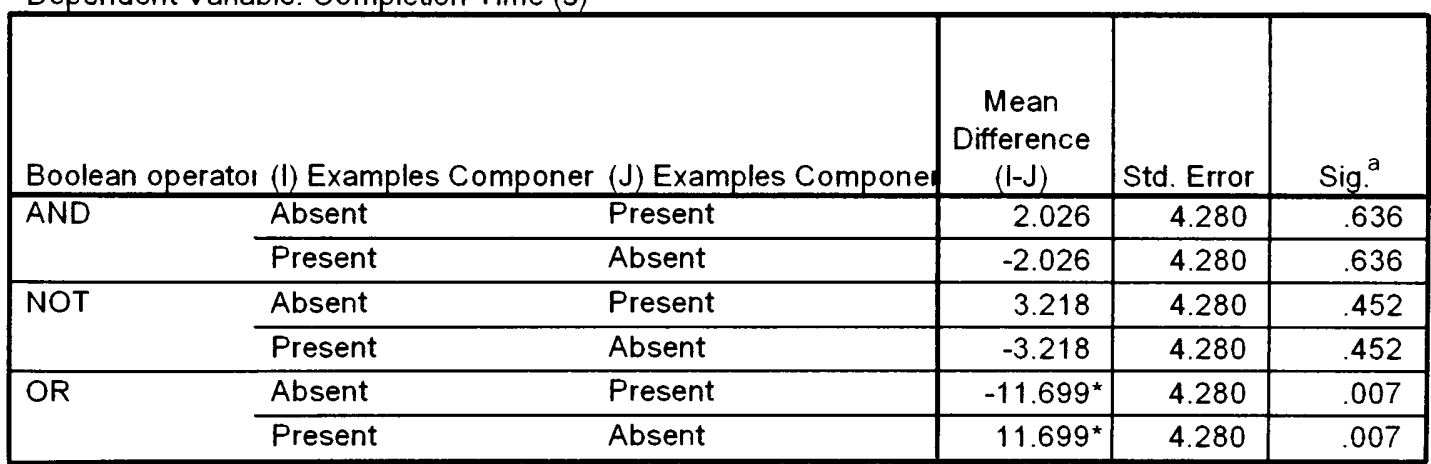

Based on estimated marginal means

*. The mean difference is significant at the .05 level.

a. Adjustment for multiple comparisons: Bonferroni. 


\section{Post Hoc Tests}

\section{Boolean operator}

\section{Multiple Comparisons}

Dependent Variable: Completion Time (s)

Bonferroni

\begin{tabular}{|ll|c|c|c|}
\hline & & $\begin{array}{c}\text { Mean } \\
\text { Difference } \\
(\mathrm{I}-\mathrm{J})\end{array}$ & Std. Error & \multicolumn{1}{c|}{ Sig. } \\
\hline (I) Boolean operator & $(\mathrm{J})$ Boolean operator & 2.5770 & 2.98747 & 1.000 \\
& NOT & $-8.0635^{\star}$ & 2.98747 & .022 \\
\hline NOT & OR & -2.5770 & 2.98747 & 1.000 \\
& AND & $-10.6405^{\star}$ & 2.98747 & .001 \\
\hline OR & OR & $8.0635^{\star}$ & 2.98747 & .022 \\
& AND & $10.6405^{\star}$ & 2.98747 & .001 \\
\hline
\end{tabular}

Based on observed means.

${ }^{*}$. The mean difference is significant at the .05 level. 


\section{Crosstabs}

Semantic Component * In favor of using search interface Crosstabulation

Count

\begin{tabular}{|c|c|c|c|c|}
\hline & & $\begin{array}{c}\text { In favor of } \\
\text { int }\end{array}$ & search & \\
\hline & & No & Yes & Total \\
\hline Semantic Component & Absent & 60 & 180 & 240 \\
\hline & Present & 30 & 210 & 240 \\
\hline Total & & 90 & 390 & 480 \\
\hline
\end{tabular}

Syntactic Component * In favor of using search interface Crosstabulation

Count

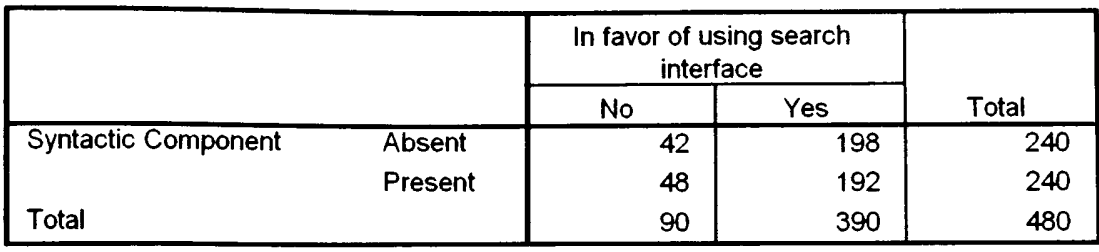

Examples Component * In favor of using search interface Crosstabulation

Count

\begin{tabular}{|c|c|c|c|c|}
\hline & \multicolumn{2}{|c|}{$\begin{array}{l}\text { In favor of using search } \\
\text { interface }\end{array}$} & \multirow[b]{2}{*}{ Total } \\
\hline & & No & Yes & \\
\hline \multirow[t]{2}{*}{ Examples Component } & Absent & 48 & 192 & 240 \\
\hline & Present & 42 & 198 & 240 \\
\hline Total & & 90 & 390 & 480 \\
\hline
\end{tabular}

\section{Means}

Report

\begin{tabular}{|ll|r|r|r|r|r|}
\hline $\begin{array}{l}\text { Number of Search } \\
\text { Hint Components }\end{array}$ & $\begin{array}{c}\text { Correct } \\
\text { Semantics }\end{array}$ & $\begin{array}{c}\text { Correct } \\
\text { Syntax }\end{array}$ & $\begin{array}{c}\text { Pre-click } \\
\text { Confidence }\end{array}$ & $\begin{array}{c}\text { SUS } \\
\text { Questionnaire }\end{array}$ & $\begin{array}{c}\text { Completion } \\
\text { Time (s) }\end{array}$ \\
\hline 0 & Mean & .18 & .00 & 4.17 & 80.250 & 21.6548 \\
& $\mathrm{~N}$ & 60 & 60 & 60 & 60 & 60 \\
& Std. Deviation & .390 & .000 & 1.196 & 10.3611 & 17.46237 \\
\hline 1 & Mean & .56 & .37 & 4.25 & 78.583 & 26.1821 \\
& $\mathrm{~N}$ & 180 & 180 & 180 & 180 & 180 \\
& Std. Deviation & .498 & .485 & 1.232 & 12.1906 & 20.45453 \\
\hline 2 & Mean & .58 & .34 & 4.23 & 80.000 & 33.5846 \\
& $\mathrm{~N}$ & 180 & 180 & 180 & 180 & 180 \\
& Std. Deviation & .494 & .475 & 1.349 & 11.5792 & 35.81506 \\
\hline 3 & Mean & .57 & .23 & 4.18 & 73.000 & 24.8465 \\
& $\mathrm{~N}$ & 60 & 60 & 60 & 60 & 60 \\
& Std. Deviation & .500 & .427 & 1.321 & 15.8167 & 23.12331 \\
\hline Total & Mean & .52 & .30 & 4.22 & 78.625 & 28.2251 \\
& $\mathrm{~N}$ & 480 & 480 & 480 & 480 & 480 \\
& Std. Deviation & .500 & .457 & 1.280 & 12.4371 & 27.53750 \\
\hline
\end{tabular}

